\title{
The effect of low and high fertility treatments on soil quality, yields, pest incidence and labor requirements of a post- transitional organic market garden system
}

Todd Bradley Childers

West Virginia University

Follow this and additional works at: https://researchrepository.wvu.edu/etd

\section{Recommended Citation}

Childers, Todd Bradley, "The effect of low and high fertility treatments on soil quality, yields, pest incidence and labor requirements of a post-transitional organic market garden system" (2005). Graduate Theses, Dissertations, and Problem Reports. 2285.

https://researchrepository.wvu.edu/etd/2285

This Thesis is protected by copyright and/or related rights. It has been brought to you by the The Research Repository @ WVU with permission from the rights-holder(s). You are free to use this Thesis in any way that is permitted by the copyright and related rights legislation that applies to your use. For other uses you must obtain permission from the rights-holder(s) directly, unless additional rights are indicated by a Creative Commons license in the record and/ or on the work itself. This Thesis has been accepted for inclusion in WVU Graduate Theses, Dissertations, and Problem Reports collection by an authorized administrator of The Research Repository @ WVU. For more information, please contact researchrepository@mail.wvu.edu. 
The Effect of Low and High Fertility Treatments on Soil Quality, Yields, Pest Incidence and Labor Requirements of a Post-transitional Organic Market Garden System

\title{
Todd Bradley Childers
}

Thesis submitted to the Davis College of Agriculture, Forestry, and Consumer Sciences at West Virginia University in partial fulfillment of the requirements for the degree of

\author{
Master of Science \\ in
} Horticulture

\author{
Sven Verlinden, Ph.D., Chair \\ James Kotcon, Ph.D. \\ Linda Butler, Ph.D. \\ Division of Plant and Soil Sciences
}

\author{
Morgantown, West Virginia \\ 2005
}

Keywords: Vegetable production, Sustainable agriculture, Organic agriculture, Organic matter, Crop yield 


\begin{abstract}
The Effect of Low and High Fertility Treatments on Soil Quality, Yields, Pest Incidence and Labor Requirement of a Post-transitional Organic Market Garden System
\end{abstract}

\title{
Todd Bradley Childers
}

In a two-year study, eight vegetable crops were grown as part of a certified organic four-year crop rotation. High input plots received off-farm composted cow manure and cover crops, and low input plots were managed with the use of cover crops only. High input plots produced higher yields than low input plots in all crops, except peas, which yielded higher in low input plots. Soil organic matter levels were significantly higher in the high input than the low input plots and increased from 2003 to 2004 in both treatments. Available soil phosphorus levels in the high input plots were excessive, while potassium levels were excessive in both treatments. The addition of manure-based composts can increase yields in a post-transitional organic market garden system. However, farmers should balance the costs of either production or purchase of compost against the benefits in yield, increased soil fertility, and possible negative effects associated with excess nutrients. 


\section{Acknowledgments}

I would like to thank Dr. Sven Verlinden and Dr. Barton Baker for allowing me the opportunity to participate in this unique organic research project at WVU. I would also like to recognize Dr. James Kotcon and Dr. Linda Butler for their contribution as committee members. Thanks to Dr. George Seidel for his statistical contribution. Finally, I would like to thank Maggie Lozier, Dr. Mike Bomford, Dr. Louis McDonald, Dr. Bill Bryan, Mihaela Iordachescu, Sue Myers, Marvin Clark, and Joan Wright for their encouragement and support of my efforts here at WVU. 


\section{Table of Contents}

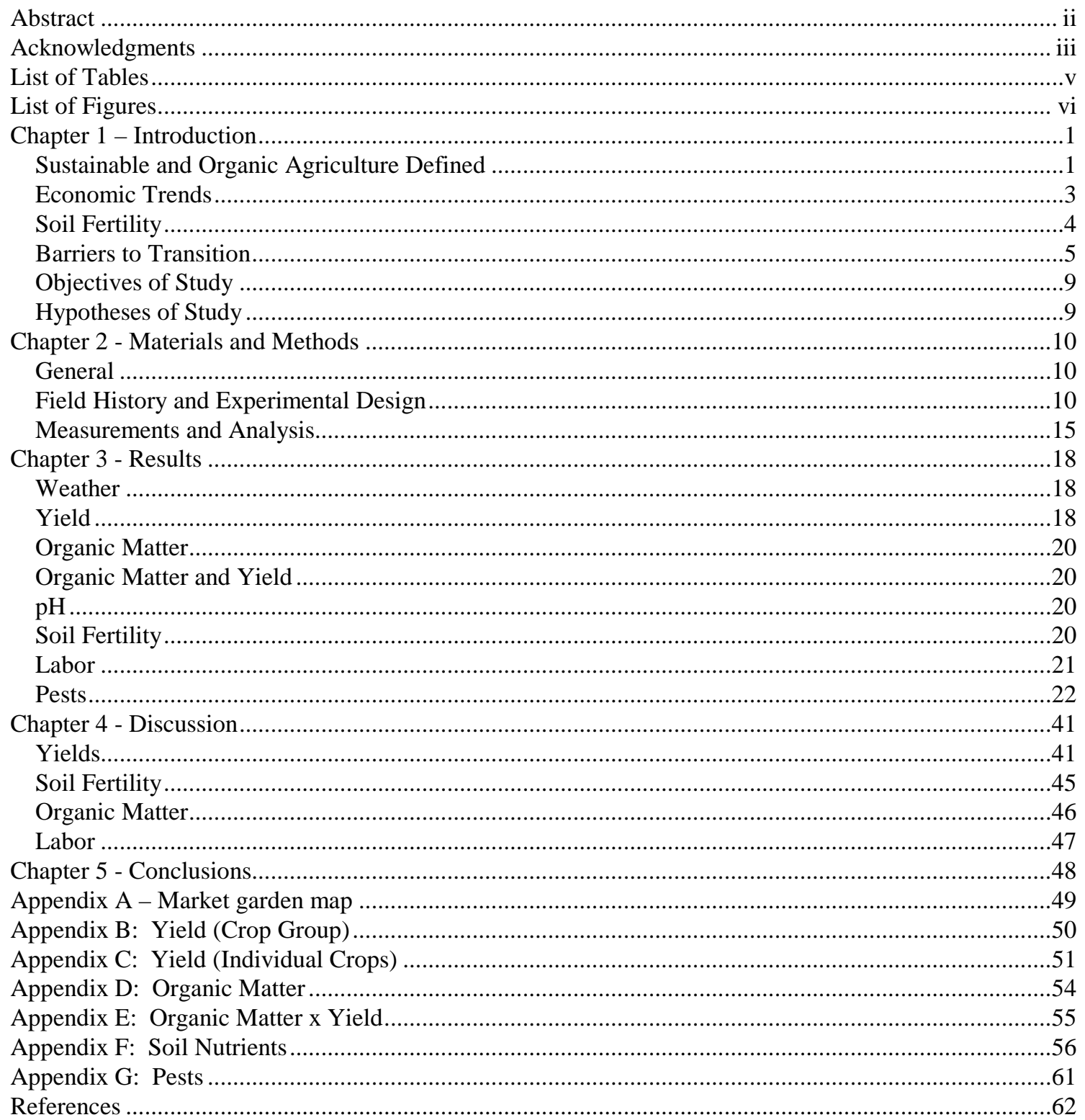




\section{List of Tables}

Table 1. Crops, varieties, and seed sources used in the market garden in the 2003-2004 growing season...11

Table 2. Chemical properties of compost used on experimental plots in 2003 and $2004 \ldots \ldots \ldots \ldots \ldots \ldots \ldots \ldots . . . . . .12$

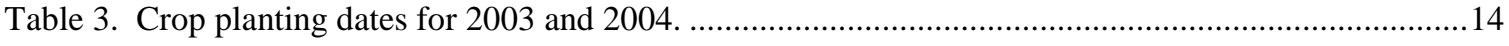

Table 4. Analysis of variance of crop yield by crop groups .........................................................50

Table 5. Analysis of variance of crop yield by individual crops.....................................................51

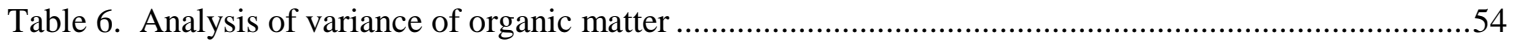

Table 7. Analysis of variance correlating organic matter to yield of individual crops ................................55

Table 8. Analysis of variance of $\mathrm{pH}$, correlating $\mathrm{pH}$ to organic matter, and of individual soil nutrients......56

Table 9. Analysis of variance of emergence rates for peas in 2003 and spinach in 2003 and 2004 ...........61

Table 10. Analysis of variance of tomato early blight in 2004 ........................................................61 


\section{List of Figures}

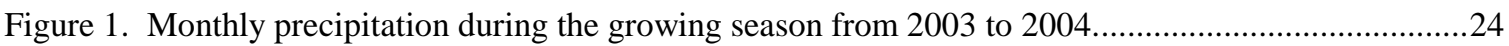

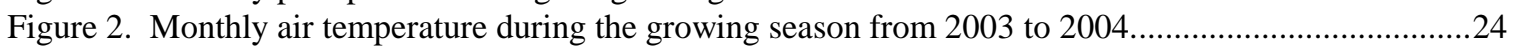

Figure 3. Pea yields in high and low input plots in 2003 and 2004 .......................................................25

Figure 4. Spring bean yields in high and low input plots in 2003 and 2004..............................................25

Figure 5. Fall bean yields in high and low input plots in 2003 and 2004 .................................................26

Figure 6. Pepper yields in high and low input plots in 2003 and 2004....................................................26

Figure 7. Tomato yields in high and low input plots in 2003 and 2004..................................................27

Figure 8. Zucchini yields in high and low input plots in 2003 and 2004 ..................................................27

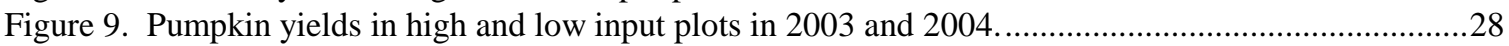

Figure 10. Spring lettuce yields in high and low input plots in 2003 and 2004 ......................................28

Figure 11. Fall lettuce yields in high and low input plots in 2003 and 2004 .........................................29

Figure 12. Spinach yields in high and low input plots in 2003 and 2004 ................................................29

Figure 13. Pea emergence in high and low input plots in 2003...............................................................30

Figure 14. Organic matter in high and low input plots in 2003 and 2004..................................................30

Figure 15. pH levels in high and low input plots in 2003 and 2004.......................................................31

Figure 16. Potassium averages in high and low input plots in 2003 and 2004. ........................................31

Figure 17. Phosphorus averages in high and low input plots in 2003 and 2004........................................32

Figure 18. Sodium averages in high and low input plots in 2003 and 2004.........................................32

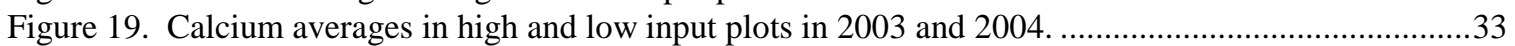

Figure 20. Magnesium averages in high and low input plots in 2003 and 2004 .......................................33

Figure 21. Copper averages in high and low input plots in 2003 and 2004..............................................34

Figure 22. Manganese averages in high and low input plots in 2003 and 2004.......................................34

Figure 23. Zinc averages in high and low input plots in 2003 and 2004 .................................................35

Figure 24. Bean labor in high and low input plots in 2003 and 2004 .......................................................35

Figure 25. Tomato labor in high and low input plots in 2003 and 2004..................................................36

Figure 26. Pumpkin labor in high and low input plots in 2003 and 2004 ...............................................36

Figure 27. Spinach labor in high and low input plots in 2003 and 2004..................................................37

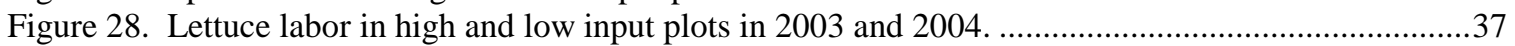

Figure 29. Pea labor in high and low input plots in 2003 and 2004 ........................................................38

Figure 30. Pepper labor in high and low input plots in 2003 and 2004....................................................38

Figure 31. Zucchini labor in high and low input plots in 2003 and 2004 ..................................................39

Figure 32. Spinach emergence in high and low input plots in 2003 and 2004..........................................39

Figure 33. Tomato early blight in high and low input plots in 2004 ......................................................40

Figure 34. Powdery mildew levels in high and low input plots in 2003....................................................40 


\section{Chapter 1 - Introduction}

\section{Sustainable and Organic Agriculture Defined}

Agriculture could be considered to be in the midst of a transition. A gradual move from conventional agricultural methods to more sustainable systems in recent years has stemmed from social, environmental, and economic concerns (Allen et al., 1991). Although conventional agriculture has taken us forward in some respects - technologically, socially, and in terms of sheer volume of food produced - there are negative aspects. In conventional vegetable production, the uses of synthetic pesticides and fertilizers, genetically modified organisms, monocultures, and massive automation have resulted in extremely high productivity. The tradeoffs for this productivity include water contaminated with pesticides and excess nutrients, seed companies holding great power over farmers, depleted soils, and fewer people making a living in agriculture. More and more people argue that conventional agriculture is shortsighted, and a shift to more sustainable methods seems to be taking place (ERS, 2004).

It is becoming increasingly apparent that conventional agriculture can lead to profound negative consequences (Klaas, 1982; Papendick et al., 1986; Hamilton and Helsel, 1995). Some of the fundamental criticisms of conventional agriculture are that it harms the environment and soil structure, that it consumes too much energy, that it results in human health hazards and decreased food quality, and that it is unnecessarily expensive to society as a whole (Lampkin, 2002). Taxpayers must often pay for the cost of cleaning up soil and water contaminated with pesticides and fertilizers (Nielson and Lee, 1987). Farm workers can suffer the consequences of prolonged exposure to dangerous pesticides (Harper and Zilberman, 1992; Arcury and Quandt, 1998). Consumers are growing increasingly concerned about the potential health risks of consuming produce that may contain traces of chemicals applied during production or processing (O’Keeffe and Kennedy, 1998). The sale of genetically engineered seed by corporations 
threatens farmer's independence and puts the purity of organic growers' products at risk through the possibility of genetic drift. As a result of these and other unintended consequences of conventional agriculture, sustainable agricultural systems, which may have less of a negative impact on the environment, producers, and consumers, are being explored.

Sustainable agriculture is defined by Allen et al. (1991) as “...equitably balancing concerns of environmental soundness, economic viability and social justice among all sectors of society.” Many similar definitions exist in the current literature (Lockeretz, 1988; Ruttan, 1988; Lampkin, 2002), however, this definition recognizes that one must consider the entire world and all life upon it, and the present and future viability of those ecosystems. Conventional agriculture has a tendency to focus on short-term economic goals instead of long-term environmental and social goals (Allen et al., 1991). Any discussion of sustainable agriculture must consider both the small and large scale consequences of a farming system. At the farm level, one must consider factors such as productivity, profitability, resource conservation, and worker satisfaction. On a global scale, a sustainable agriculture system must concern itself with environmental consequences, agricultural economics, and social problems, such as unequal food distribution and the cost of food.

Organic agriculture falls under the umbrella of sustainable agriculture, but is concerned more than any other systems approach with specific production practices. When seeking a definition of organic agriculture, a fundamental debate emerges in the literature - that of whether it is a matter of reducing certain inputs or of using methods that make those inputs unnecessary (Lockeretz, 1988; Lampkin, 2002). Negative definitions (those which focus on prohibited inputs) were created primarily to protect organic product consumers (Stanhill, 1990). The current USDA definition presents a wider, more substantive definition, while including protections for consumers. It states that organic agriculture is "a production system that is managed in accordance with the Act and regulations in this part to respond to site-specific 
conditions by integrating cultural, biological, and mechanical practices that foster cycling of resources, promote ecological balance, and conserve biodiversity” (USDA, 2004). Some commonly accepted organic practices include the use of crop rotations, animal and green manures, composting, pest-resistant plant varieties, and biological pest control (FernanadezCornejo et al., 1998; Lampkin, 2002).

In October 2002, the USDA adopted rules requiring that products marketed as organic must be certified by a USDA-accredited certifying agent (USDA, 2004). The new organic rule describes acceptable and unacceptable practices, methods and substances that may be used in producing organic products. For a cropping system, these include managing soil fertility through cultivation and tillage, crop rotations, cover crops and compost applications. Pests must be controlled primarily by physical, mechanical, and biological methods. If available, organic seed must be used. The use of sewage sludge, ionizing radiation and genetic engineering is strictly prohibited. Before products are eligible for certification, the land upon which they're grown must not have had any prohibited substances applied to it for the previous three years. This three-year period during which products may not be labeled as organic is referred to as the transition phase.

\section{Economic Trends}

The fastest growing component in U.S. agriculture for the past decade has been organic farming (Economic Research Service, 2004). In the year 2000, $\$ 7.8$ billion was spent on organic products in the U.S., more than half of which was spent in conventional supermarkets. In the early 1990’s, the bulk of organic products were marketed through natural products retailers, suggesting that organic products are moving more into the mainstream. In 2001, 0.3\% of all U.S. cropland was certified organic (ERS, 2004). Organic products account for about $2 \%$ of the total retail food sales in the U.S. (Thompson, 2000), while world retail sales of organic products in 
2001 reached \$21 billion (International Trade Centre, 2004). Organic agriculture is clearly a significant segment of the agricultural market, and appears to be experiencing substantial growth.

Organic food consumption tends to be the highest in countries with high per capita incomes (Thompson, 2000). This fact, combined with the price premium for organic products (ITC, 2004), make organic products luxury items. Although price premiums obviously benefit organic farmers, they restrict the availability of organic food to a large segment of the population. If organic agriculture seeks to be truly sustainable, its’ products must be made available to more of the population.

\section{Soil Fertility}

Numerous studies have been conducted comparing the soil properties of organic and conventional farming systems. Overwhelmingly, these studies have found organically managed soils to have higher levels of organic matter than conventional soils (Reganold, 1988; Gerhardt, 1997; Clark et al., 1998). Organic matter plays a crucial role in many soil processes. Perhaps most fundamentally, organic matter regulates nutrient availability by regulating soil cation exchange capacity (Poincelot, 2004). In addition, organic matter also increases the water retention of soils, decreases erosion, improves soil tilth, and boosts microbial activity in the soil (Poincelot, 2004). Studies have also shown organically managed soils to have higher levels of exchangeable potassium, soluble phosphorus, pH, and water content (Clark et al., 1998; Reganold, 1998). Organically managed systems have also proven to be more efficient at storing excess nitrogen inputs (Clark et al., 1998), perhaps due to the higher levels of organic matter.

A commonly cited concern regarding conventional farming methods is the amount of nitrate leaching that can occur using inorganic fertilizers. In a 22-yearlong study by Goldstein et al. (1998) it was found that drainage water from fields fertilized with only composted and liquid manures had $\mathrm{NO}_{3}$ concentrations less than $2 \mathrm{ppm}$. After the same fields were converted to being 
fertilized with the recommended rates of anhydrous ammonia, $\mathrm{NO}_{3}$ concentrations rose 7 to 10 -

fold. Other studies have suggested that organic and low-input agricultural systems have a greater potential to store excess nitrogen and cause less environmental pollution than conventional systems (Poudel et al., 2001). However, in a survey of the literature, Kirchmann and Bergstrom (2001) found that the amount of leaching losses, taking into account nutrient inputs and yields, are not significantly different between organic and conventional farming systems. They found that the factor that had the largest effect on nitrate leaching was crop rotation. In their final analysis, they stated that it is not a matter of organic or conventional practices that most affect nitrate leaching, but the levels of nitrogen introduced into the system, the use of catch crops, and tillage practices that are most able to reduce the amount of nitrate leached from the farming system. Organic systems tend to utilize practices that decrease the amount of nitrate leaching from the soil, indicating a need to transition to more sustainable agricultural practices.

\section{Barriers to Transition}

Many barriers stand in the way of a transition to sustainable agricultural systems. Dahlberg (1987) explores some deeply rooted cultural biases and assumptions that slow the development of sustainable agriculture. Our culture's idea that the natural world is to be dominated runs contrary to a system that, at its core, is attempting to mimic nature. The idea that humans are not a part of nature is also inconsistent with steps toward sustainability. Dahlberg states that we (humans) are unable to see how we fit in and describes how dependent we are upon the natural systems that we are destroying. Dahlberg also suggests that our tendency to view progress as being measured by the use of more technology is inconsistent with the goals of sustainable agriculture. Conventional agriculture has made great strides using prevailing technologies, but generally fails to achieve the goals that sustainable agriculture seeks. Despite 
these cultural barriers, progress is being made toward greater agricultural sustainability and many people are beginning to recognize the need for a change.

During the conversion from conventional to organic agriculture, a farmer must move from being reactive to specific problems, to being proactive in creating a cropping system that is balanced and diverse in order to divert potential problems before they occur. This shift in thinking and action applies to every aspect of a farming operation - from soil fertility to pest management to marketing. In dealing with pests, the farmer may no longer simply apply the recommended pesticide for a quick fix. Instead, the organic farmer utilizes preventative techniques, such as the use of cover crops and resistant cultivars, intercropping, crop rotations, and predator/parasite introductions in managing pest problems (McSorley, 2002; Zinati, 2002). Mineral fertilizer may not be applied in organic systems, leaving the farmer to rely on composts and crop residues for soil nutrition. Studies have shown that these organic methods of providing soil fertility increase organic matter content, phosphorus, potassium, and microbial biomass levels, while decreasing plant parasitic nematodes (Scow et al, 1994).

Conventional farmers face many real and perceived barriers when they consider adopting organic methods. Blobaum (1982) conducted a survey of organic farmers in the Midwestern U.S. seeking their reasons for, and difficulties in, converting to organic agriculture. Their concerns were as follows: weed control, higher labor costs, lack of special markets, and access to reliable information. It is interesting to note that in Blobaum's survey, no farmers expressed concern over potential decreased profitability when they were considering conversion to organic methods. Economic studies have shown that organic agriculture is on par with conventional agriculture in terms of net profits (Dabbert and Madden, 1988; Smolik and Dobbs, 1991).

Chief among organic farmers’ concerns is weed control (Blobaum, 1982; Organic Farming Research Foundation, 2001). Many reports exist showing higher weed species diversity and lower overall weed populations on organic farms (Hald, 1999; Liebman and Davis, 2000; 
Van Elsen, 2000). Ngouajio and McGiffen (2002) state that the increased soil microbial activity in organic soils causes the death and decay of many weed seeds. These studies seem to suggest that with proper management, weeds in an organic system should not be a major source of concern for farmers.

Another concern of farmers is the marketing of their products. Organic farmers must be innovative in their approach to marketing, as the traditional marketing channels do not often handle organic produce. Natural food stores and conventional grocery stores together account for about one-half of total organic food sales (ERS, 2001). Small organic growers, however, rely more on marketing their product directly to the consumer through channels such as farmers’ markets and community supported agriculture (Fernandez-Cornejo et al., 1998; ERS, 2001). Through direct marketing, a personal relationship is established between the farmer and the consumer. The farmer is able to sell his/her goods locally at retail price to an appreciative customer who, in turn, receives the freshest produce possible. As an indirect consequence of direct marketing, less energy is expended in transporting products long distances to their eventual place of sale.

It is generally believed that organic farms - especially small-scale fruit and vegetable farms - tend to require more labor input than conventional farms. However, it is difficult to make generalizations regarding labor costs, as different cropping systems and different soils each have their own specific labor requirements. In Lampkin’s (2002) analysis of European farms, as much variability was found regarding labor requirements as there was variability in the types of enterprises. Other literature suggests labor requirements for organic farms tend to be near equal to, or slightly higher than those of conventional farms (Diebel et al., 1993; Sellen et al., 1995).

Perhaps the most important factor for a farmer to consider during and after their conversion to organic practices is the fertility of the soil. Conventional and organic farmers alike are generally not aware of the complex processes that occur in the soil. Although a deep 
scientific knowledge of soil processes is not necessary to be a successful farmer, a basic understanding of the need to manage a soil's fertility status is essential. Conventional farmers supply their crops with the needed nutrients using inorganic fertilizers. Organic farmers tend to think less in terms of "feeding" their crops and more about "building" soil that is able to grow successful crops. This is generally accomplished using composts, green manures, cover crops, rotations, and biologically based soil amendments. There is a great need to study how to manage soil fertility before and after conversion to organic practices.

The body of research in market garden scale organic horticultural practices has been steadily growing in recent years. Many researchers are finding similar trends recurring in organic systems. The beneficial effects of composts and green manures on soil fertility, and on soil organic matter levels specifically, have been widely noted by researchers (Power and Doran, 1984; Scow, 1994; Gerhardt, 1997; Clark et al., 1998). During conversion to organic methods, pest populations seem to shift, and may require a new pest management strategy (McSorley, 2002; Ngouajio and McGiffen, 2002). Yields in organic systems are generally lower than those in conventional systems, however, lower overall inputs balance out the loss incurred in lower yields (Dabbert and Madden, 1988; Sellen et al., 1995; McSorley et al., 1999).

The reason for conducting a study to determine the effects of fertility treatments on a small-scale vegetable operation is that it can be difficult for farmers to produce enough quality compost to use on their own fields. If farmers are not producing their own compost, it may be too expensive to buy or ship sufficient compost in to the farm site. We specifically hoped to determine what the yield, pest, labor, and soil fertility trade-offs are of using or not using manure-based composts. 


\section{Objectives of Study}

1. To determine whether the addition of off-farm, manure based composts improve yields during the two years after transitioning to organic production.

2. To determine the effects of off-farm, manure-based compost additions on soil organic matter during the two years after transitioning to organic production.

3. To determine the effects of off-farm, manure-based composts on the soil nutrient status during the two years after transitioning to organic production.

4. To determine whether soil organic matter affects yields during the two years after transitioning to organic production.

5. To determine the effects of off-farm, manure-based composts on pest incidence during the two years after transitioning to organic production.

6. To determine whether the addition of off-farm, manure based compost has an effect on labor requirements during the two years after transitioning to organic production.

\section{Hypotheses of Study}

1. High input plots (those receiving 10 tons/acre of compost in the spring) will produce higher yields than the low input plots (those receiving no compost) during the two years after transitioning to organic production.

2. High input treatments result in higher soil organic matter content during the two years after transitioning to organic production.

3. Higher soil organic matter content results in higher yields during the two years after transitioning to organic production.

4. High input plots will have lower incidence of pests that commonly affect the crops under investigation, during the two years after transitioning to organic production.

5. High input plots will require more labor than the low input plots. 


\section{Chapter 2 - Materials and Methods}

\section{General}

The West Virginia University organic research farm is located on 63 acres near the Mileground area of Morgantown, West Virginia ( $\left.39^{0} 39^{\prime} \mathrm{N}, 79^{0} 55^{\prime} \mathrm{W}\right)$. Research projects in various disciplines - horticulture, plant pathology, entomology, soil microbiology, and animal sciences - have been in progress on the site since its acquisition in 1916. The farm converted to organic practices in the fall of 1999 and was certified organic according to USDA standards in the summer of 2003.

The market garden section of the farm consists of 0.9 acres (0.36 ha) of Tilsit (Typic Fragiudult) and Dormont (Ultic Hapludalf) series soils. These soils are silt loams of moderate natural fertility (Soil Conservation Service, 1982). The site is tile drained with a 2-6\% slope. Thirty-two plots make up the market garden (Appendix A). From 2000 to 2002, the plots were 4.9 meters wide and 15.2 meters long. In 2003 and 2004, the plots were reduced to half of their original size in order to reduce labor, resulting in 4.9 x 7.6 meter plots with 0.61 meter alleyways between plots. Larger alleyways, measuring 3.05 meters, separated the rows of plots. Alleyways were planted to Kentucky bluegrass and mixed clover.

\section{Field History and Experimental Design}

In the fall of 1999, rye and vetch were sown in all of the plots. The following spring, red clover was sown in the low input plots as a nitrogen-fixing green manure. The low input plots did not produce a cash crop until 2001. The high input plots received the aforementioned rates of compost in the spring of 2000 and began the four-year crop rotation, which consisted of Leguminosae, Solanaceae, Cucurbitaceae, and leafy crops. Crop varieties and seed sources are listed in Table 1. 
Table 1. Crops, varieties, and seed sources used in the market garden in the 2003 - 2004 growing season.

\begin{tabular}{|l|l|l|}
\hline Crop & Variety & Seed Source \\
\hline Peas (Pisum sativum) & Oregon Giant & Seeds of Change \\
\hline Beans (Phaseolus vulgaris) & Provider & Johnny's Selected Seeds \\
\hline Tomatoes (Lycopersicon esculentum) & WV63 & WVU seed stock \\
\hline Peppers (Capsicum annuum) & Red Knight & Johnny's Selected Seeds \\
\hline Zucchini (Cucurbita pepo) & Raven & Johnny's Selected Seeds \\
\hline Pumpkins (Cucurbita maxima) & Rocket & Johnny's Selected Seeds \\
\hline Spinach (Spinacia oleracea) & Space & Johnny's Selected Seeds \\
\hline Lettuce (Lactuca sativa) & Winter Density & Johnny's Selected Seeds \\
\hline
\end{tabular}

The two factors under investigation were the input treatments (high vs. low) and the crop groups (Solanaceae (tomatoes and peppers), Leguminosae (peas and green beans), Cucurbitaceae (zucchini and pumpkins), and leafy crops (spinach and lettuce)), which lead to two levels of input treatments and four levels of crop groups, resulting in eight experimental treatments, which were replicated four times - a total of 32 plots. In each plot, two crops of each crop group were grown.

In this completely randomized design, half of the main plots (16) received a high input treatment and half of the main plots (16) received a low input treatment. The high input treatment consisted of compost applied at 10 tons (dry weight) per acre in spring, before planting. No compost was applied on the low input treatment plots. The compost was measured using 5-gallon buckets emptied into a wheelbarrow. From the wheelbarrow, the compost was applied directly onto the plots and was raked to spread evenly. Then, it was incorporated into the 
soil by rototilling. The compost was derived from the West Virginia University livestock farm and consisted of approximately 1 part cow manure and 1 part leaf litter. Compost samples were analyzed for nutrient content each year by the West Virginia Department of Agriculture's Moorefield Nutrient Management and Water Quality Lab in Moorefield, WV (Table 2).

Table 2. Chemical properties of compost used on experimental plots in 2003 and 2004.

\begin{tabular}{|c|c|c|c|c|c|c|}
\hline Year & \% Nitrogen & \% Phosphate & \% Potash & \% Calcium & \% Magnesium & C:N ratio \\
\hline 2003 & 0.4 & 0.48 & 0.4 & 1.1 & 0.06 & 30.89 \\
\hline 2004 & 0.43 & 0.47 & 0.63 & 1.1 & 0.05 & 38.27 \\
\hline
\end{tabular}

Winter cover crops were established in both high and low input treatments after harvest in the fall and summer cover crops were established during the summer when a fallow period of at least one month was anticipated. Both the high and low input treatments received a cover crop of winter rye and hairy vetch, planted at a rate of 90/20 pounds per acre, respectively, in September or October, depending on the preceding crop. The rye/vetch was cut and incorporated as green manure at different times for different groups of crops, depending on when the following crops were planted. For instance, the leafy crop (spinach/lettuce) plots were the first to be cut and tilled, as they were the first spring crops (cool season vegetables) to be planted in each year of this study. This occurred some time between late April and early May, in each year of this study. The rye and vetch cover crops were cut in late May in the warm season vegetable crop plots (Solanaceous and Cucurbitaceous), before the cover crops were able to set viable seed. In early June, these plots were tilled and planted. In 2003 and 2004, summer green manure crops of buckwheat were grown in the legume and leafy crop plots between the spring and fall plantings. Buckwheat was seeded at a rate of 90 pounds per acre on both the high and low input plots. This green manure was cut after a month of growth to avoid seed-set. A buckwheat 
summer cover crop was not utilized during the first three years (transition years) of the experiment. The cover crops were always allowed to lie on the surface of the soil for at least 5 days after cutting to break down somewhat before incorporation into the soil.

Green manures and compost were incorporated with a BCS tiller in preparation for planting in all plots. Depending on the amount of material to be incorporated and the state of the soil, one or two passes were made with the tiller. No more than two passes were made per cultivation to avoid over-cultivation and harming soil structure.

Crop spacing was chosen that would provide maximum yield while utilizing the most space available in the plots. Within their respective plots, the following crops were planted (Table 3). Spinach was direct-seeded in four rows sown 1 foot apart, with 12 seeds per foot. Lettuce transplants were grown in the WVU greenhouse for approximately one month in a medium composed of one part peat, one part perlite, and one part composted cow manure. Four rows of lettuce transplants were planted one foot apart with one foot between plants. Peas were inoculated with a slurry of Rhizobium leguminosarum biovar phaseoli (Johnny’s Selected Seeds), and direct-seeded by hand in three rows, spaced two feet apart. Peas were planted twelve seeds per foot. Due to the high percentage of seed rot of peas in 2004, the entire crop was replanted with transplants grown in the WVU greenhouse. Seeds were germinated in trays and transplanted to the field in small clumps of 4-8 plants. Spring and fall crops of beans were inoculated with of Rhizobium phaseoli (Johnny's Selected Seeds), and direct-seeded by hand in mid-May and late July, respectively. Four rows of beans, one foot apart, were planted at a rate of 12 seeds per foot. Both peas and beans were inoculated with a slurry of Rhizobium bacteria before planting to insure good nodulation and atmospheric nitrogen fixation. Tomatoes, peppers, and zucchini were all started in flats in the greenhouse using the aforementioned potting medium. Two rows of tomatoes and peppers were planted four feet apart. Tomatoes were spaced $1-1 / 2$ feet between each plant and peppers were planted with one foot between plants. Two rows of 
zucchini transplants were planted two feet inside the border of the plots with one foot between plants. Pumpkin seeds were sown by hand in one row between the two rows of zucchini. Three pumpkin seeds were sown every three feet.

Table 3. Crop planting dates for 2003 and 2004.

\begin{tabular}{|l|c|c|}
\hline & \multicolumn{2}{|c|}{ Planting date } \\
\hline Crop & 2003 & 2004 \\
\hline Peas & $4 / 30$ & $5 / 17$ \\
\hline Spring beans & $5 / 22$ & $5 / 14$ \\
\hline Fall beans & $7 / 30$ & $5 / 28$ \\
\hline Tomatoes & $6 / 2$ & $5 / 30$ \\
\hline Peppers & $6 / 6$ & $6 / 16$ \\
\hline Zucchini & $6 / 25$ & $6 / 24$ \\
\hline Pumpkins & $7 / 1$ & $5 / 24$ \\
\hline Spring lettuce & $6 / 2$ & $9 / 7$ \\
\hline Fall lettuce & $9 / 11$ & $4 / 21$ \\
\hline Spinach & $4 / 30$ & \\
\hline
\end{tabular}

The Cucurbitaceae (zucchini and pumpkin) crops experienced heavy pressure from striped and spotted cucumber beetles during the first three years of the experiment. As the beetle population grew year by year, the yields steadily declined. To combat this problem, beginning in 2003, row covers were used during the first month of growth of zucchini and pumpkin. The row covers were put in place immediately after planting, and held in place with soil around the edges leaving plenty of slack for the plants to grow. The covers were removed approximately one month after planting, just as flowering began. 
Weed control in the market garden was accomplished using a variety of different methods, depending on the crop. The leafy (lettuce and spinach) and leguminous (peas and beans) crops were hand-hoed using a stirrup-type hoe about two to three weeks after planting. This initial hoeing was usually enough to keep the weeds under control until the crop was able to shade out any slower germinating weeds. Occasionally another round of hoeing was undertaking if it appeared the first round did not adequately control the weeds. The solanaceous (tomato and pepper) and cucurbitaceae (zucchini and pumpkin) crops were mulched immediately after planting. The mulch consisted of one layer of newspaper covered with approximately two inches of hay. Three bales of hay were used per plot. At the end of the season, these mulches were rototilled into the soil along with the crop debris.

\section{Measurements and Analysis}

The following measurements were taken each year: soil analysis (including $\mathrm{Na}, \mathrm{K}, \mathrm{Ca}$, Mg, P, Cu, Mn, Zn, organic matter, and $\mathrm{pH}$ ), compost nutrient analysis (including $\mathrm{N}, \mathrm{P}, \mathrm{K}, \mathrm{Ca}$, Mg, and C:N ratio) (Table 1), total yields, average weight of individual crops, and insect and disease incidence. Soil and compost samples were collected each spring before compost was applied. Soil samples were taken at a depth of 0-3 inches. The nutrients Na, K, Ca, Mg, P, Mn, and Zn were extracted using a Mehlich 1 solution as described by Wolf and Beegle (1995) and Sims (1995). Soil organic matter was determined by the loss on ignition method as described by Nelson and Sommers (1996). Soil pH was determined by creating a slurry of soil and distilled water and using an electronic pH meter as described by Eckert and Sims (1995). Weather data was obtained from the National Weather Service station at Morgantown Municipal Airport. Total marketable yields were recorded from each plot for each harvest. Tomatoes, beans, peas, zucchini and peppers were harvested multiple times throughout the season as they became ripe or of a marketable size. Spinach, pumpkins, and lettuce were harvested one time. Ten randomly 
selected individual fruits or vegetables were weighed from each harvest to determine their average weights in order to allow us to compare harvests within and between years of the same crops. Diseases and insects were monitored three times during the life cycle of all crops approximately 2 weeks after establishment, midway through the crops' lifecycle, and after the final harvest. In addition to the first scouting, the crops were monitored as follows: spinach - 20 days and 40 days after establishment; zucchini, lettuce, and beans - 25 days and 50 days after establishment; peas and peppers - 30 days and 60 days after establishment; tomatoes - 30 days and 70 days after establishment; pumpkins - 50 days and 100 days after establishment. Exceptions to this rule occurred when a particular disease (such as early blight in tomatoes) or insect (such as cucumber beetles in squash) rapidly affected the overall health of a crop, at which point more frequent scoutings were employed to more closely follow pest progression.

Disease and insect monitoring were performed in a similar fashion for all crops. Monitoring techniques differed according to the particular pest and the stage of growth of the crop. When monitoring for insects in the early stages of plant growth, five plants were randomly selected from each plot and the number of insects and their respective life stage found on those plants was recorded. A visual assessment of the degree of damage to the crop was also performed. In this assessment the approximate percentage of damage or defoliation was recorded. Further on in the life cycle of a crop, 20 leaves were chosen at random for inspection. From these leaves, the number of insects was recorded. A visual estimation of overall damage or defoliation was also recorded. In monitoring diseases, a visual estimation of total leaf area affected by the disease was recorded.

Labor data were recorded daily for all activities. Times were recorded on the basis of crop (i.e. 60 minutes tilling all zucchini plots). As data for each plot were not kept separately, no statistical analyses were conducted. 
The data were subjected to analysis of variance using SAS software (SAS Institute, Cary, NC), based on a completely randomized design. Due to the design of the experiment (with 2 crops of each crop family being grown in the same plot), the analysis of variance for yields was divided into two parts. One analysis was concerned with the variance between the yields of the four crop groups, while the other analysis of variance was focused on the variance of individual crop yields. In the first analysis of variance (analyzing the variance between crop groups), yield values were replaced by ranks and analyzed with a generalized linear model (GLM) in order to compensate for the lack of uniform distribution of values (Appendix B). In the second analysis of variance, actual yield data were used to determine the variance in individual crop yields (Appendix C). Organic matter was also subjected to an analysis of variance (Appendix D). The effects of organic matter on yield were analyzed using all 16 yield data points (8 plots per crop x 2 years) in a regression with organic matter levels (Appendix E). Individual soil nutrients were subjected to an analysis of variance as well (Appendix F). Also included in this analysis were $\mathrm{pH}$ and the effect of $\mathrm{pH}$ on organic matter levels. Tests were also run to determine whether a correlation between individual soil nutrients and yield existed (Appendix G). The pest data were analyzed as differences among high and low treatments using a regression analysis for the tomato early blight and a T-test for the emergence rates (Appendix H). 


\section{Chapter 3 - Results}

\section{Weather}

Although the 2003 growing season experienced more total rainfall, in 2004, the precipitation was more evenly distributed over the growing season and closer to the normal amounts of precipitation expected in our region (Figure 1). Irrigation was not used in either year as rainfall was evenly distributed (about one rain per week) and no long dry periods occurred during the growing season. The air temperature for both years did not deviate drastically from the normal temperatures from the years 1971 to 2000 . However, the only significant departure from the normal range of temperatures occurred in the spring of 2004, when average temperatures were higher than normal in April and May (Figure 2).

\section{Yield}

When analyzed by crop groups, a significant difference was observed in crop yields from 2003 to 2004, the first two years following transition to organic practices. An analysis of variance (replacing yield data with ranks) was conducted for yield data by crop groups (solanaceous, leguminous, cucurbitaceous, and leafy crops) and by individual crops (using actual yield data) (Appendices B and C, respectively). Higher yields were seen in $2004(P<0.0001)$. The main reason for this difference can be attributed to the significantly higher yields in the leguminous crops (peas and beans) $(P<0.0001)$, the solanaceous crops (tomatoes and peppers) ( $P<0.0001$ ), and the cucurbitaceous crops (zucchini and pumpkins) $(P=0.0233)$ in 2004. The leafy crops (spinach and lettuce) as a group did not show a significant difference when compared between years $(P=0.1194)$.

When considered individually (Appendix C), all crops except peas (Figure 3) and spinach (Figure 12) showed a significant difference in yield between years (Spring beans (Figure 4), fall beans (Figure 5), peppers (Figure 6), tomatoes (Figure 7), zucchini (Figure 8), pumpkins 
(Figure 9), spring lettuce (Figure 10)). This significant year effect was associated with increasing yields from 2003 to 2004 in all cases except the pumpkins, which showed decreasing yields from year to year.

A significant treatment effect on yield was observed in both years of the study. When analyzed by crop groups (replacing yield data with ranks), high input plots yielded more than the low input plots $(P=0.0063)$. The additive effects of the rotation and the compost application over the years must also be considered when comparing compost application to yields. Significant differences where found when comparing the year effect to the treatment effect $(P=0.0038)$, as well as the treatment by crop by year effect $(P=0.0052)$. High input plots showed significantly higher yields for both years combined in many individual crops, including spring beans ( $P=0.0158$ ) (Figure 4), zucchini $(P=0.0224)$ (Figure 8), pumpkins ( $P=0.0021)$ (Figure 9), and spinach ( $P=0.0144$ ) (Figure 12). A significant treatment effect on yield was observed in the peas $(P=0.0476)$ (Figure 3). However, this was the only crop that showed significantly higher yields in the low input plots. Low input pea plots yielded 38\% and 36\% higher than high input plots in both 2003 and 2004 respectively. Pea emergence levels in 2003 were 13\% higher in the low input plots (Figure 13). Treatment did have a significant effect on spinach in $2003(P=0.0069)$, but not in 2004 (Figure 12). Treatment had no significant effect on pumpkin yields in 2003, but did have a significant effect on yield in $2004(P=0.0027)$ (Figure 9). Peppers showed a trend toward higher yields in the high input treatments; however, these differences were not significant (Figure 6). Tomatoes did not show an overall treatment effect for both years combined, however, in 2004, the high input plots showed significantly higher yields ( $P=0.0427)$ (Figure 7). The high input spring lettuce yields in 2003 were $75 \%$ higher than the low input plots in terms of number of heads per plot. In 2004, however, the low input spring lettuce crop showed an 8\% higher number of heads than the high input (Figure 10). In neither year were these differences significant. 


\section{Organic Matter}

The organic matter in the market garden soil has been steadily increasing since the project's inception. A significant increase in the percentage of soil organic matter was observed from 2003 to 2004 (Appendix D, $P=0.0002$ ). The average organic matter in the high input plots increased $0.96 \%$, while in the low input plots it increased $0.23 \%(P=0.0245)$ (Figure 14). A treatment effect was observed, with the high input plots showing higher soil organic matter than the low input plots $(P<0.0001)$.

\section{Organic Matter and Yield}

Organic matter levels showed a significant correlation with the yield of peppers and zucchini ( $P=0.0313$ and $P=0.0016$ respectively). No other crops showed a correlation between yield and organic matter levels. Appendix E contains the result of the analysis of variance testing regressions of organic matter and yield for each crop.

\section{pH}

The $\mathrm{pH}$ of soil from the plots also rose from 2003 to 2004 (Appendix F, $P<0.0001$ ). In both years, the $\mathrm{pH}$ of the high input plots was greater than that of the low input plots, however, these trends were not statistically significant. From 2003 to 2004, the pH of the high input plots rose from 6.42 to 6.72 , while the $\mathrm{pH}$ of the low input plots rose from 6.37 to 6.62 (Figure 15).

\section{Soil Fertility}

With the exception of copper, all of the soil nutrients tested showed higher

concentrations in the high input treatments for both years (Appendix F). In 2003 and 2004, soil potassium levels in the high input plots were $37 \%$ and $36 \%$ higher, respectively, than the levels observed in the low input plots $(P<0.0001)$ (Figure 16). Soil phosphorus levels in the high input plots were significantly higher than the levels seen in the low input plots - 43\% and 58\% higher, 
respectively, in years 2003 and $2004(P=0.0001)$ (Figure 17). The level of sodium in the soil dropped from 2003 to 2004 ( $P=0.0002)$ and was lower in low input plots than high input plots $(\mathrm{P}=0.0015)$ (Figure 18). No significant differences in calcium levels were observed between years or treatments (Figure 19). Soil magnesium levels in the high input plots were nearly double the levels found in the low input plots both years $(P<0.0001)$. The magnesium levels were significantly greater in 2004 than in $2003(P=0.0091)$, with similar trends in both high and low input plots (Figure 20). Copper concentrations in the soil were higher in the low input plots than in the high input plots $(P=0.0374)$ (Figure 21). Soil manganese levels were significantly greater in the high input plots than the low input plots $(P=0.0003)$ and were greater in 2004 than in 2003 ( $P=0.0455$ ) (Figure 22). Soil zinc levels were higher in the high input plots in both years $(P=0.0015)$. However, unlike all other soil nutrients besides sodium, the concentration of zinc dropped from 2003 to 2004 ( $P=0.0335$ ) (Figure 23).

\section{Labor}

The labor requirements for the eight market garden crops varied widely. The high input plots had higher labor totals than the low input plots in all crops except peas. The beans required the most labor of any crops over both years of the study. In 2004, 80 hours of work (both high and low input plots) were put into producing beans, the bulk of which was expended in harvesting (Figure 24). Tomatoes required the second highest amount of labor, with the bulk of the time being spent harvesting and mulching. In 2003, 44 hours were spent producing tomatoes, while 42 hours were spent on them in 2003 (Figure 25). The pumpkins required the least labor of all the crops $-5 \frac{1}{2} 2$ hours was spent each year growing pumpkins. The only difference in high and low input for the pumpkins was the compost application (Figure 26). Spinach and lettuce also required relatively little labor. The bulk of the labor for both crops was expended in planting. The difference in high and low input for both crops lies mainly in the compost 
application on the high input plots (Figures 27 and 28). Little variation was observed in the labor required for the pea crops across years and treatments. In 2003, 21 hours were spent on peas, while 22 hours were spent in 2004. The most labor was expended in the harvesting of peas (Figure 29). Aside from the compost application time, the high and low input peppers required the same amount of labor. More time was spent mulching the peppers than any other activity (Figure 30). Most of the time producing zucchini was expended in the harvest of the crop. In both 2003 and 2004, 34 hours were spent in working with zucchini (Figure 31).

\section{Pests}

Specific pests were found to be particularly harmful to certain crops in the study area. In beans, the Mexican bean beetle (Epilachna varivestis), bean common mosaic virus (BCMV), bean yellow mosaic virus (BYMV), and groundhogs (Marmota monax) were the primary pests. Root rots were the major pest concerns in peas and spinach. Tomatoes experienced limited pest pressure from Colorado potato beetles (Leptinotarsa decemlineata) early in their growth and tomato hornworms (Manduca quinquemaculata) later on in the season. Early blight (Alternaria solani) also affected tomatoes. Peppers remained relatively free of any major pest damage. Some signs of soft rot were observed in peppers; however, the issue never became problematic as the fruits were harvested green. The main pests of lettuce were groundhogs and deer, although some bottom rot occurred in damp conditions. The cucurbitaceous crops experienced pest pressure from powdery mildew (Sphaerotheca fuliginea), squash bugs (Anasa tristis), and vine borers (Melittia cucurbitae). Striped and spotted cucumber beetles (Acalymma vittatum and Diabrotica undecimpunctata howardii) were once the major pest concern for zucchini and pumpkins, however, since row covers have been utilized until the flowering stage, cucumber beetle incidence is no longer a major concern. This list certainly does not represent all the pests of these particular crops. 
The pests that have proven to be the most serious problems were Mexican bean beetles in the beans, early blight in the tomatoes, powdery mildew in the zucchini, and pre-emergence root rot in the spinach and peas. Root rots affected both the spinach and the pea crops in both years, resulting in poor stands (Figures 32 \& 13); however, there were no significant differences in emergence rates among treatments (Appendix H). In 2004, the progression of early blight in tomatoes was similar in both the high and low input plots, with no significant differences between the two (Appendix H) (Figure 33). Powdery mildew levels in 2003 in the zucchini plots were similar in both high and low input treatments, with an increasing trend over time (Figure 34). In 2004, trends were similar, again without a noticeable difference between the high and low input plots. Peppers, lettuce, and pumpkins did not experience any serious pest pressure, or insufficient data was collected. 


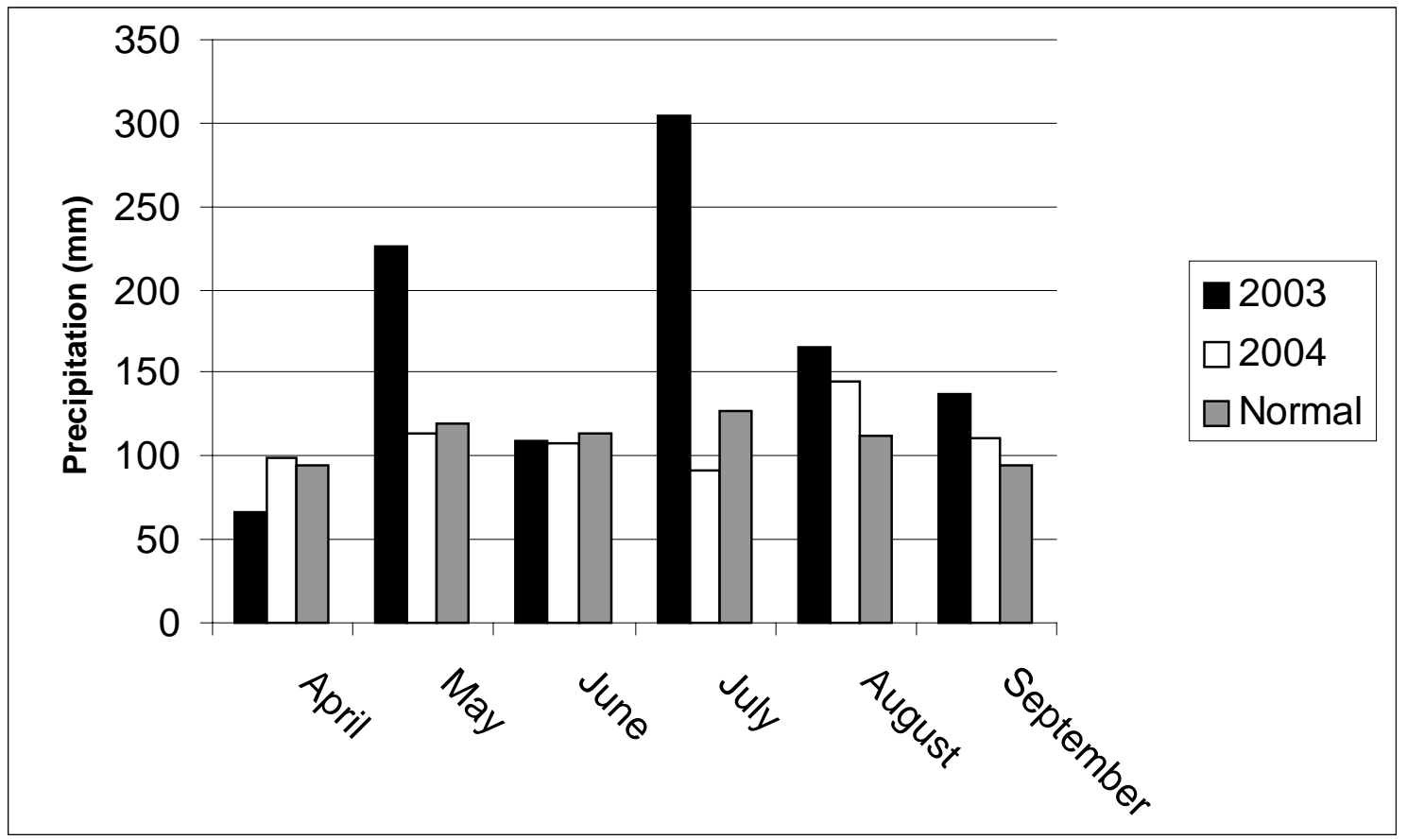

Figure 1. Monthly precipitation during the growing season from 2003 to 2004. Normal represents the average from 1971 to 2000.

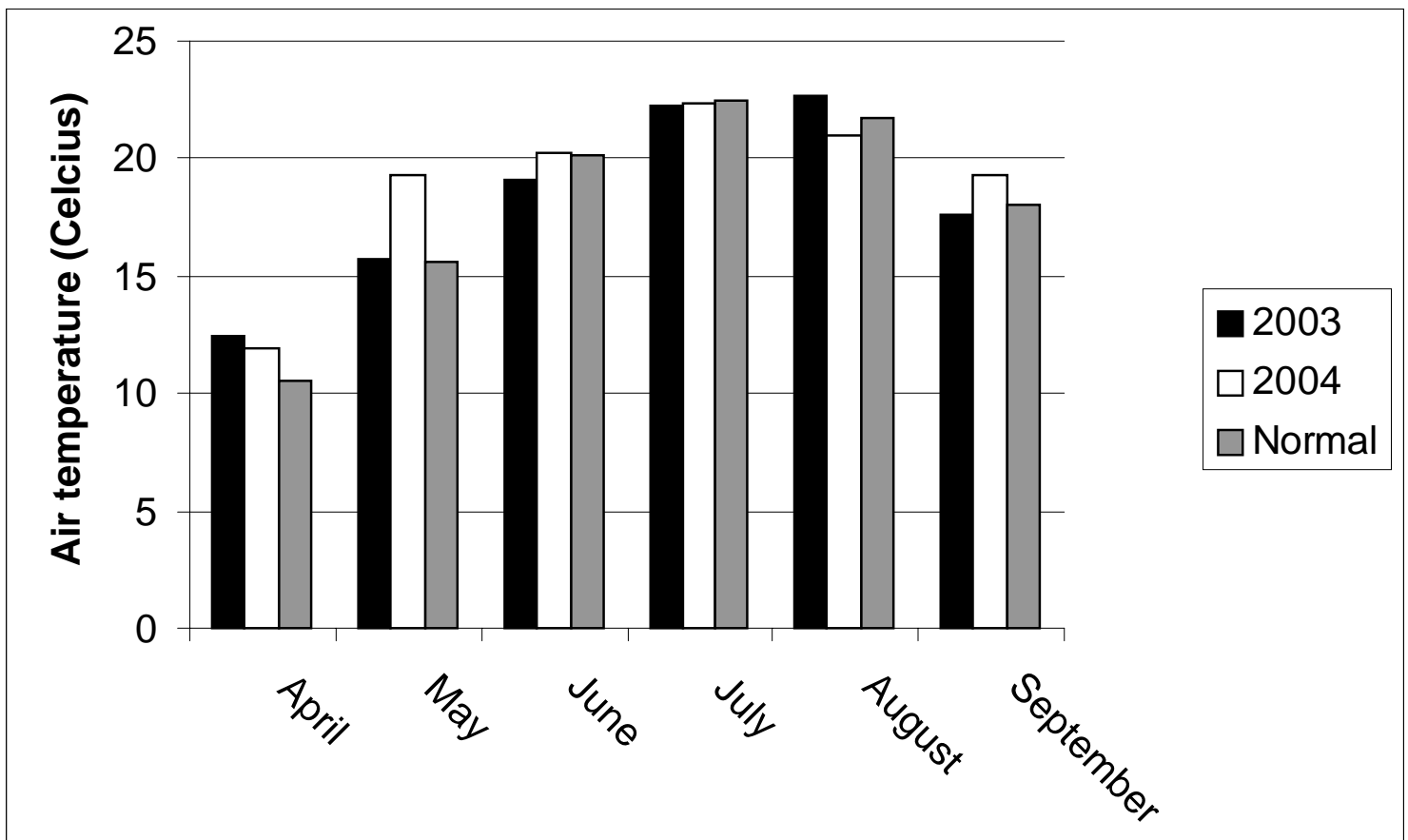

Figure 2. Monthly air temperature during the growing season from 2003 to 2004 . Normal represents the average from 1971 to 2000. 


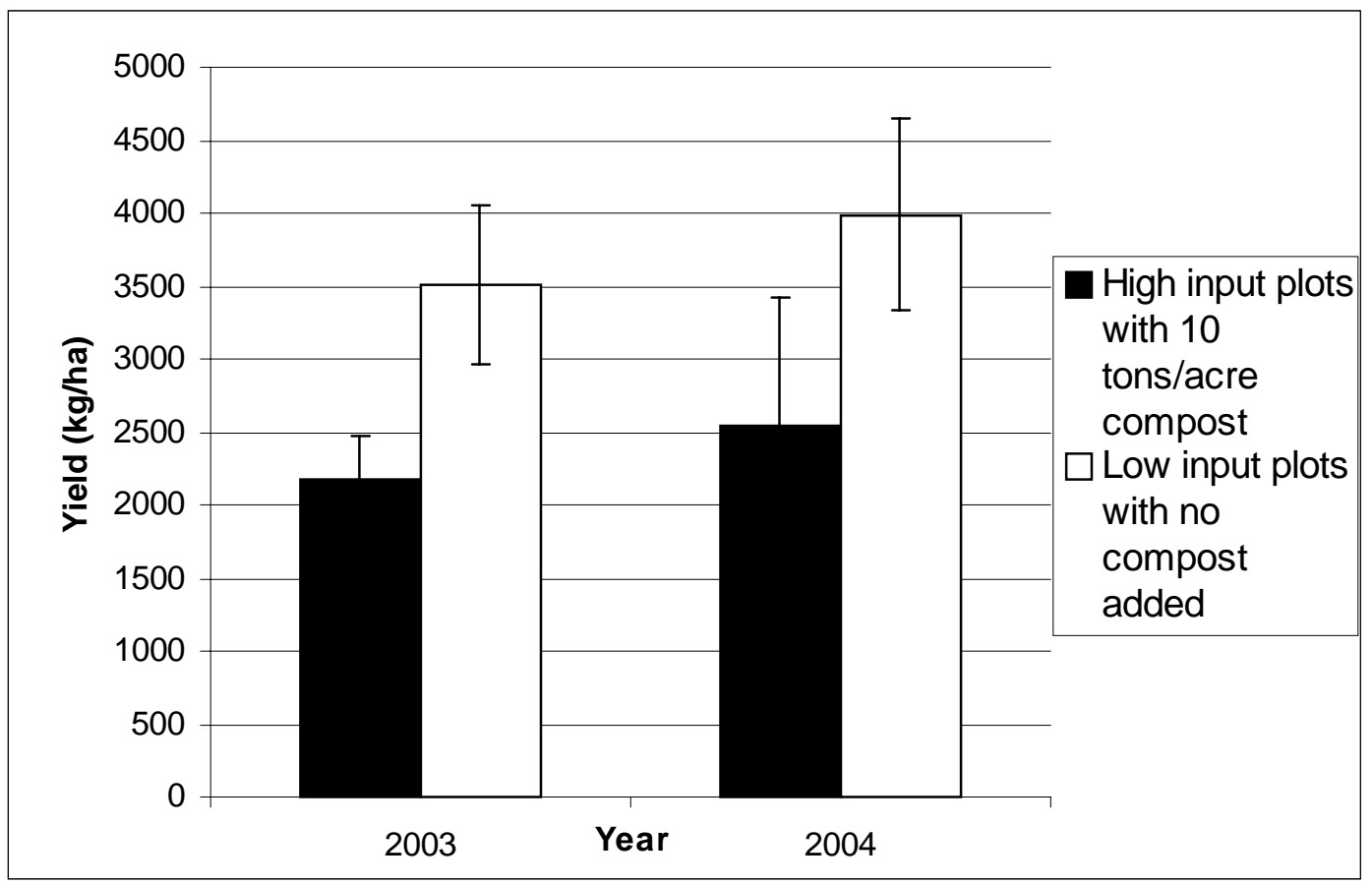

Figure 3. Pea yields in high and low input plots in 2003 and 2004. The error bars represent the standard error of the mean. Significant overall treatment effect $(P=0.0476)$.

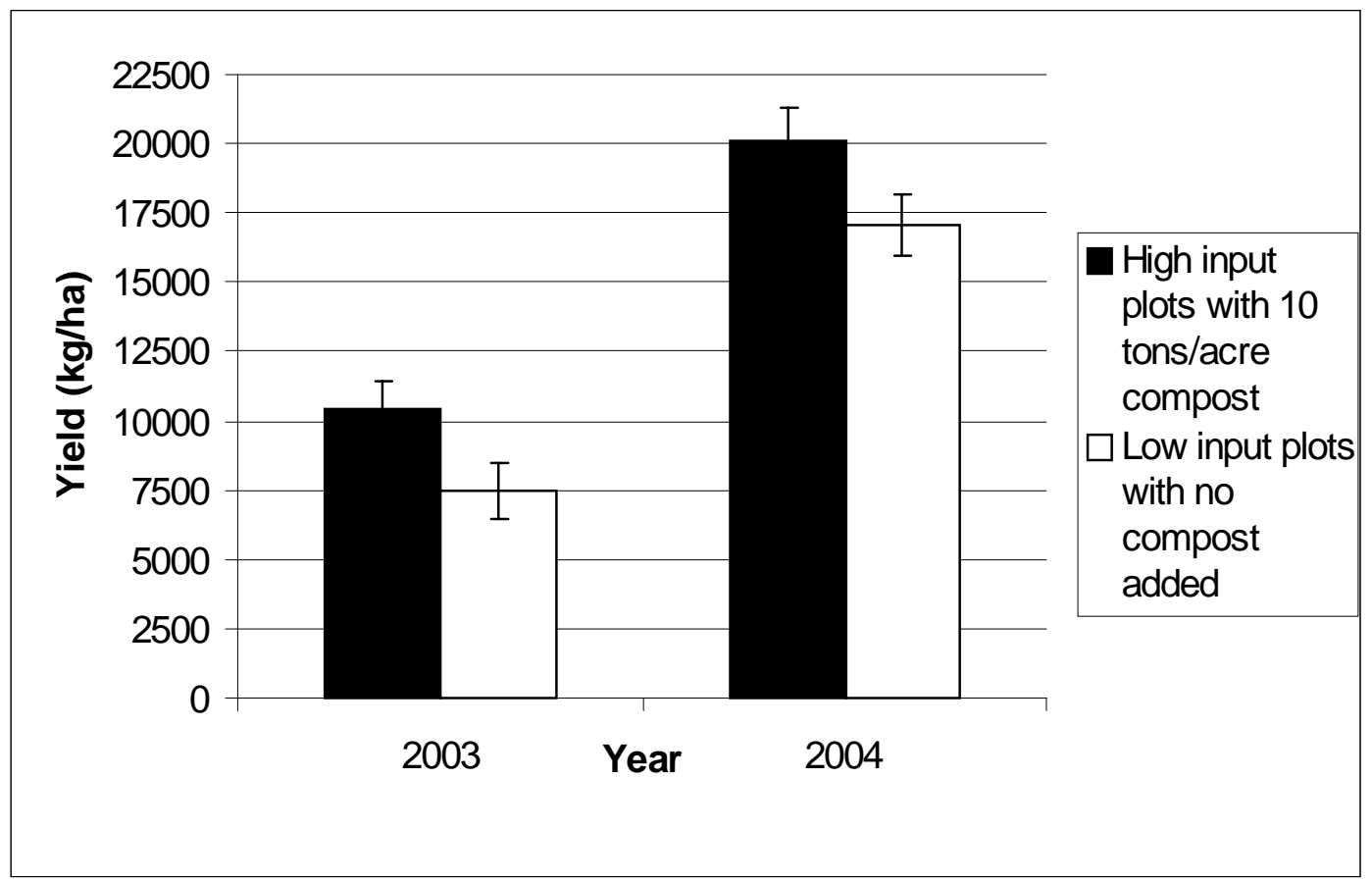

Figure 4. Spring bean yields in high and low input plots in 2003 and 2004. The error bars represent the standard error of the mean. Significant year effect $(P<0.0001)$ and overall treatment effect $(P=0.0158)$. 


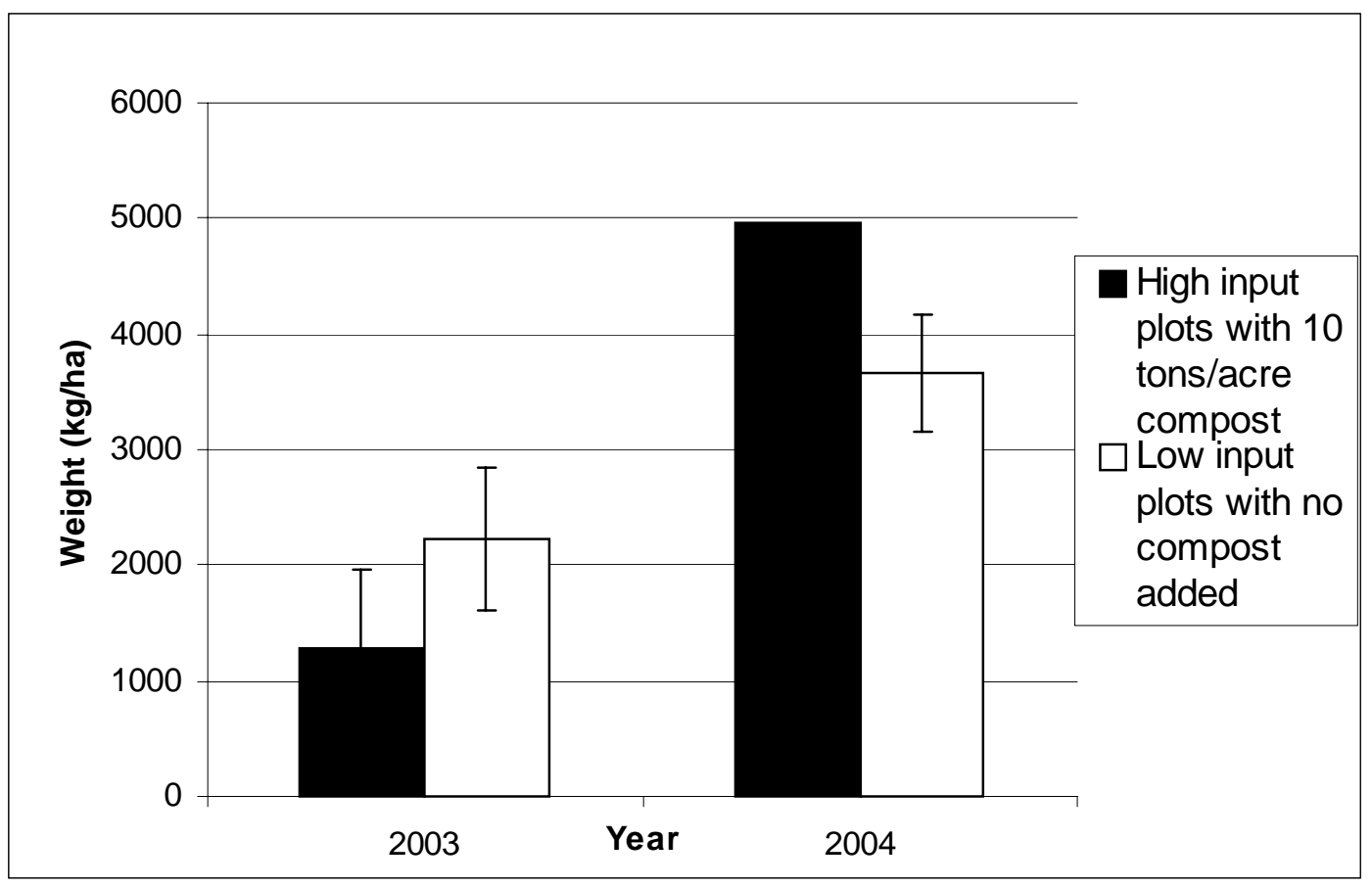

Figure 5. Fall bean yields in high and low input plots in 2003 and 2004. The error bars represent the standard error of the mean. Significant year effect $(P=0.0253)$.

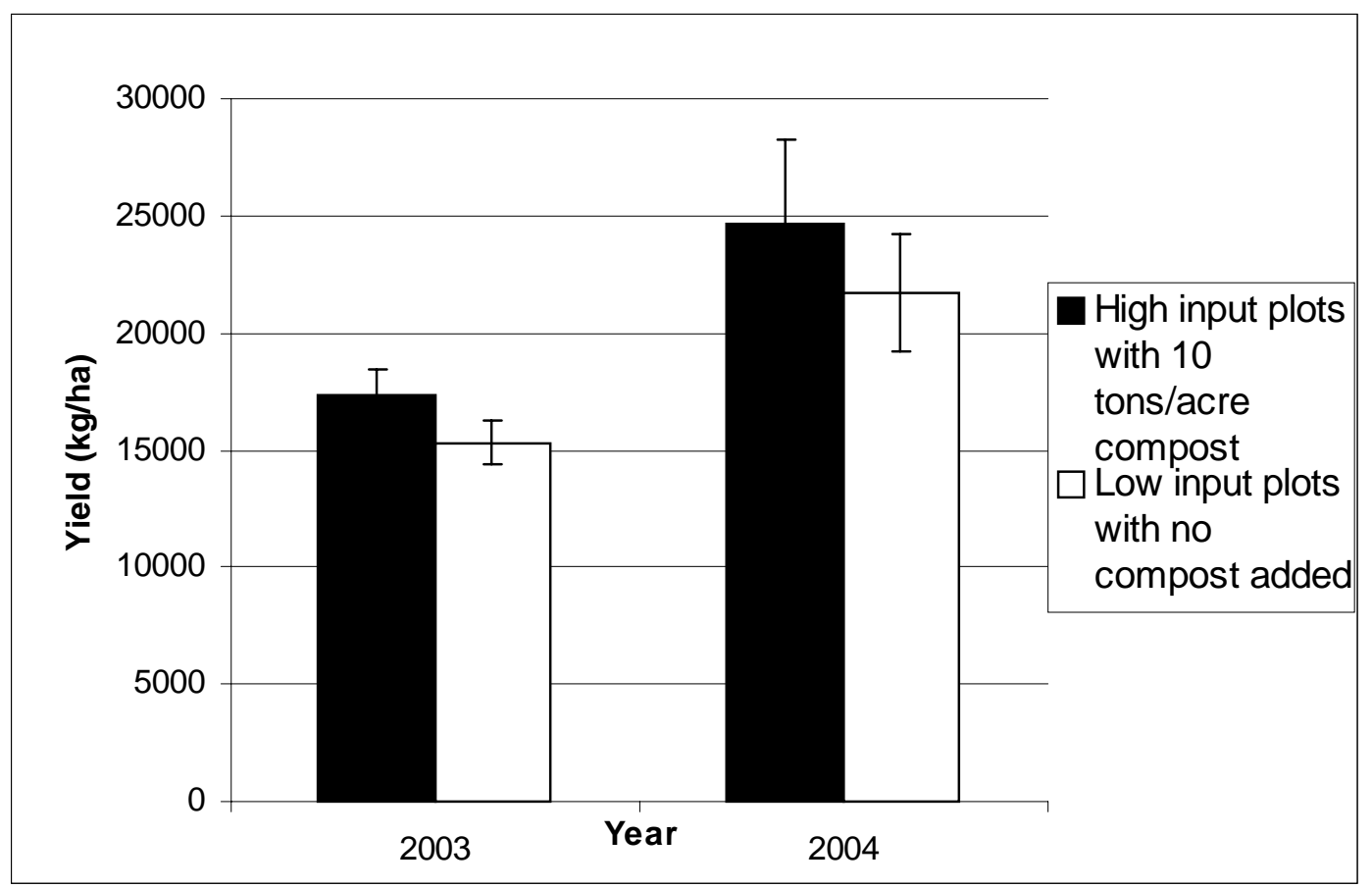

Figure 6. Pepper yields in high and low input plots in 2003 and 2004. The error bars represent the standard error of the mean. Significant year effect $(P=0.0118)$. 


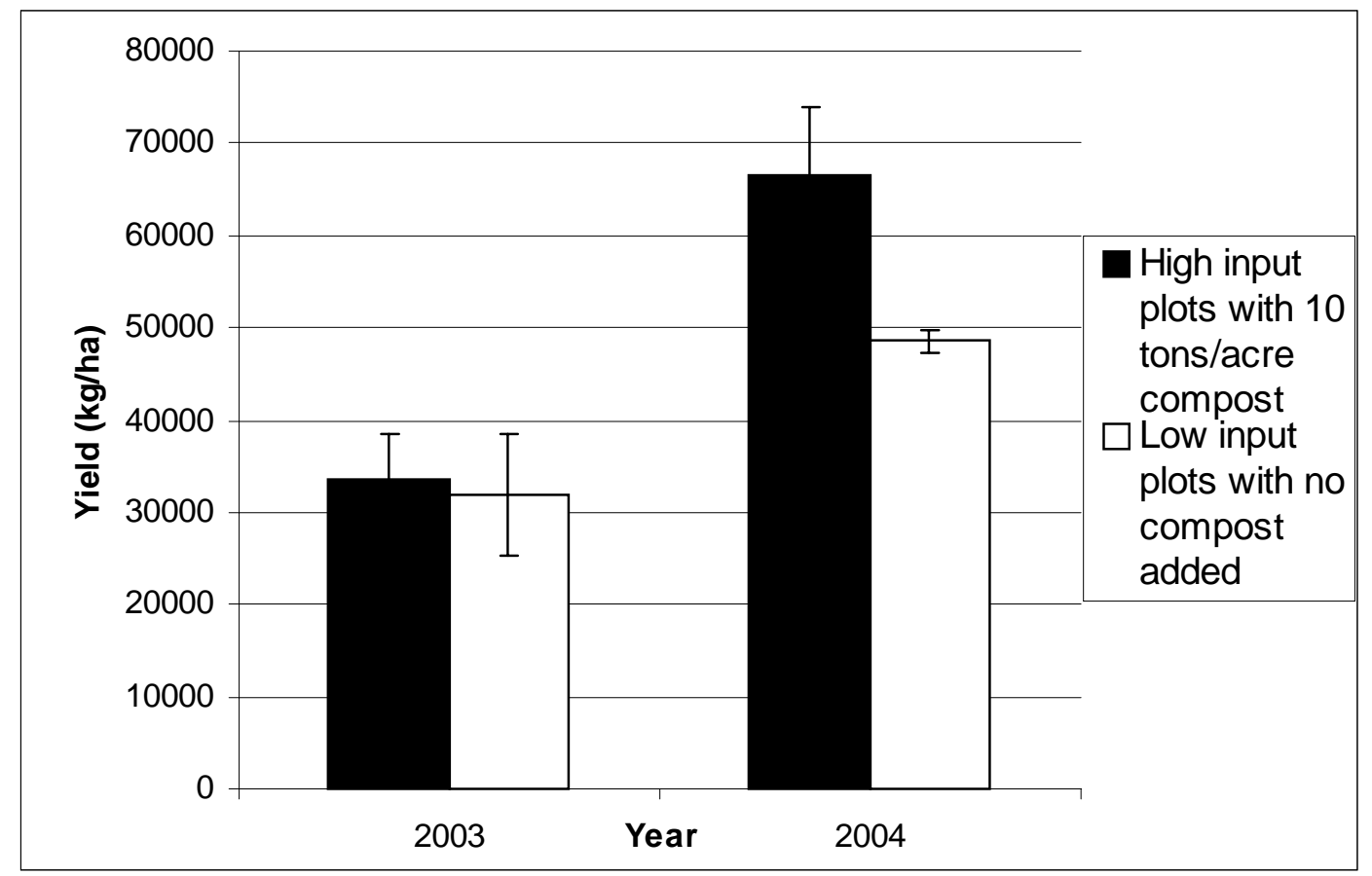

Figure 7. Tomato yields in high and low input plots in 2003 and 2004. The error bars represent the standard error of the mean. Significant year effect $(P=0.0008)$ and treatment effect in 2004 $(P=0.0427)$.

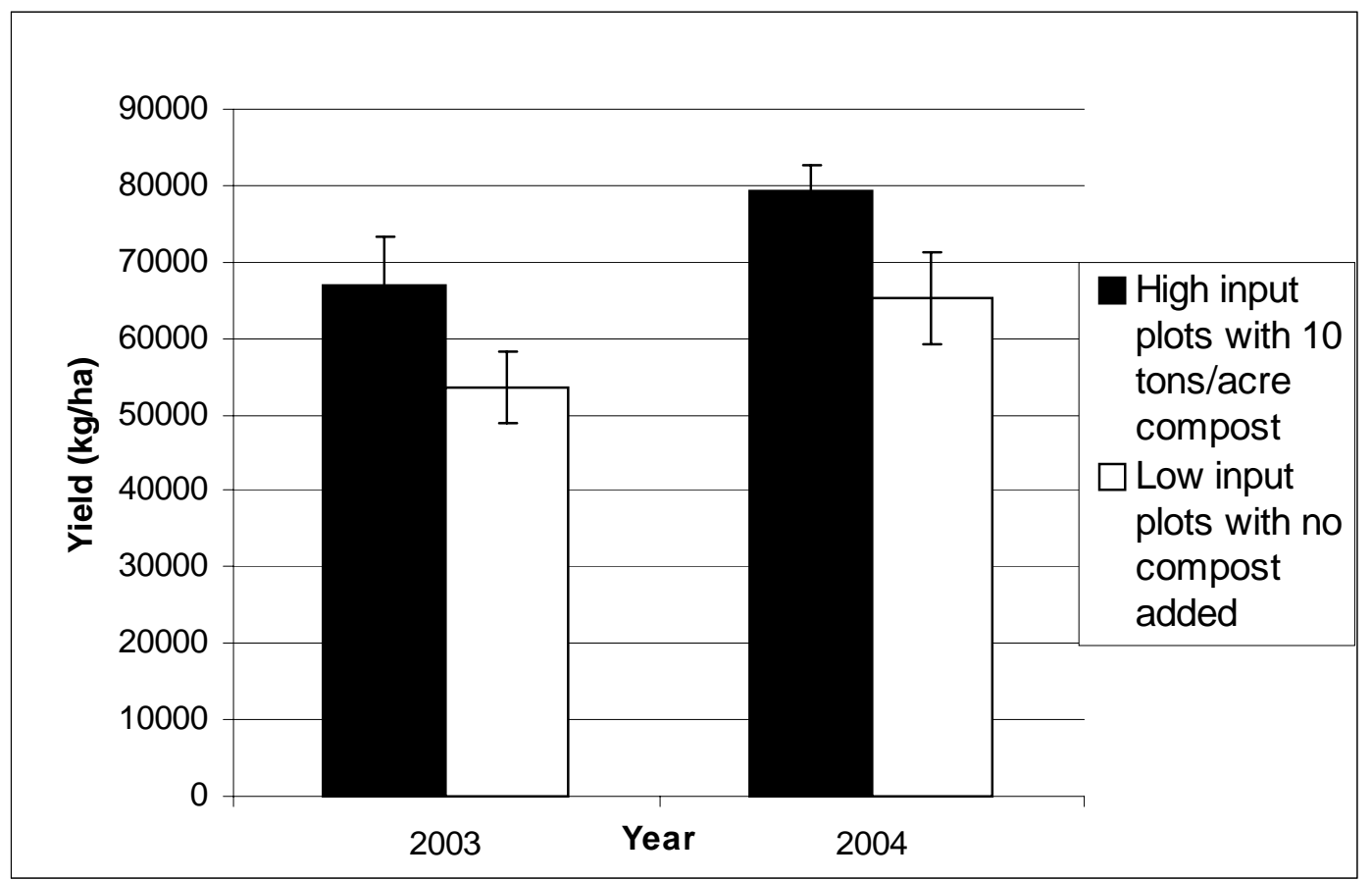

Figure 8. Zucchini yields in high and low input plots in 2003 and 2004. The error bars represent the standard error of the mean. Significant year effect $(P=0.0405)$ and overall treatment effect $(P=0.0224)$. 


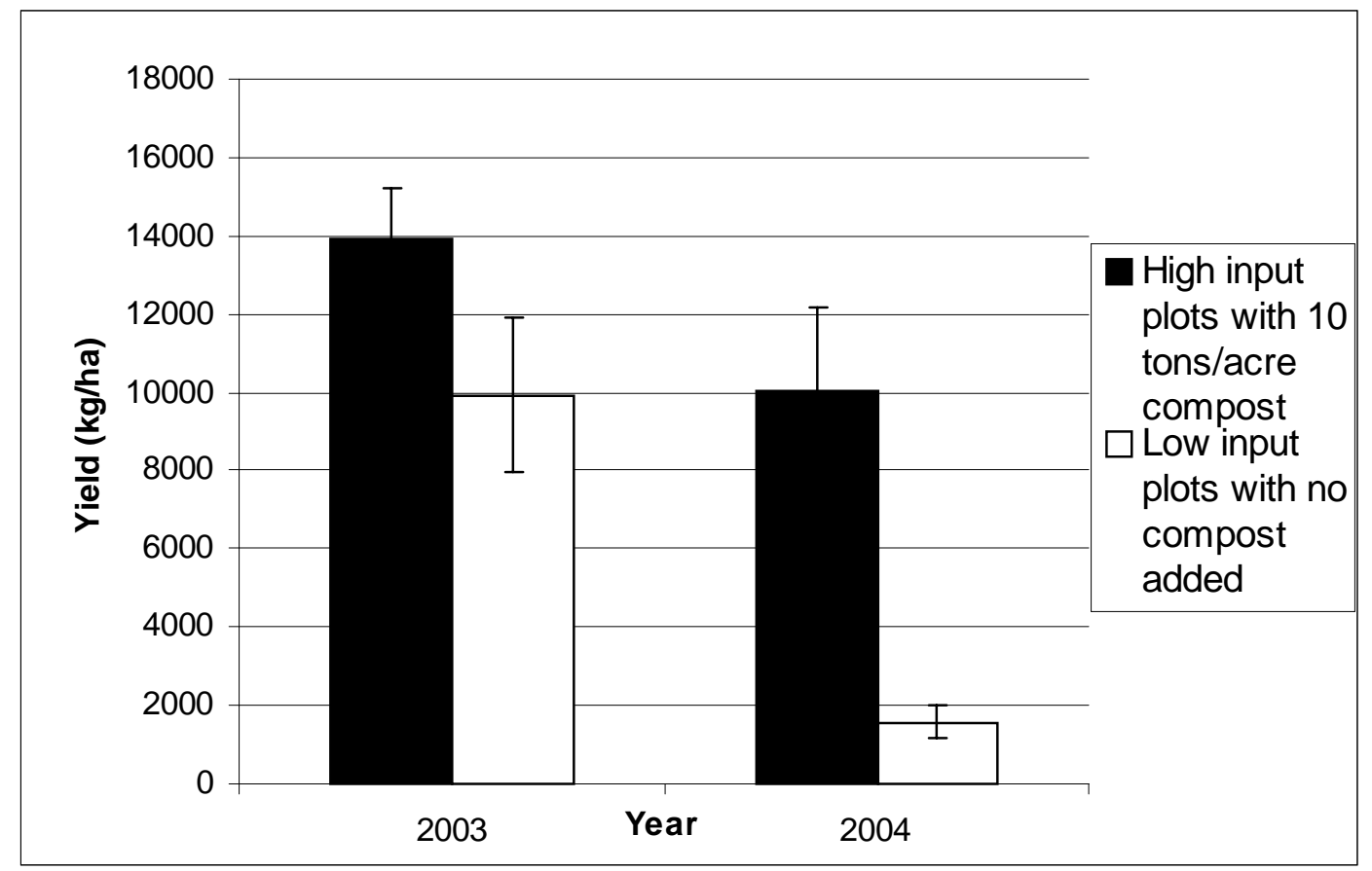

Figure 9. Pumpkin yields in high and low input plots in 2003 and 2004. The error bars represent the standard error of the mean. Significant year effect $(P=0.0024)$, overall treatment effect $(P=0.0021)$, and treatment effect in $2004(P=0.0027)$.

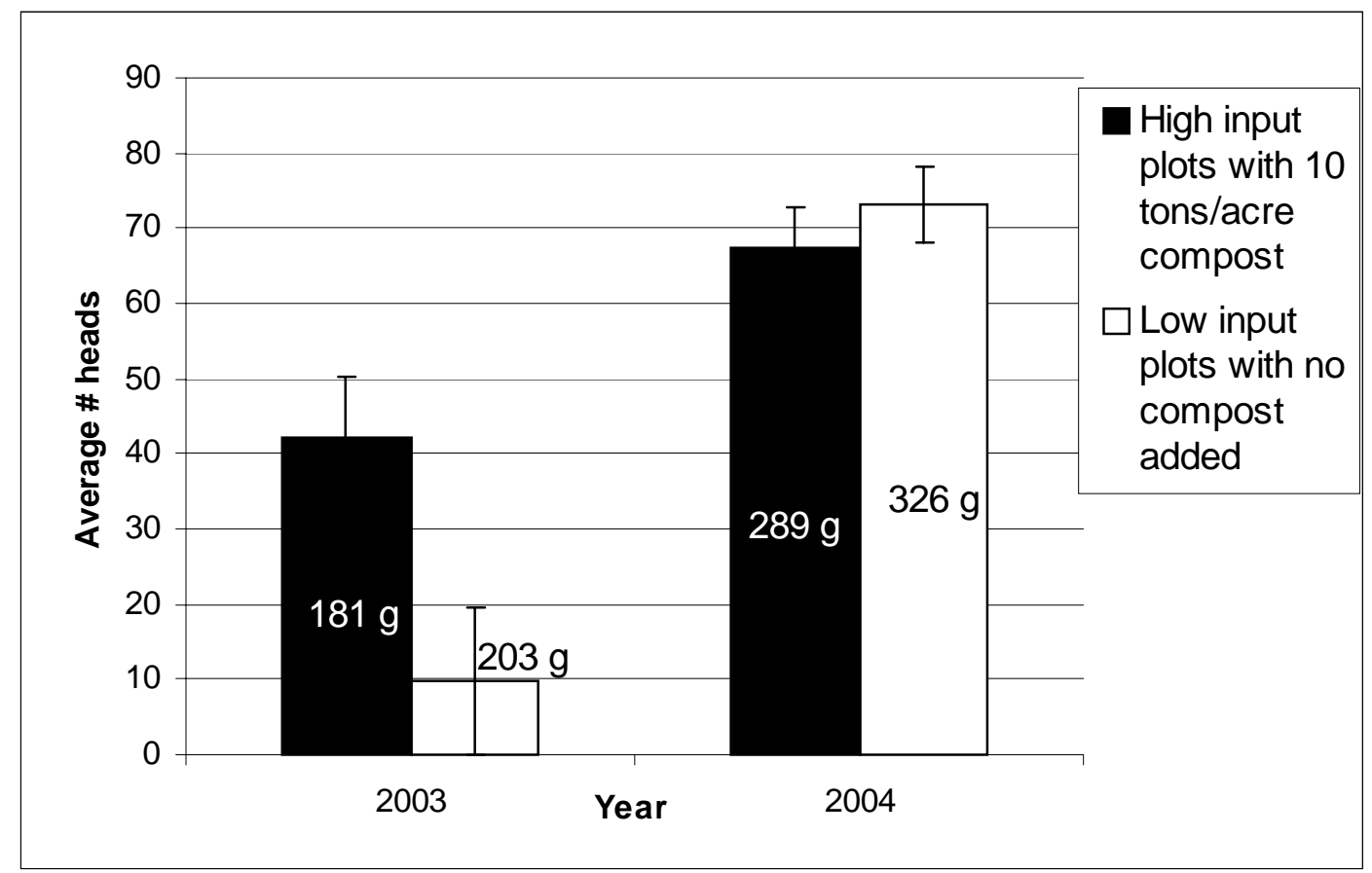

Figure 10. Spring lettuce yields in high and low input plots in 2003 and 2004. The error bars represent the standard error of the mean. Numbers contained in bars are average weight of heads. Significant year effect $(P=0.0050)$. 


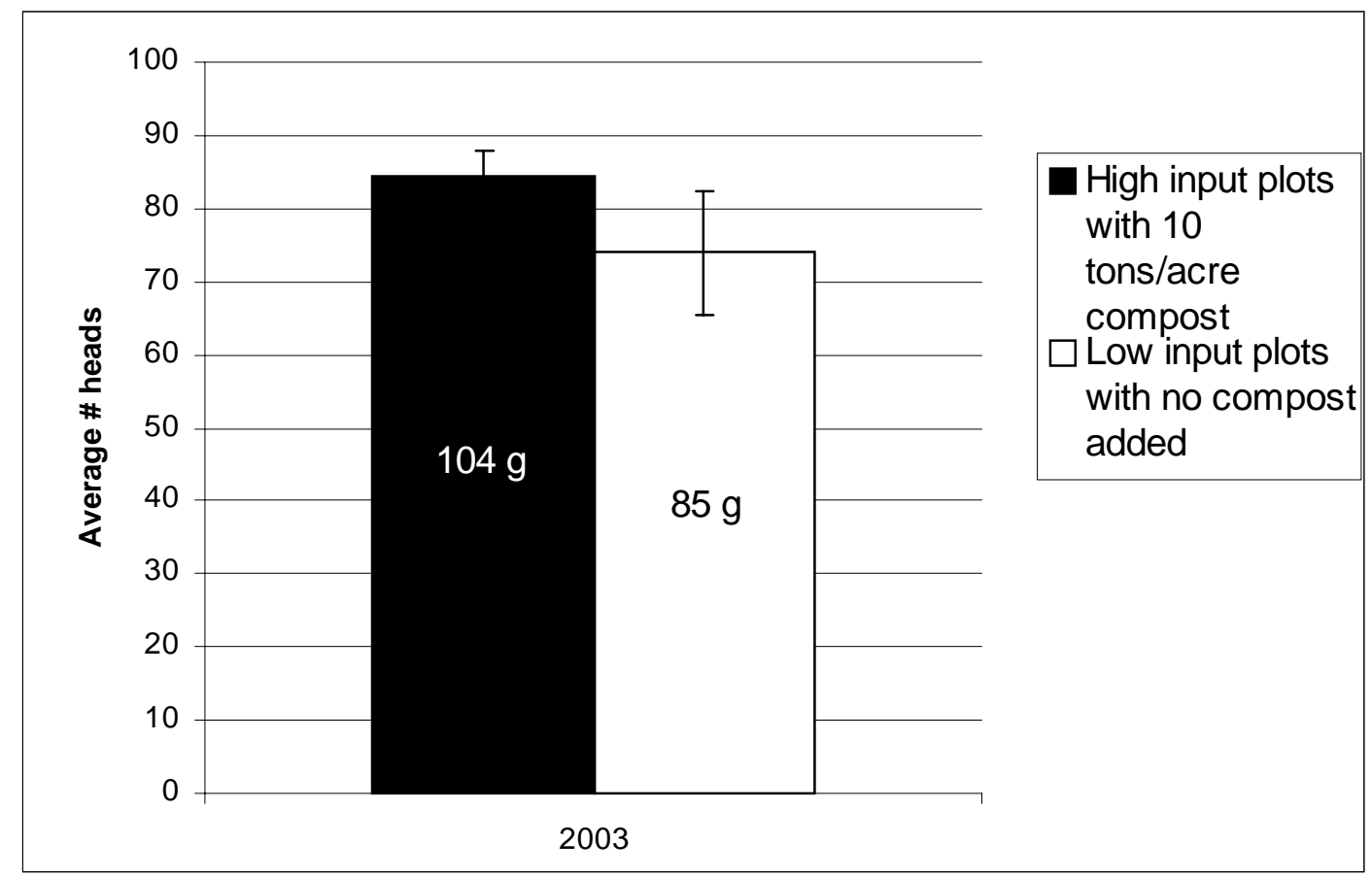

Figure 11. Fall lettuce yields in high and low input plots in 2003. The error bars represent the standard error of the mean. Numbers contained in bars are average weight of heads.

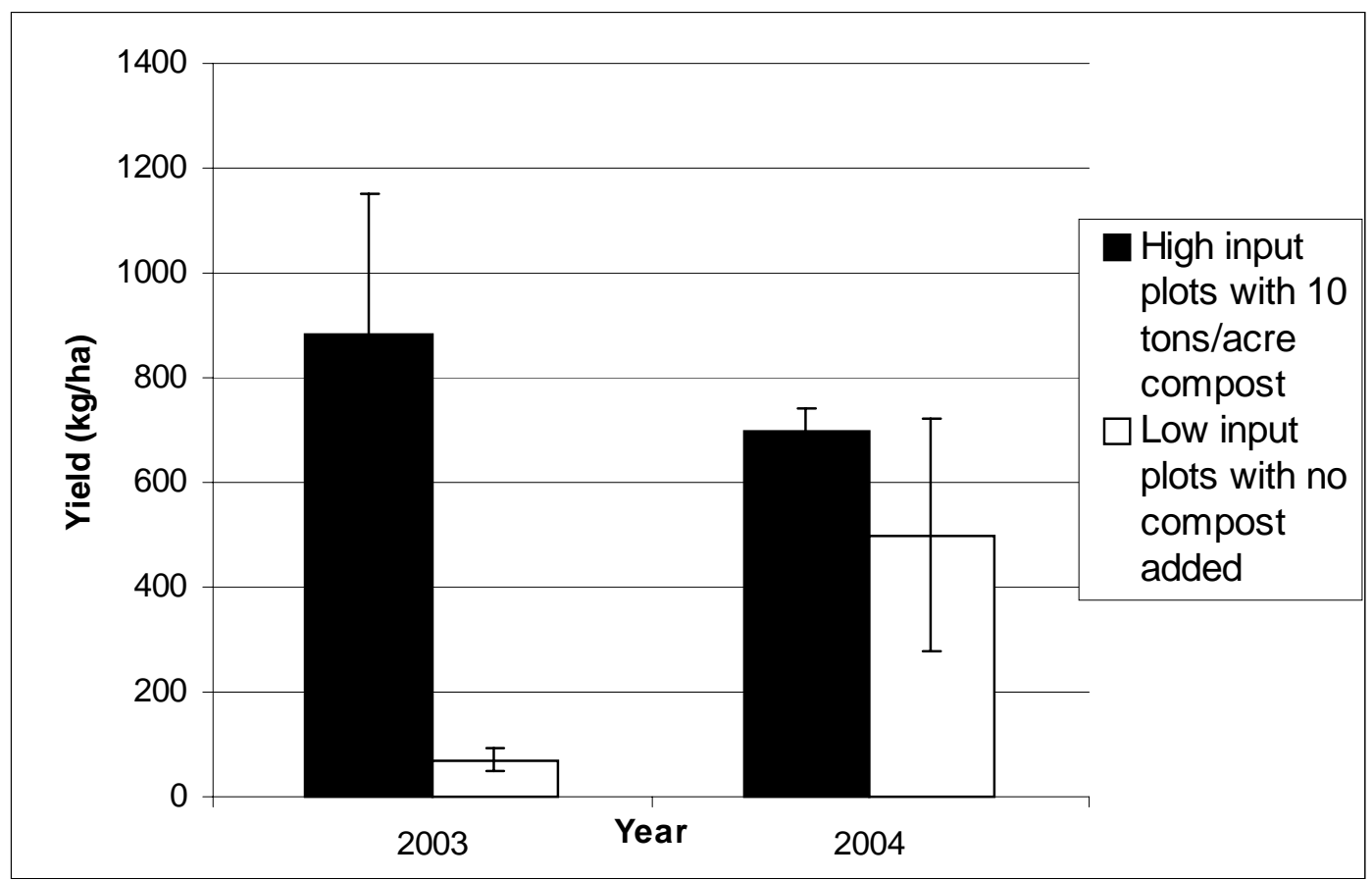

Figure 12. Spinach yields in high and low input plots in 2003 and 2004. The error bars represent the standard error of the mean. Significant overall treatment effect $(P=0.0144)$ and treatment effect in $2003(P=0.0069)$. 


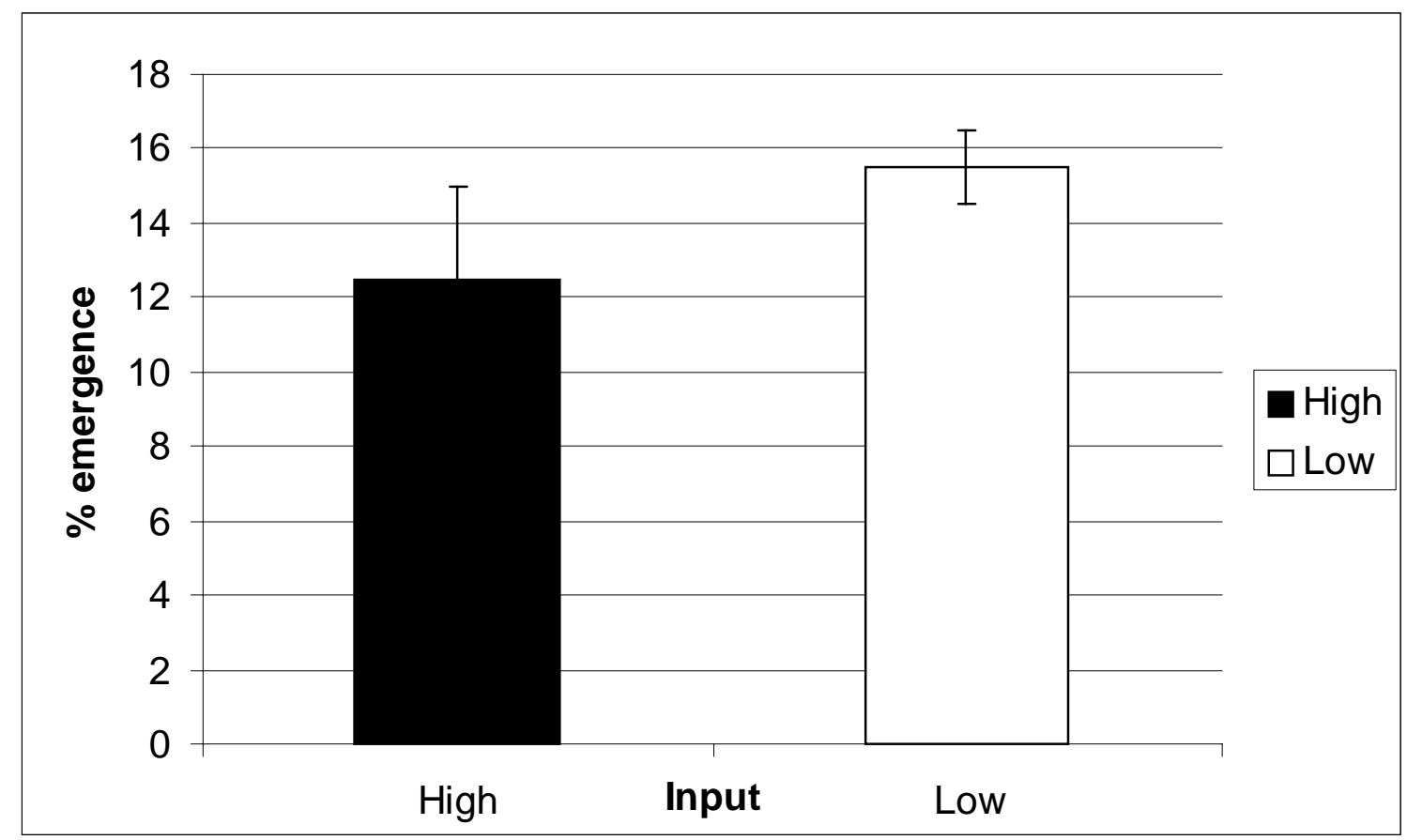

Figure 13. Pea emergence in high and low input plots in 2003. The error bars represent the standard error of the mean.

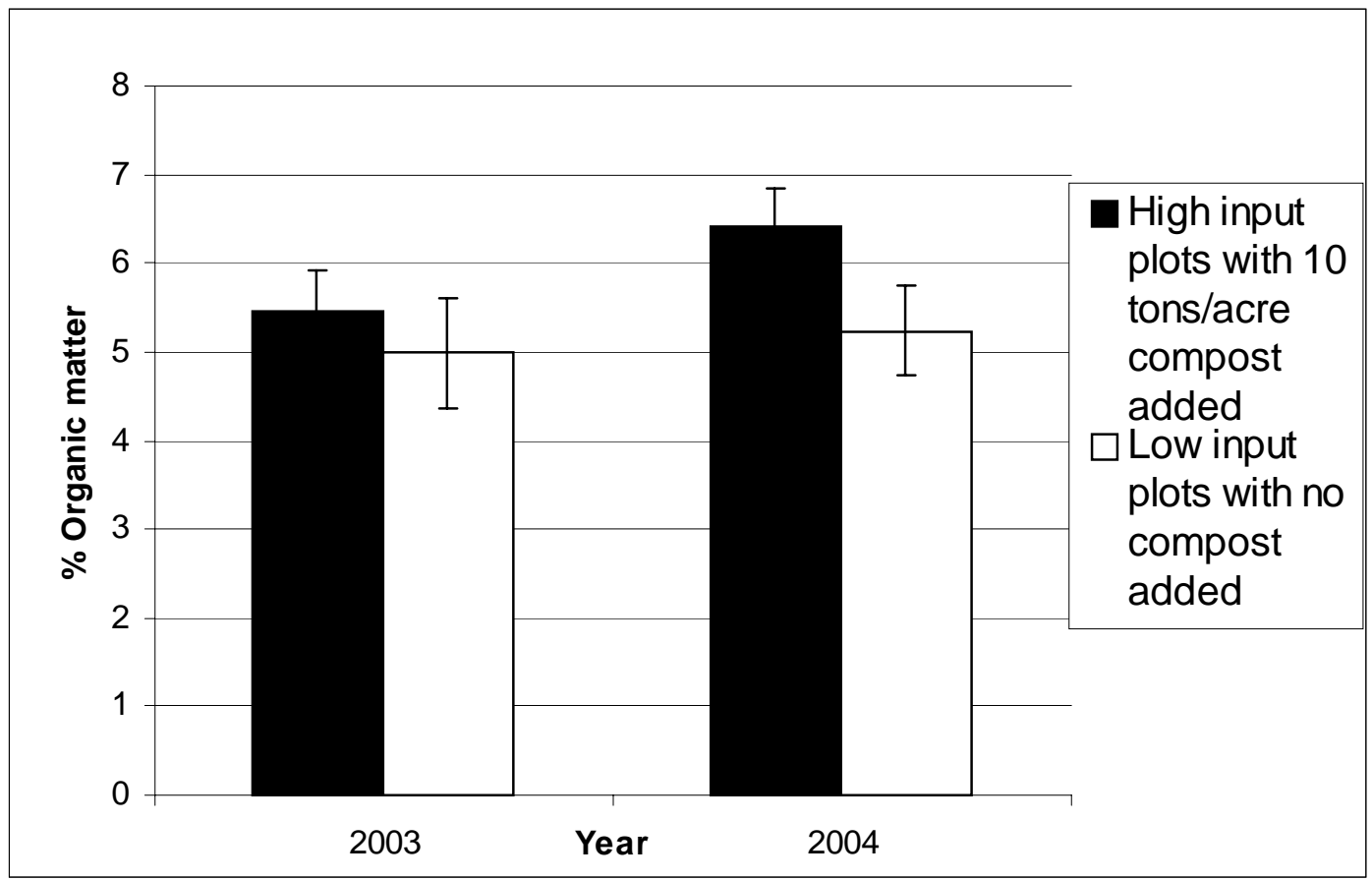

Figure 14. Organic matter in high and low input plots in 2003 and 2004. The error bars represent the standard error of the mean. Significant year effect $(P=0.0002)$ and treatment effect $(P<0.0001)$. 


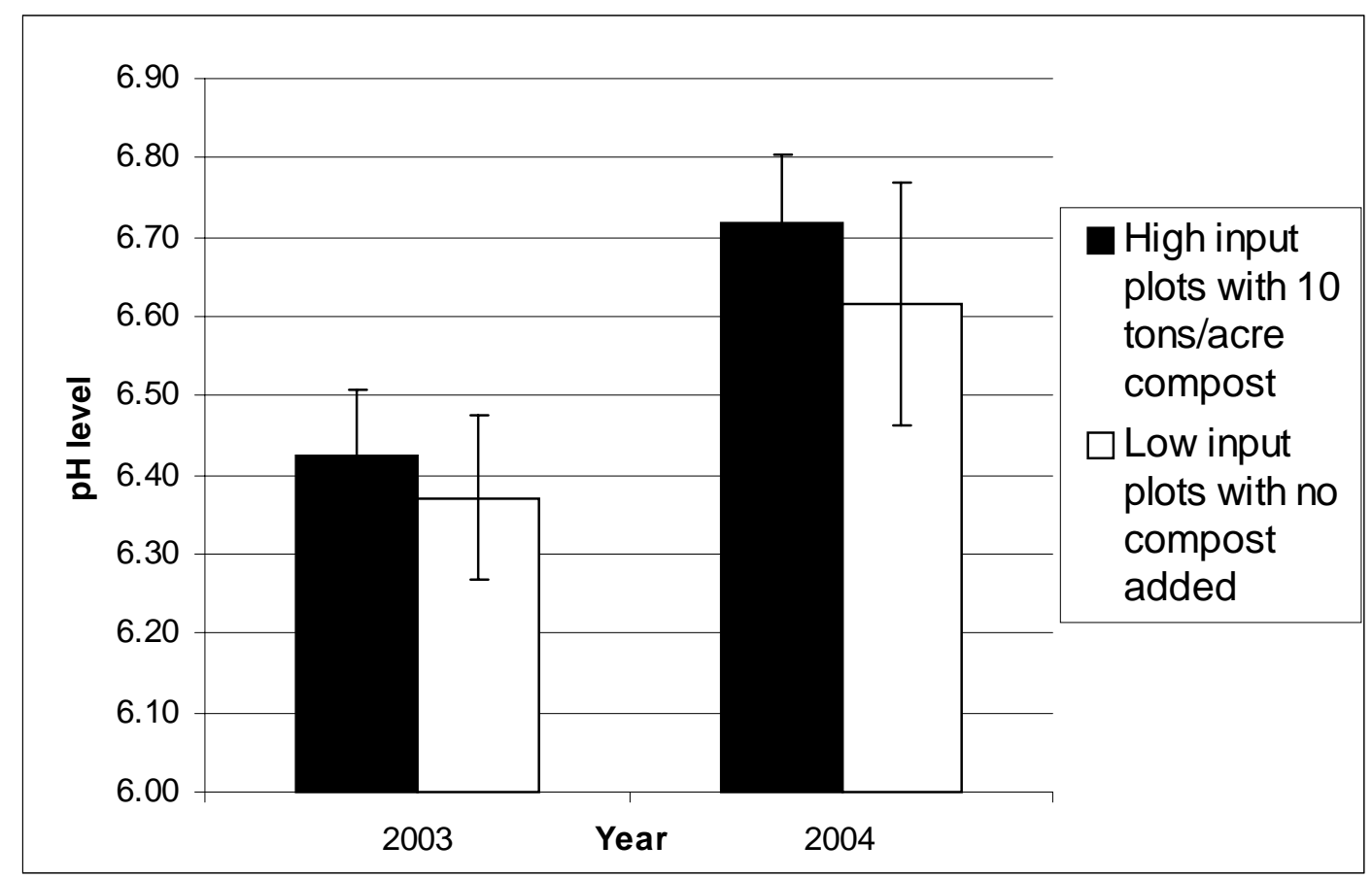

Figure 15. pH levels in high and low input plots from 2003 to 2004. The error bars represent the standard error of the mean. Significant year effect $(P<0.0001)$.

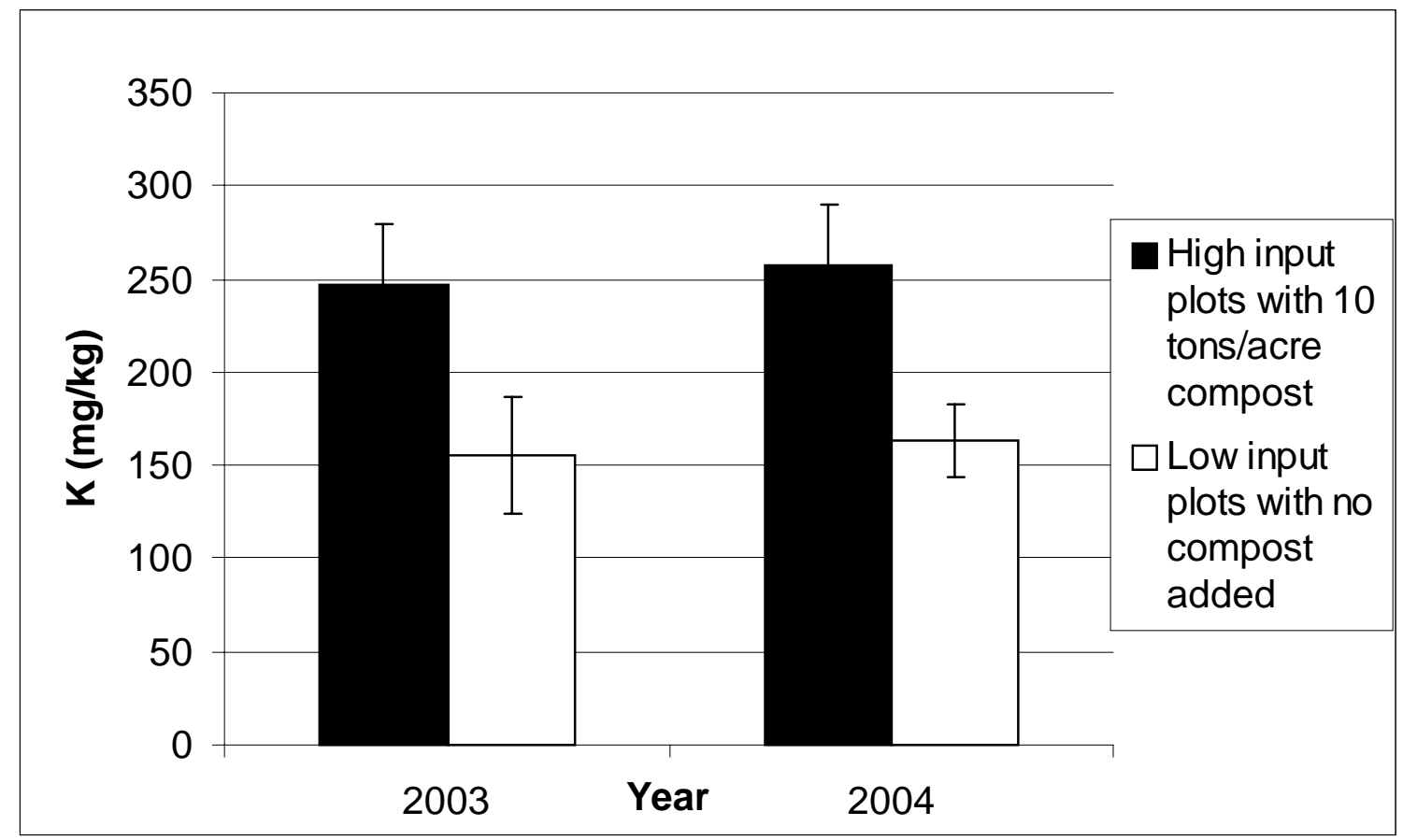

Figure 16. Potassium averages in high and low input plots in 2003 and 2004. The error bars represent the standard error of the mean. Significant treatment effect $(P<0.0001)$. 


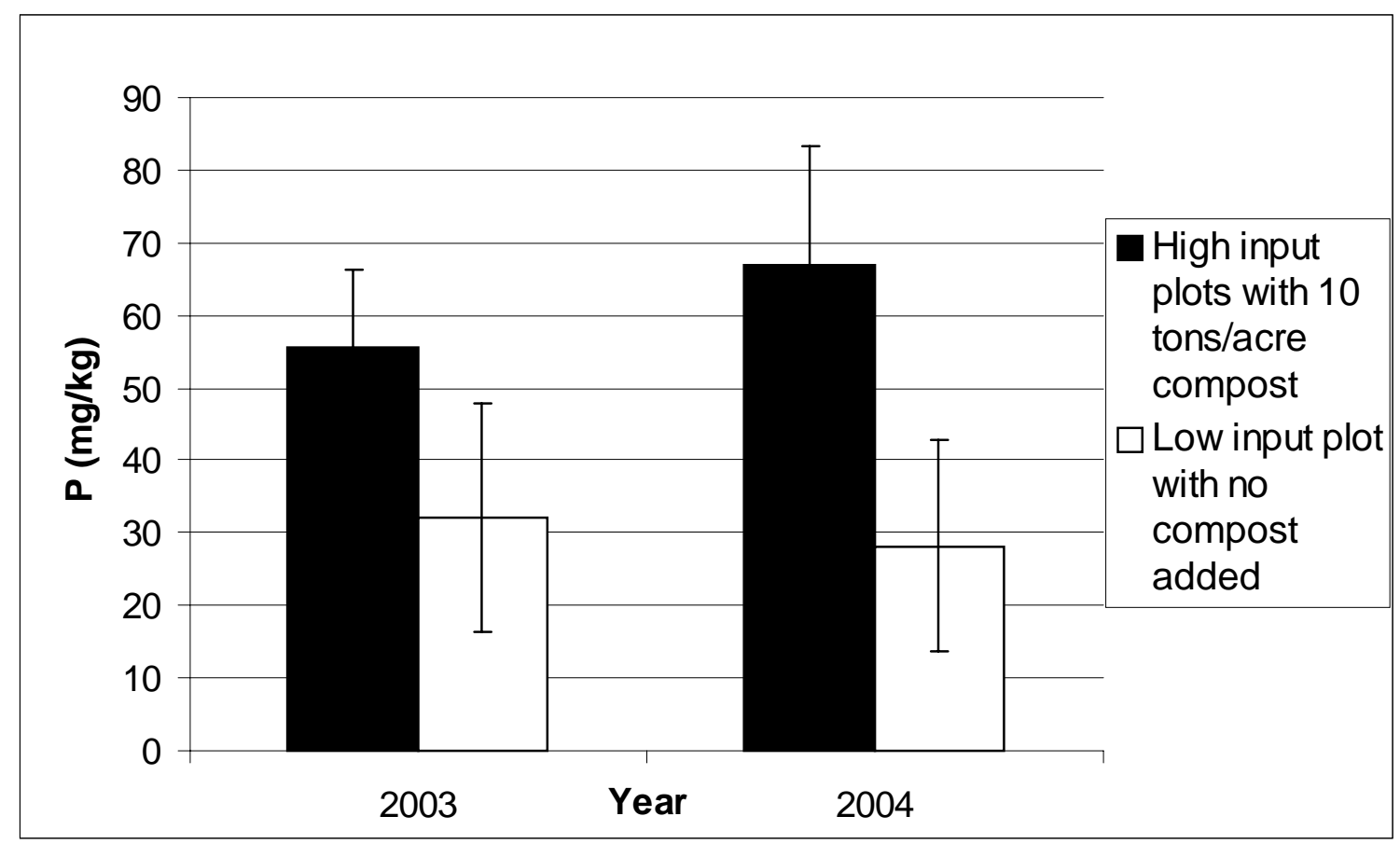

Figure 17. Phosphorus averages in high and low input plots in 2003 and 2004. The error bars represent the standard error of the mean. Significant treatment effect $(P=0.0001)$.

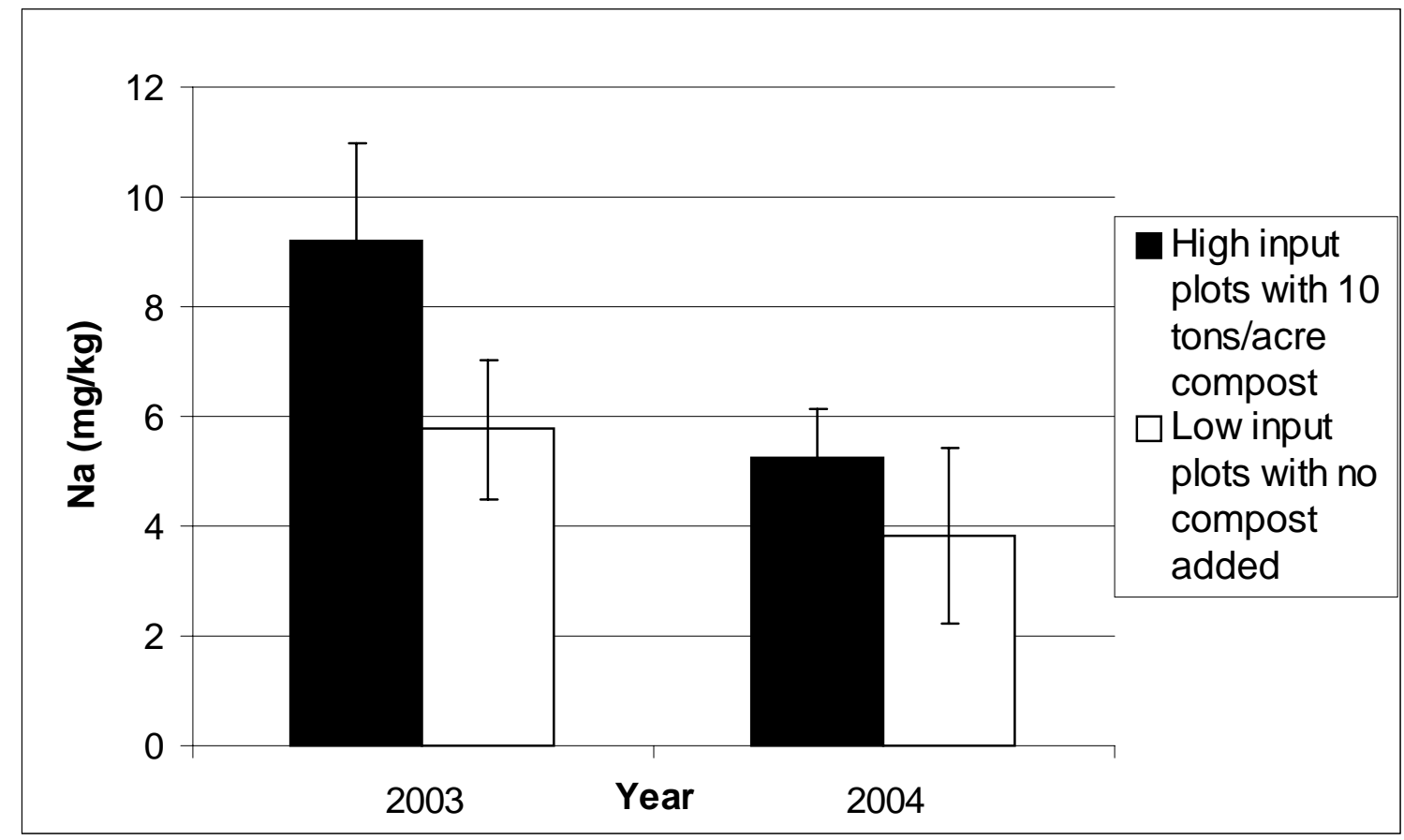

Figure 18. Sodium averages in high and low input plots in 2003 and 2004. The error bars represent the standard error of the mean. Significant year effect $(P=0.0002)$ and treatment effect $(P=0.0015)$. 


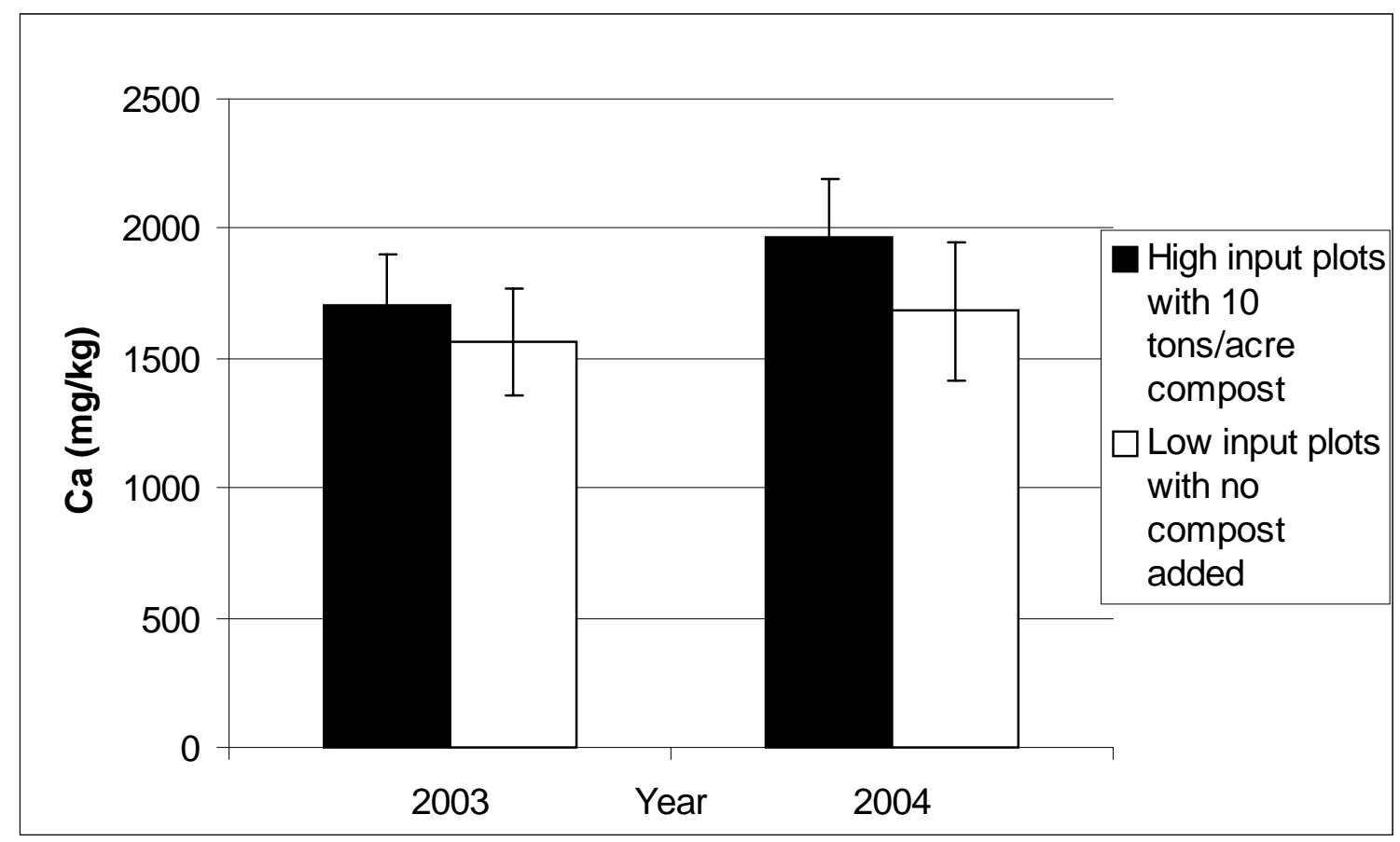

Figure 19. Calcium averages in high and low input plots in 2003 and 2004. The error bars represent the standard error of the mean.

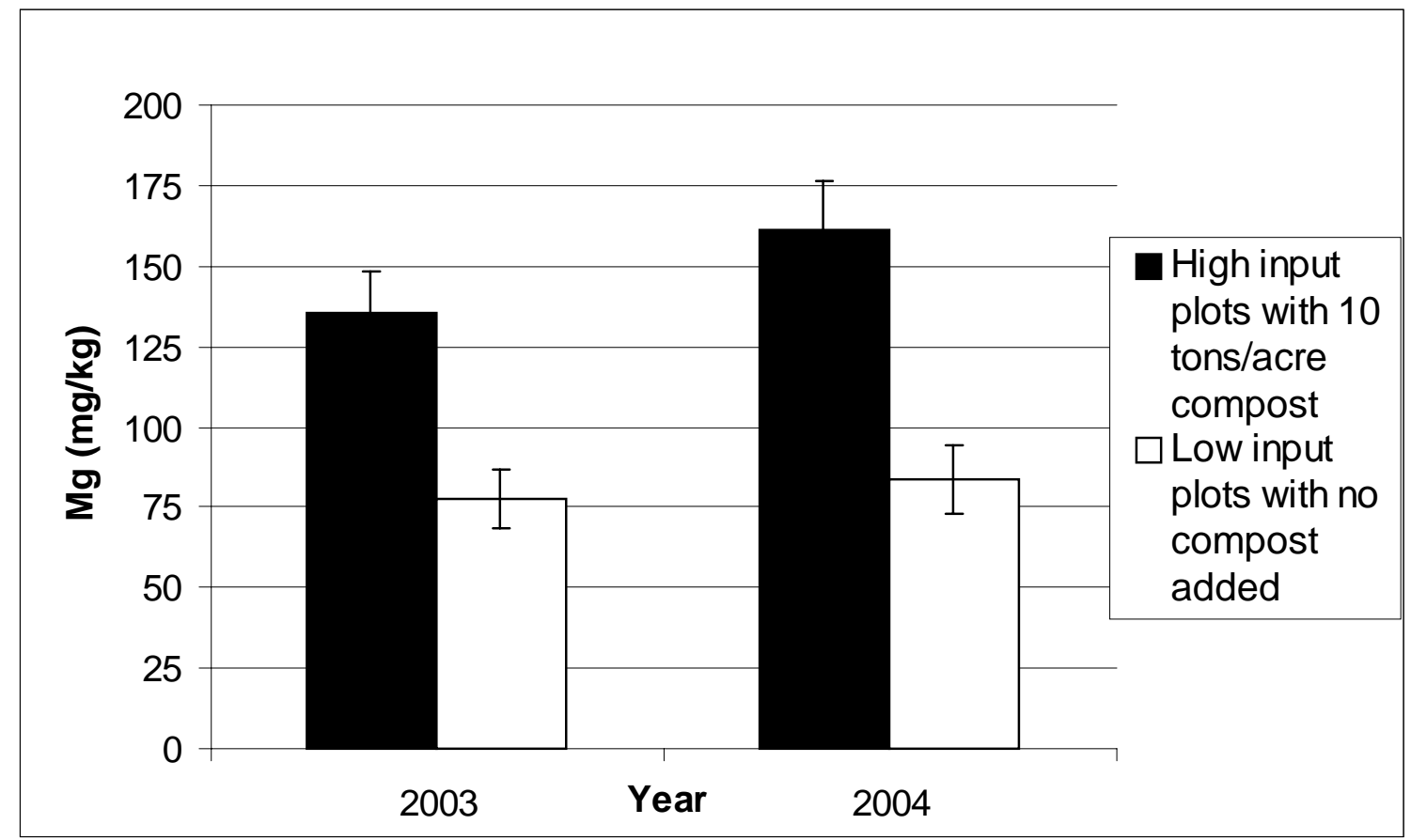

Figure 20. Magnesium averages in high and low input plots in 2003 and 2004. The error bars represent the standard error of the mean. Significant year effect $(P=0.0091)$ and overall treatment effect $(P<0.0001)$. 


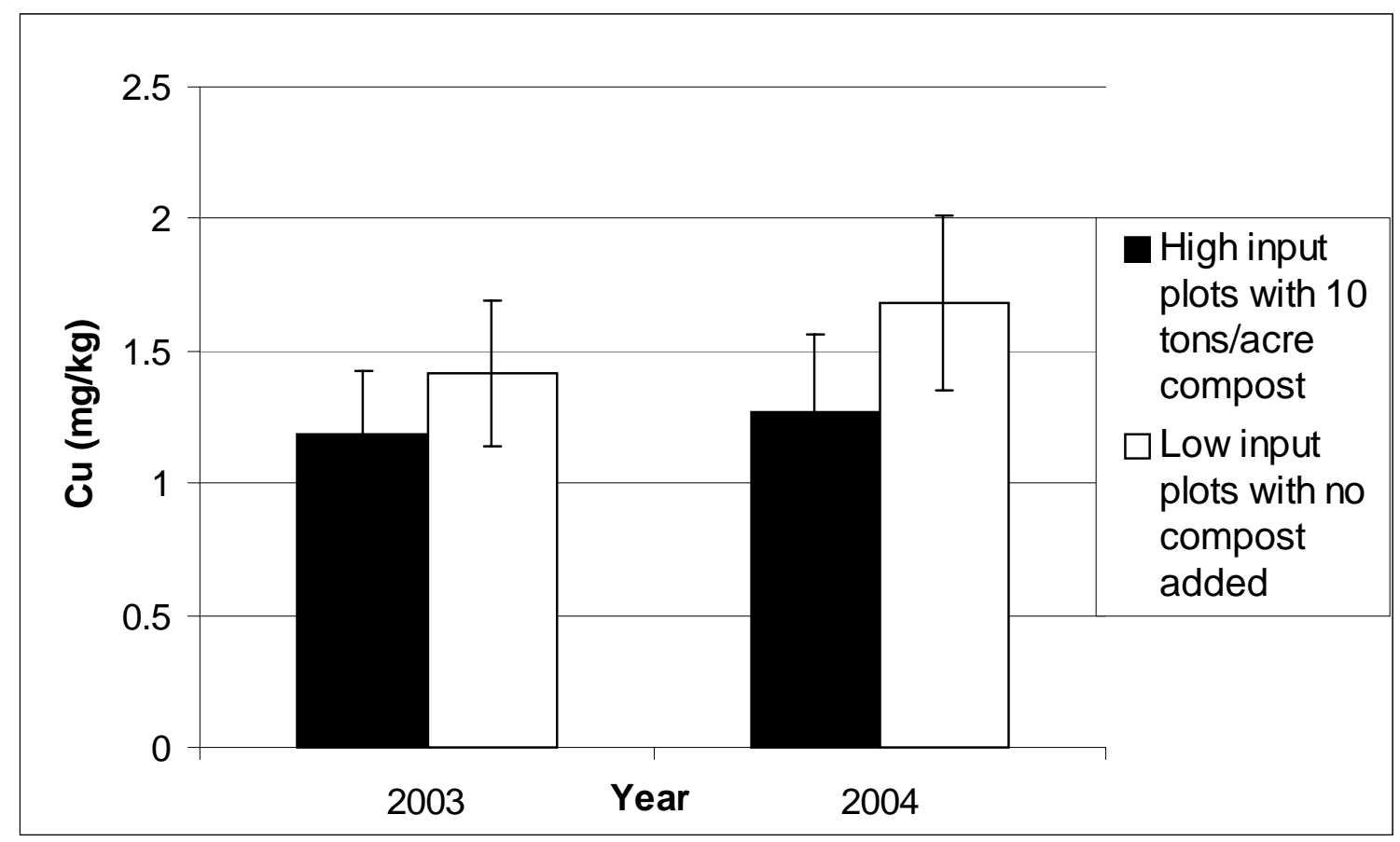

Figure 21. Copper averages in high and low input plots in 2003 and 2004. The error bars represent the standard error of the mean. Significant overall treatment effect $(P=0.0374)$.

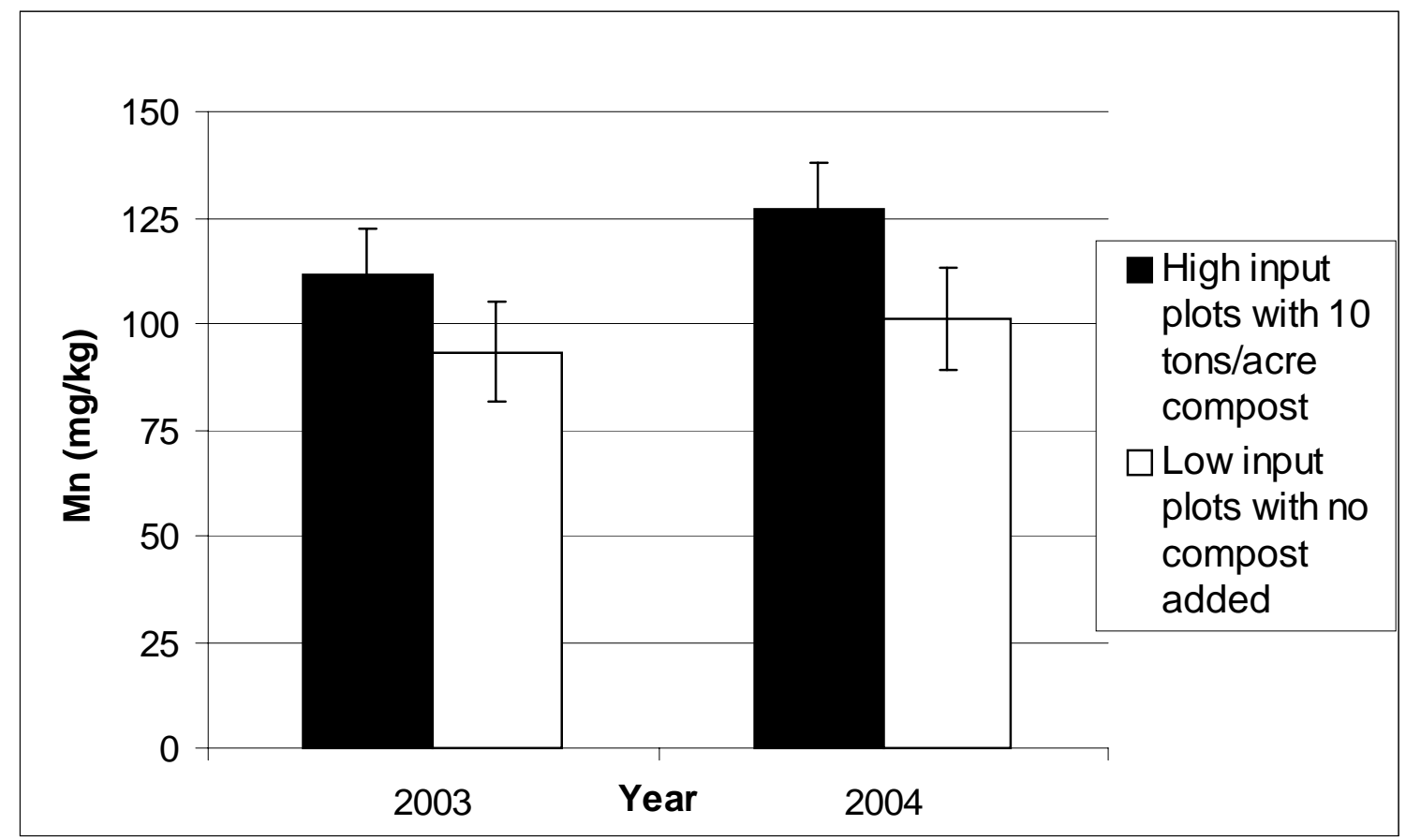

Figure 22. Manganese averages in high and low input plots in 2003 and 2004. The error bars represent the standard error of the mean. Significant year effect $(P=0.0455)$ and overall treatment effect $(P=0.0003)$. 


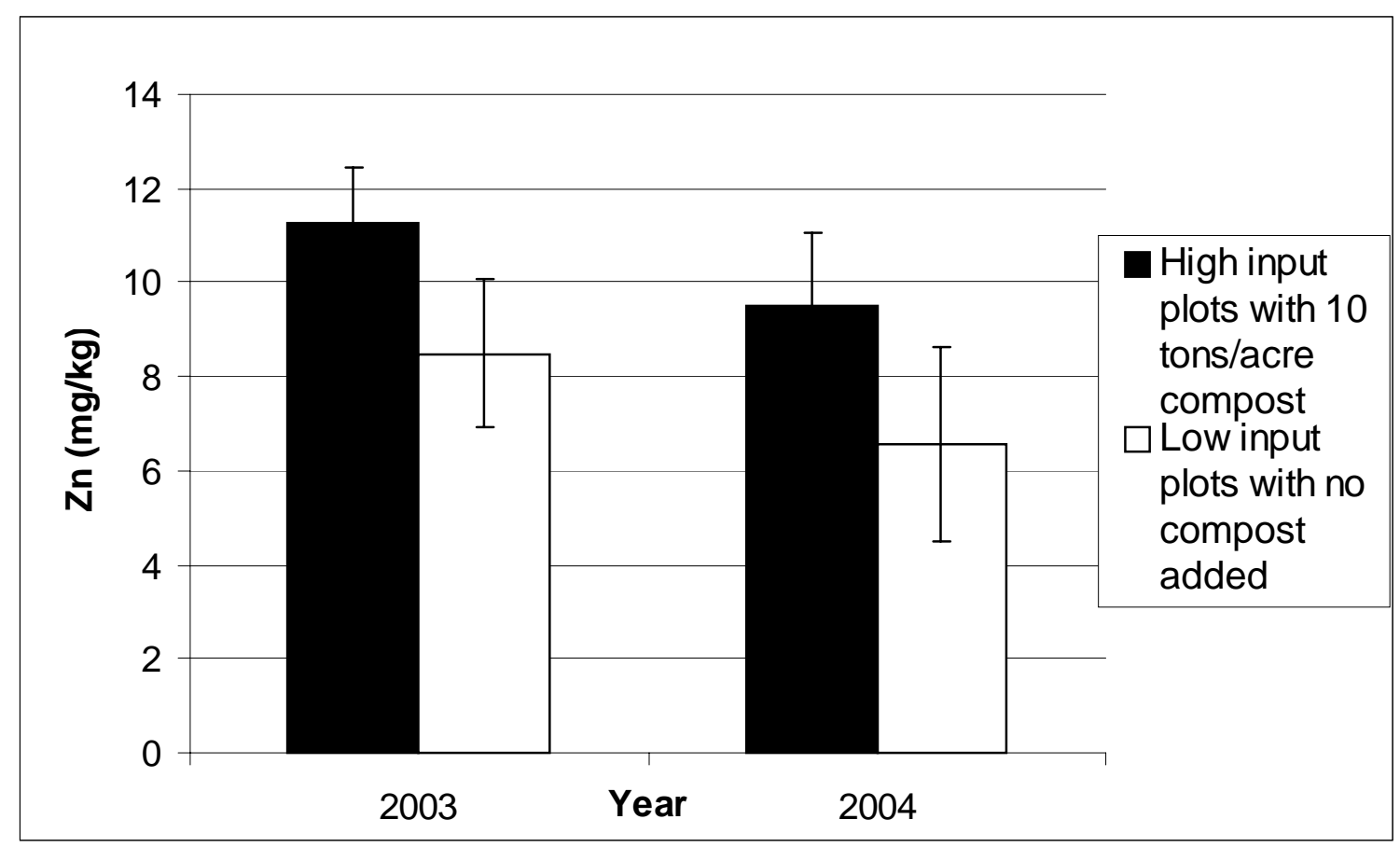

Figure 23. Zinc averages in high and low input plots in 2003 and 2004. The error bars represent the standard error of the mean. Significant year effect $(P=0.0335)$ and overall treatment effect $(P=0.0015)$.

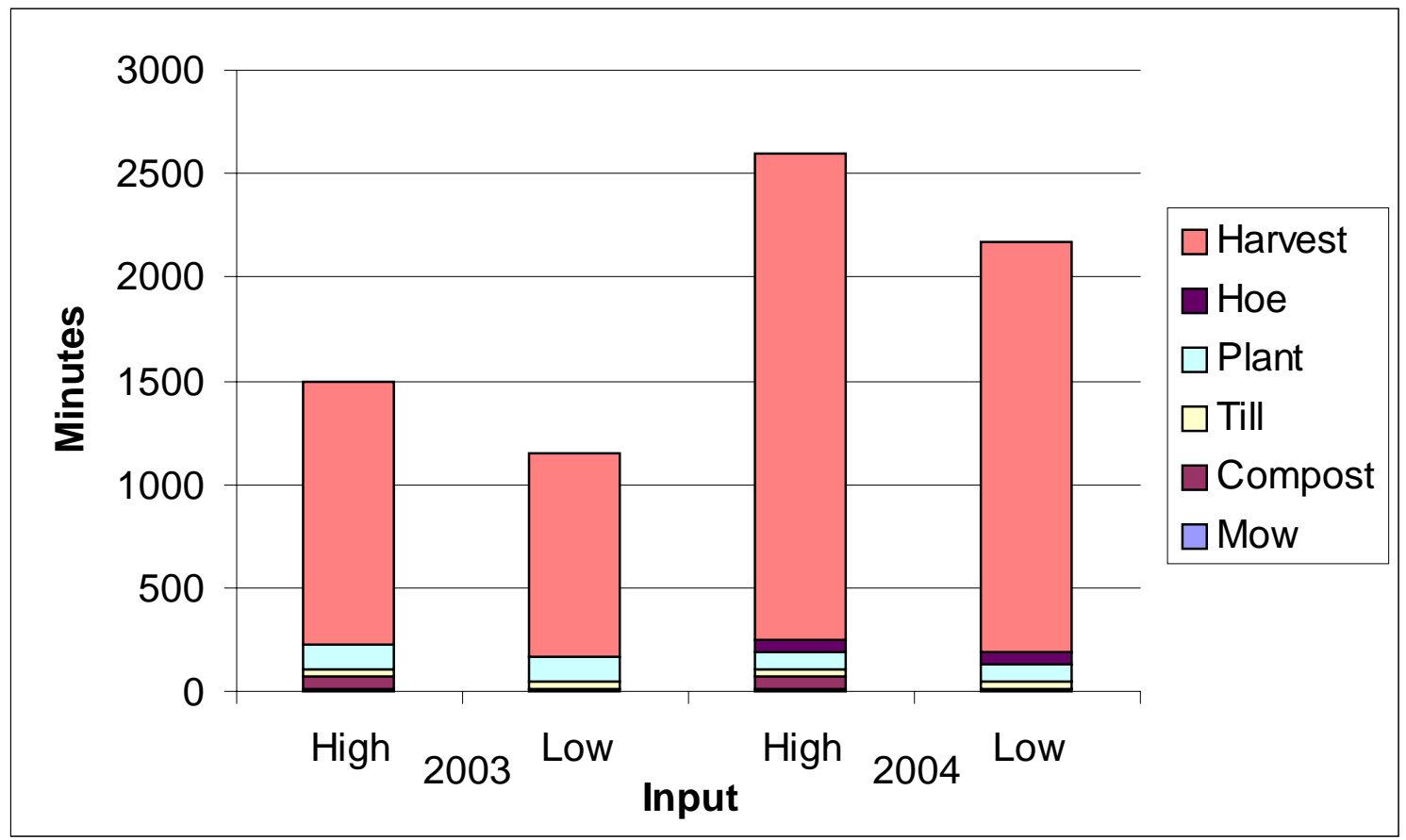

Figure 24. Bean labor in high and low input plots in 2003 and 2004. Each bar represents labor for four total plots. The legend is in the same order as the bar divisions. 


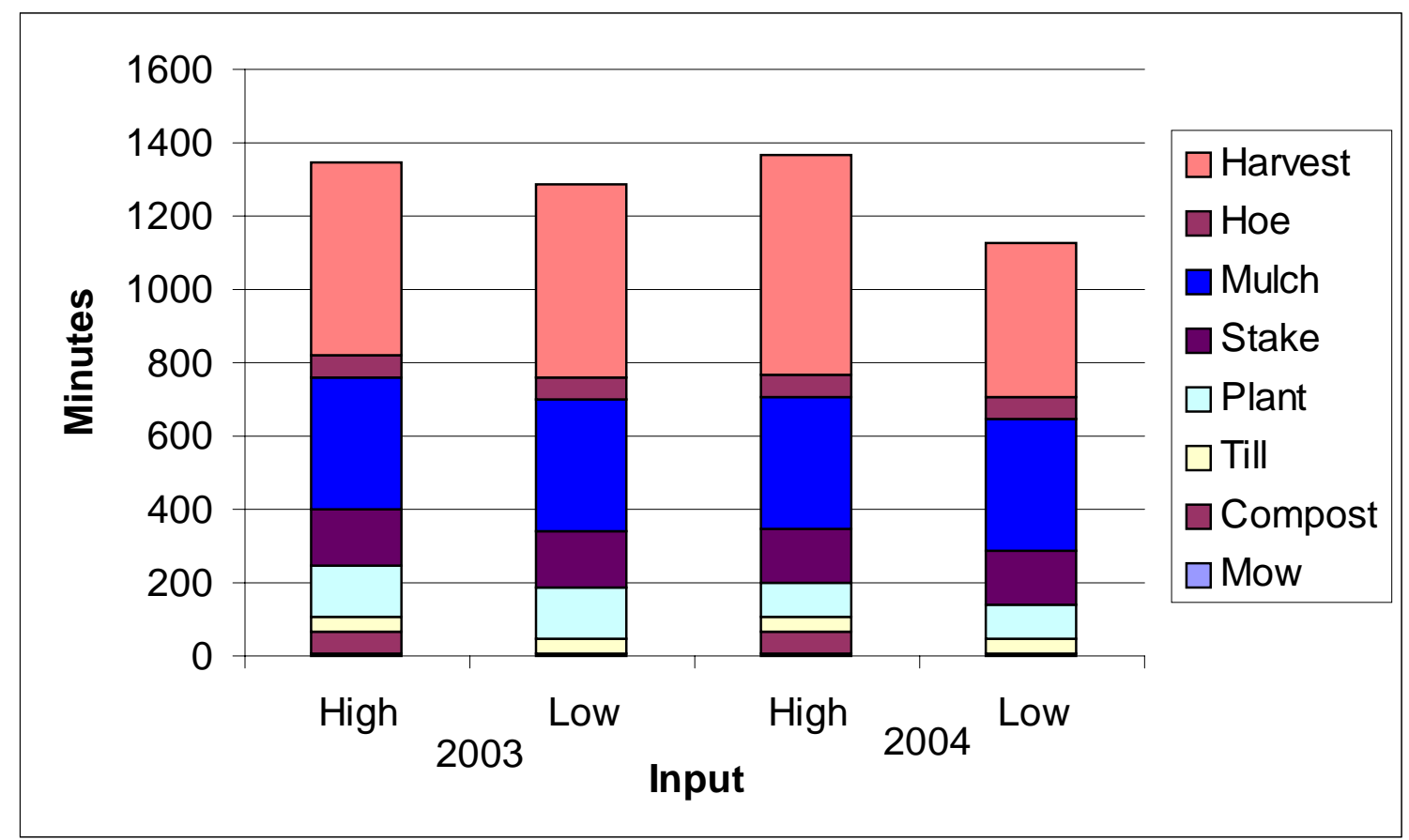

Figure 25. Tomato labor in high and low input plot in 2003 and 2004. Each bar represents labor for four total plots. The legend is in the same order as the bar divisions.

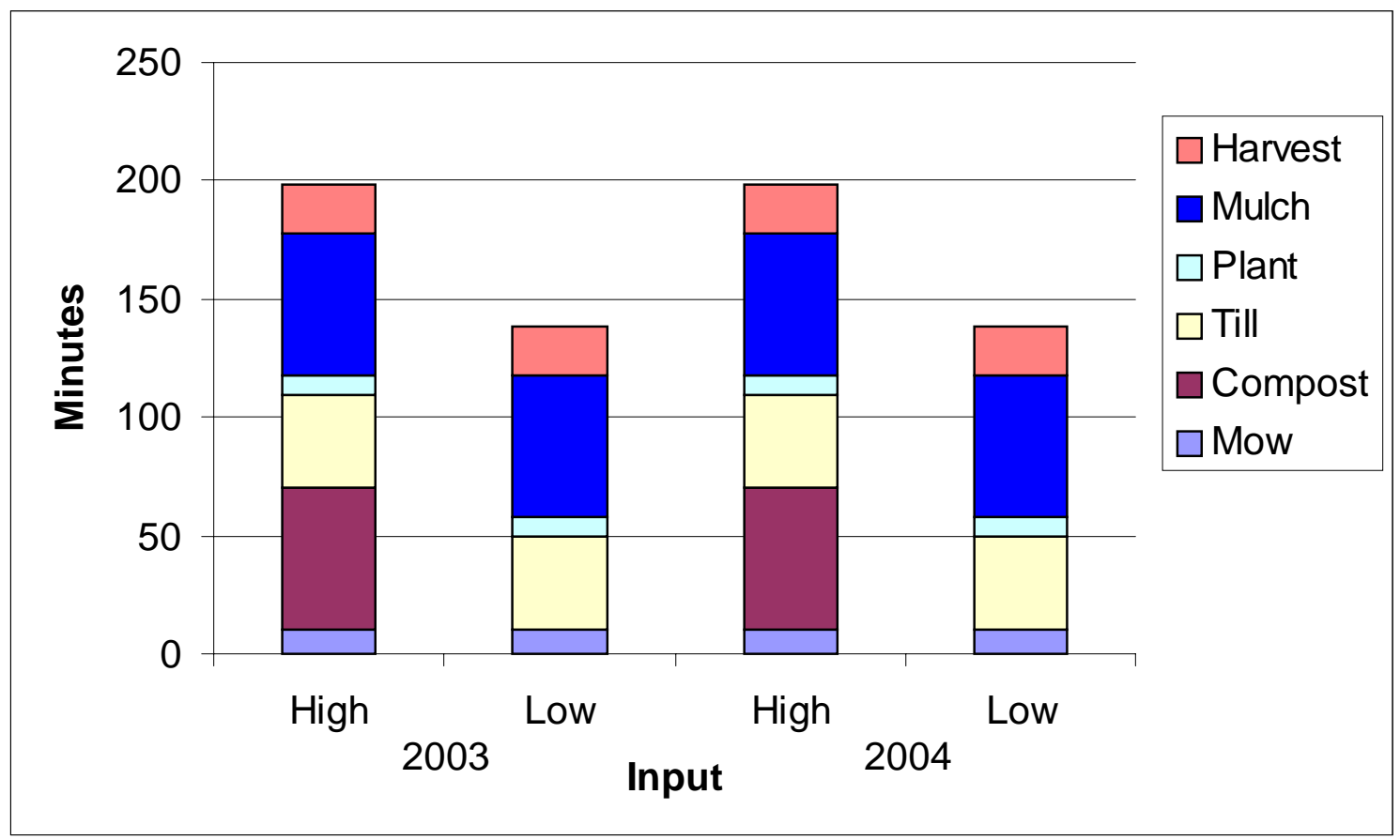

Figure 26. Pumpkin labor in high and low input plot in 2003 and 2004. Each bar represents labor for four total plots. The legend is in the same order as the bar divisions. 


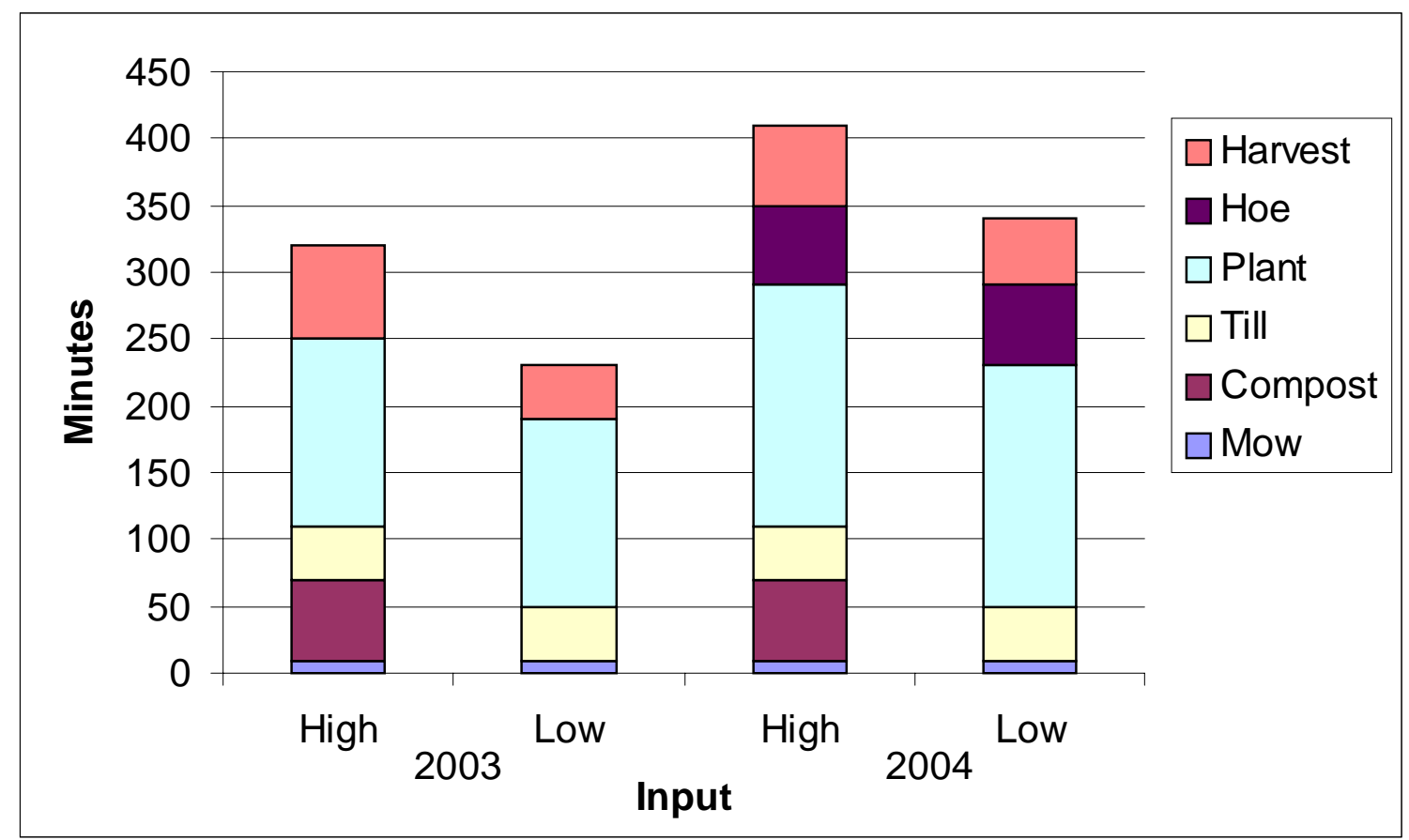

Figure 27. Spinach labor in high and low input plot in 2003 and 2004. Each bar represents labor for four total plots. The legend is in the same order as the bar divisions.

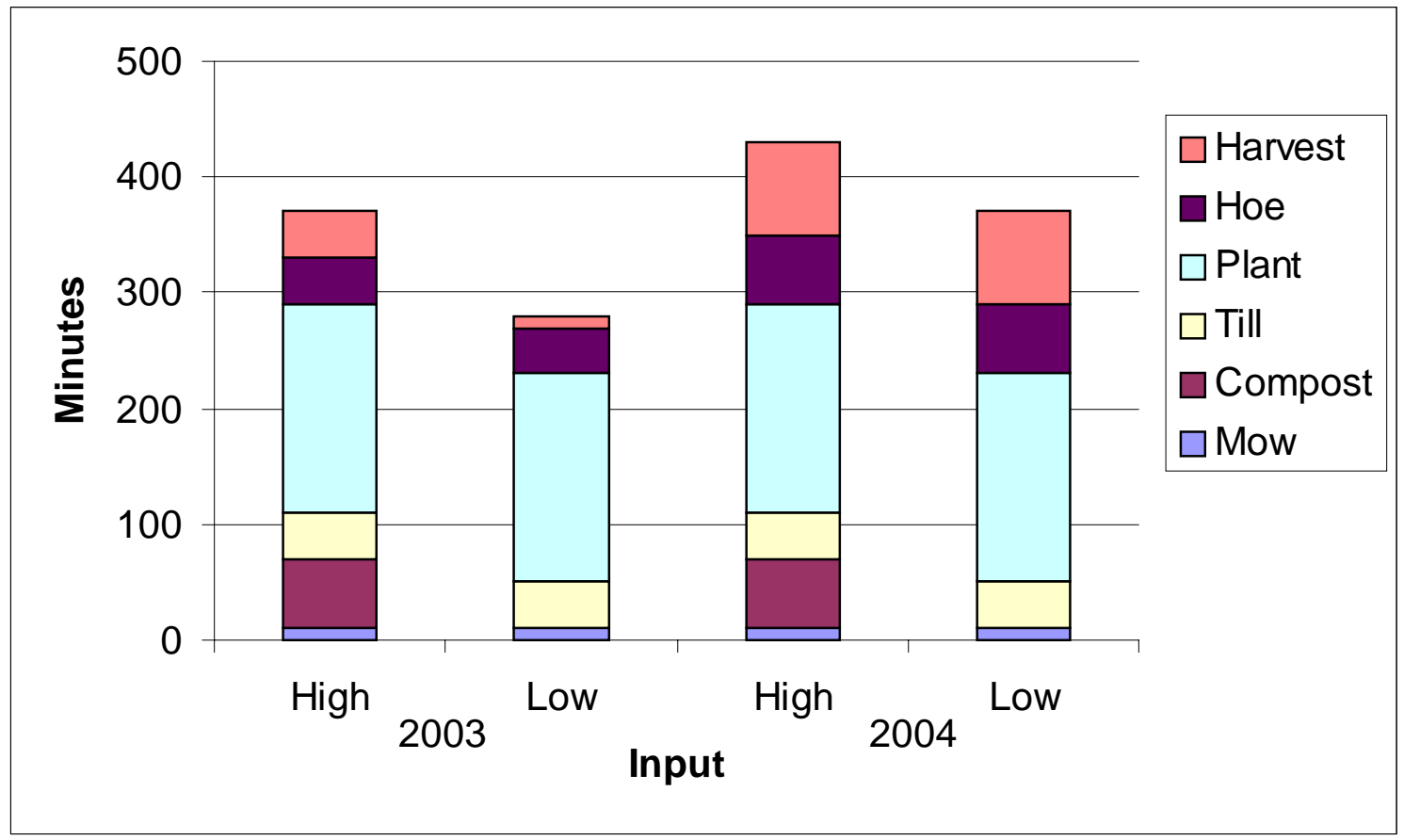

Figure 28. Lettuce labor in high and low input plot in 2003 and 2004. Each bar represents labor for four total plots. The legend is in the same order as the bar divisions. 


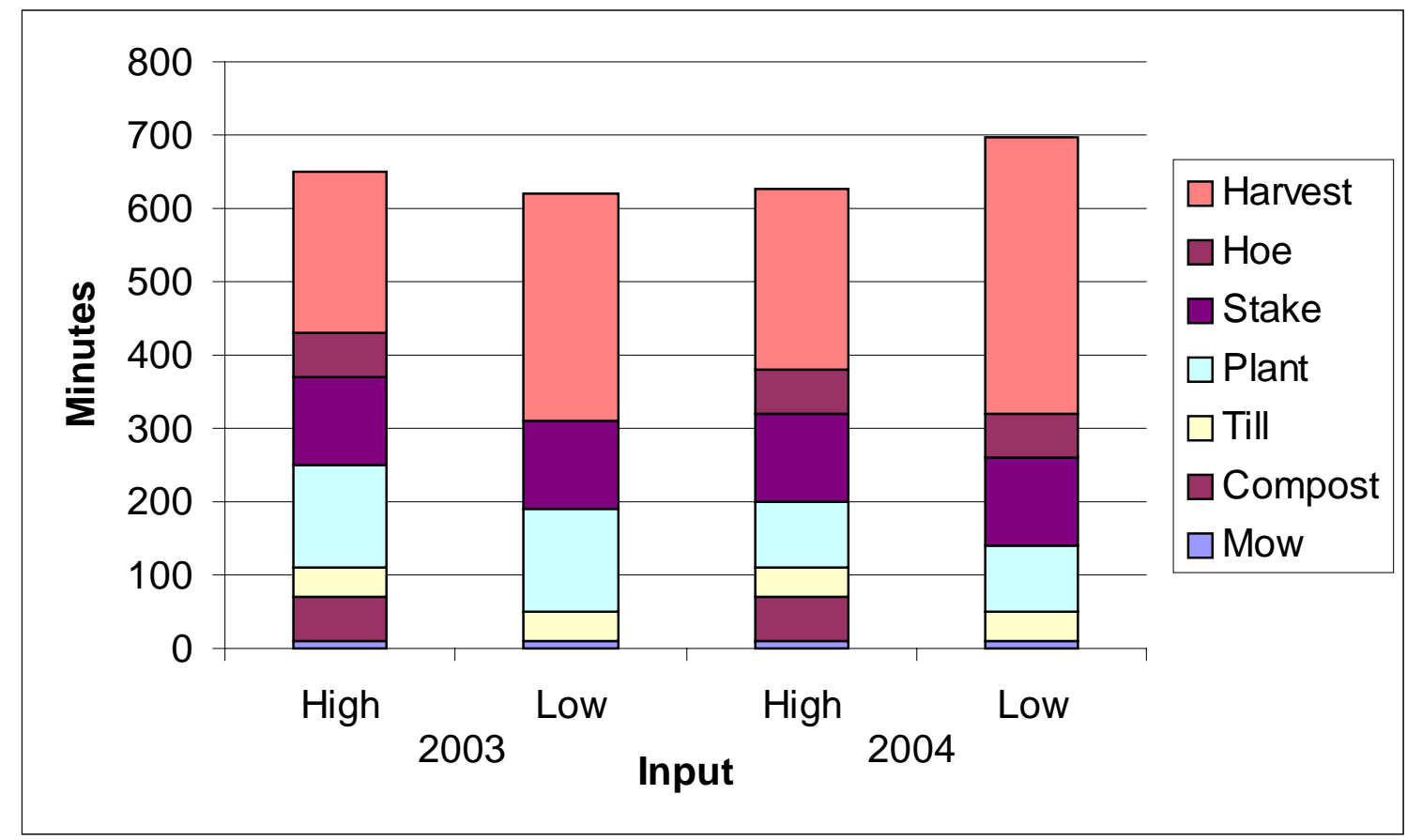

Figure 29. Pea labor in high and low input plot in 2003 and 2004. Each bar represents labor for four total plots. The legend is in the same order as the bar divisions.

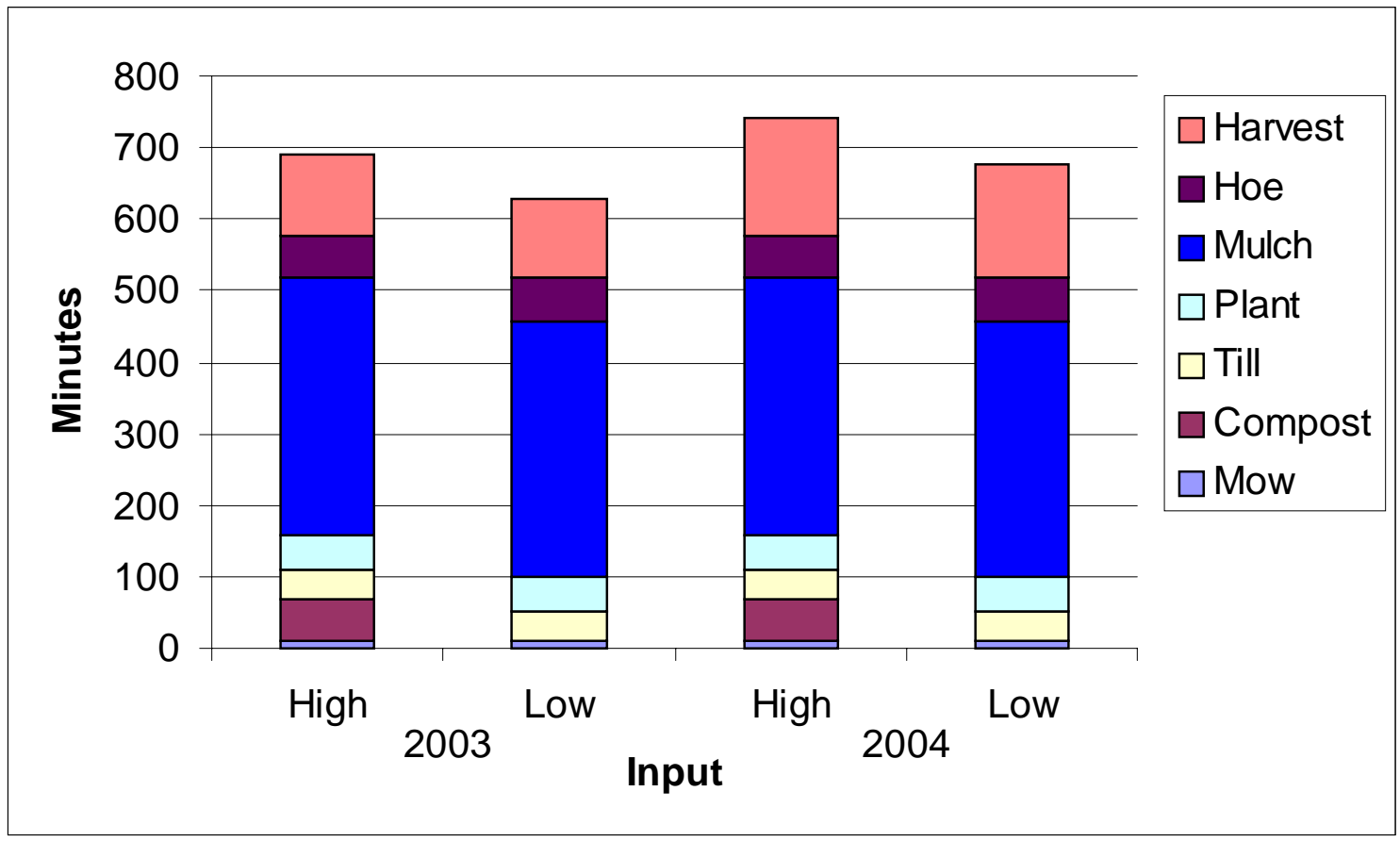

Figure 30. Pepper labor in high and low input plot in 2003 and 2004. Each bar represents labor for four total plots. The legend is in the same order as the bar divisions. 


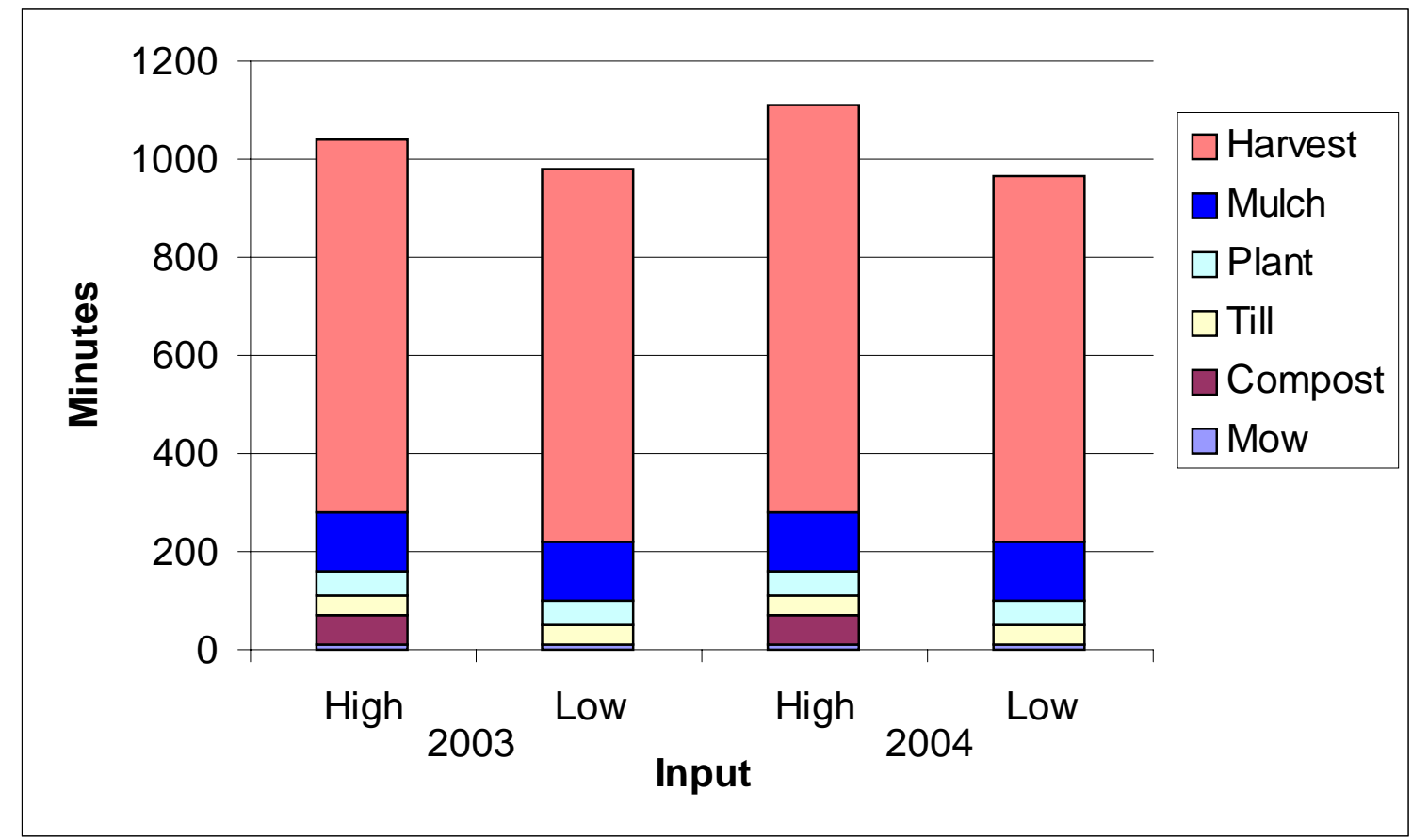

Figure 31. Zucchini labor in high and low input plot in 2003 and 2004. Each bar represents labor for four total plots. The legend is in the same order as the bar divisions.

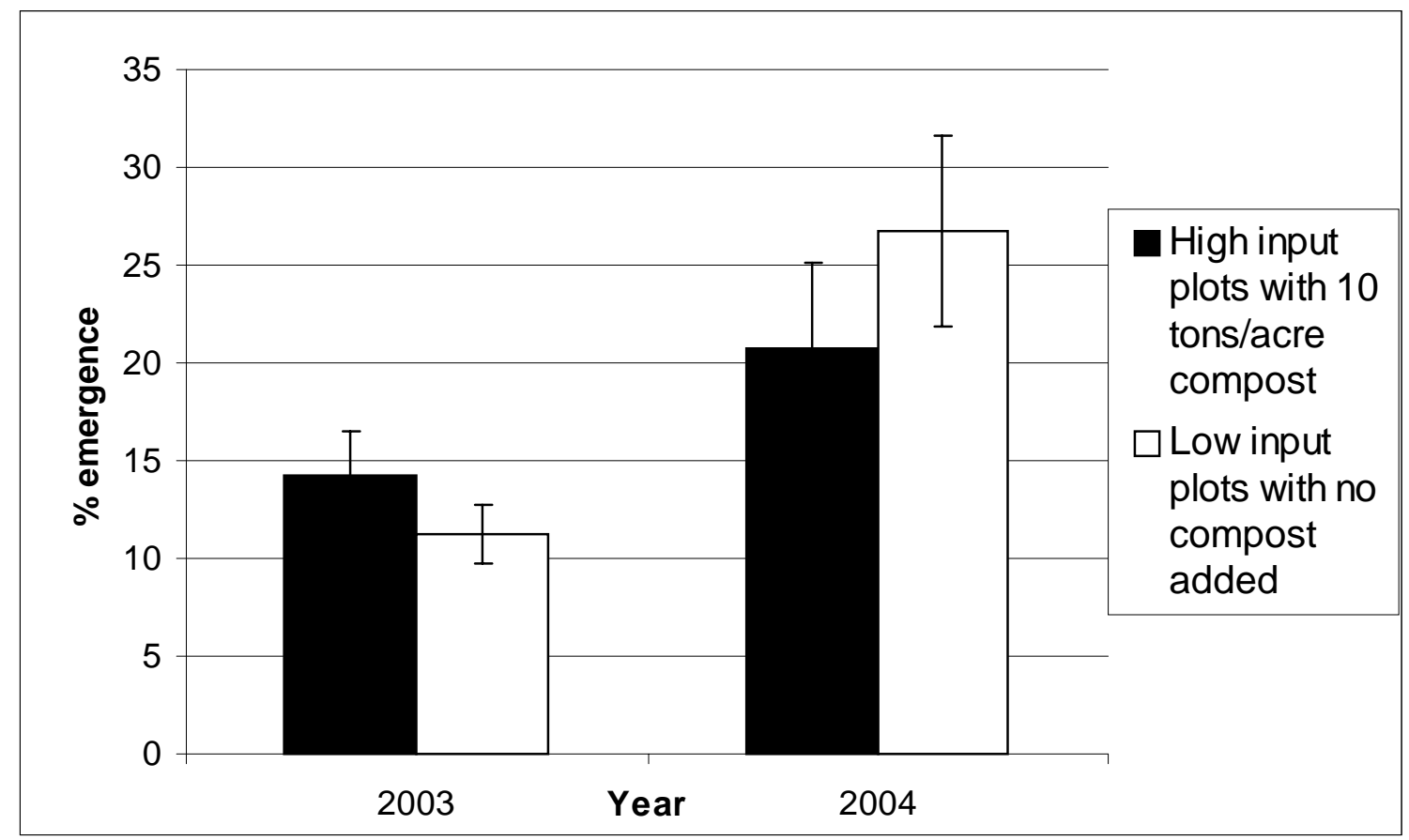

Figure 32. Spinach emergence in high and low input plots in 2003 and 2004. The error bars represent the standard error of the mean. 


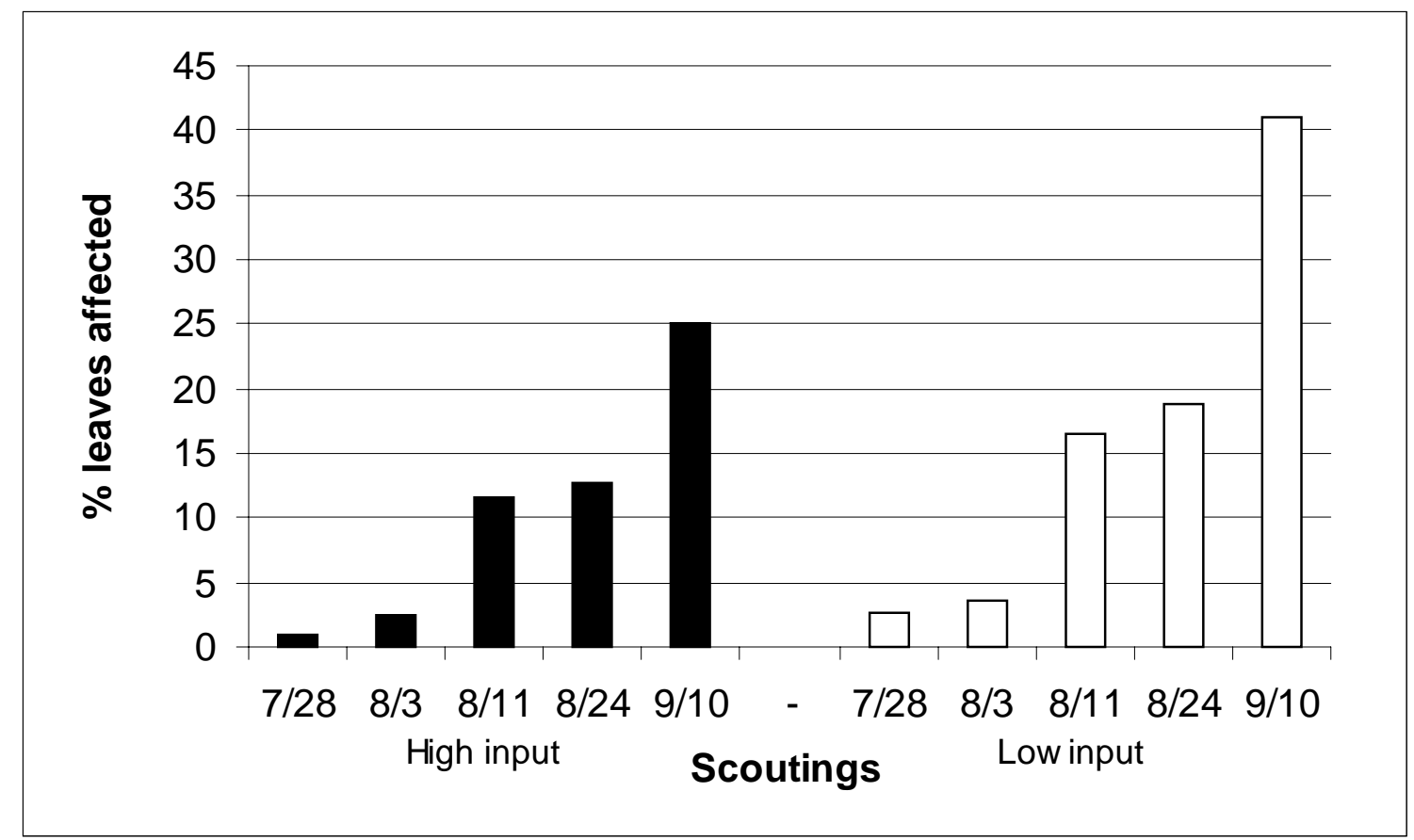

Figure 33. Tomato early blight in high and low input plots in 2004.

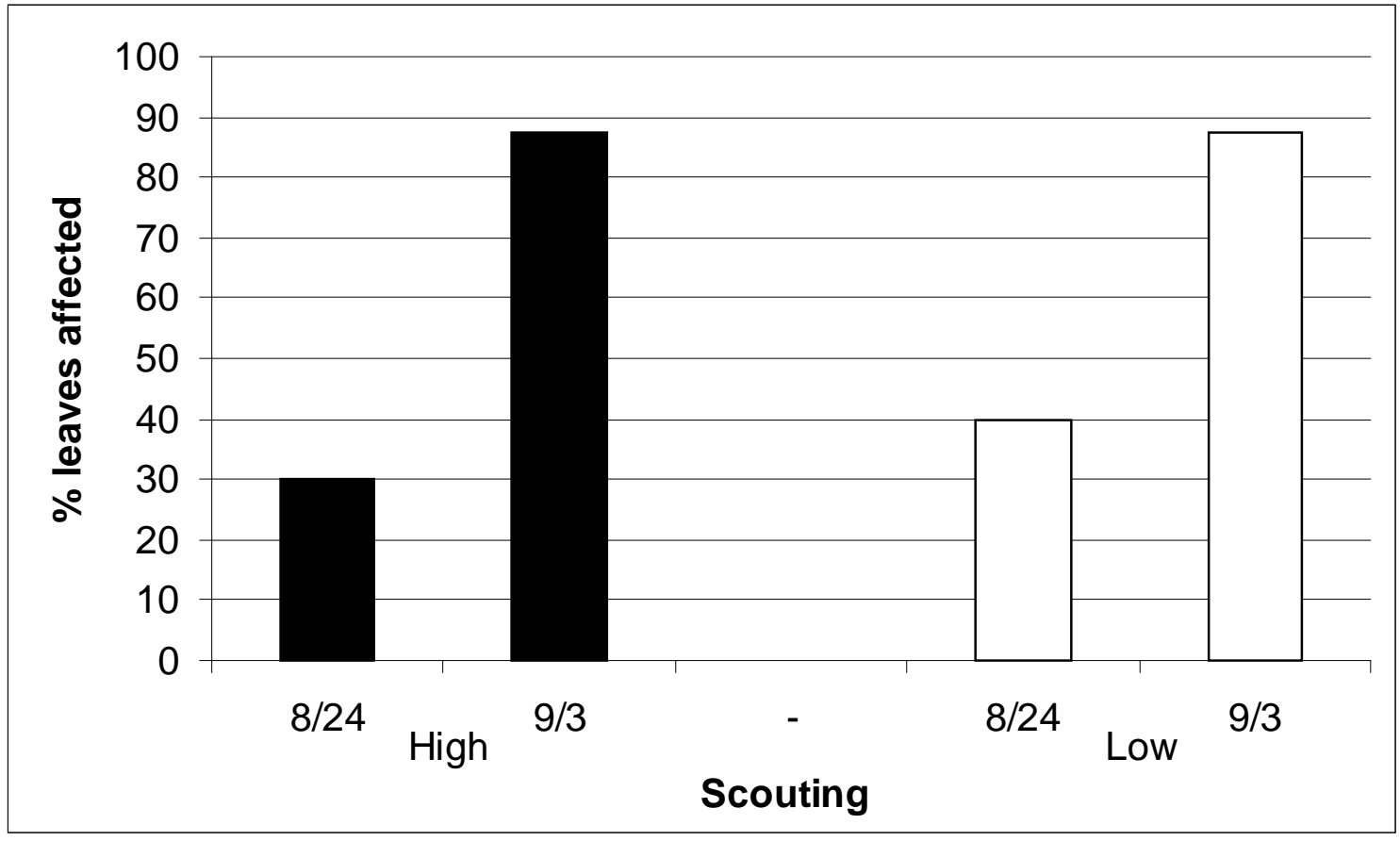

Figure 34. Powdery mildew levels in high and low input plots in 2003. 


\section{Chapter 4 - Discussion}

\section{Yields}

A significant increase in overall yield was observed between year one and two after conversion, 2003 and 2004, respectively. A possible explanation for the increase in yields is the significant increase in soil organic matter from 2003 to 2004 (Figure 14) most likely resulting in increased soil nutrient availability (see below). A direct impact of soil organic matter on soil productivity has been observed in many studies (Bauer and Black, 1994; Larney et al., 2000). These studies suggest that with increasing soil organic matter the productivity of the soil will increase leading to greater yields due to increased cation exchange capacity, increased water retention, and increased microbial activity (Havlin et al., 1999).

Another possible explanation for the higher yields observed in 2004 was that more favorable weather conditions existed (Figures 1 \& 2). In 2004, the combination of more even distribution of precipitation over the growing season and higher spring temperatures, which allowed for earlier planting, could have contributed to the higher overall yields in 2004.

Although a number of factors can explain increased overall yields (combined yields of all crops) in 2004, a number of crops showed low yields in both years due to pest problems and some crops showed decreasing yields from 2003 to 2004 for reasons that cannot clearly be linked to pest problems. Yields for the pumpkin crop were low (1,572 to 13,940 kg/ha (Figure 9)) in both years of this study compared to national averages of 22,400 kg/ha (Smith, 2000). The pumpkin crop in both years of the study showed yellowing and general stunting, possible disease symptoms, which were more pronounced in 2004 than 2003. In a study on the control of cucurbit yellow vine decline (CYVD) in acorn squash, researchers at the University of Kentucky reported symptoms of yellowing and stunting in early-infected plants. Plants infected later in their life cycle develop yellow vines and slowly decline as the fruit matured. The primary vector for the 
disease is the squash bug (Anasa tristis). The researchers noted a 5-fold increase in yields through control of the squash bug (Bessin et al., 2002). Although pest monitoring was not conducted for the squash bug in the market garden, the pest was present in the cucurbitaceous plots, suggesting the possible presence of CYVD in the pumpkin plots, in turn explaining the observed disease symptoms and low yields.

Spinach yields were also low in both years of the study. The average yield of spinach in the U.S. in 2001 was 22,646 kg/ha (ERS, 2005). In our study the yields of spinach ranged from 70 to $882 \mathrm{~kg} /$ ha (Figure 12). This was due largely to low emergence, in the range of 11 to 26\% for all eight plots in our study (Figure 32). These low emergence rates can be attributed to preemergence damping off caused by multiple species of Fusarium, especially F. solani and F. oxysporum (Dr. James Kotcon, personal communication, June 24, 2005). Rotations have long been cited as an effective means of controlling many soil-borne pathogens (Lampkin, 2002; Poincelot, 2004). However, in a study by Larsson and Gerhardson (1992), heavy spinach yield reductions due to soil borne pathogens were observed in rotated fields where spinach had been grown at least once previously, but at least one other crop preceded the spinach crop under study. The data from this study suggest that a rotation is not enough to combat some soil borne pathogens. In our study a four-year rotation is in effect. The years 2003 and 2004 were years four and five in a larger study. In 2003, the final year of the first full rotation, spinach had not yet been grown in the plots where it was planted. This would lead one to surmise that pathogenic strains of Fusarium were already present in the plots. However, it is also possible that the disease spread from plot to plot via contamination by soil movement from equipment used in the market garden.

Zucchini yields in this study (over both years and treatments) ranged from 53,525 to $79,287 \mathrm{~kg} / \mathrm{ha}$. These figures are well over the reported U.S. average summer squash yields of 20,160 kg/ha (Smith, 2000). These high yields are in large part due to the use of row covers 
during establishment of the crop, excluding the striped and spotted cucumber beetle from the crop until flowering. Other studies have shown fabric row cover to be effective in excluding striped and spotted cucumber beetles from summer squash plantings early in their life cycle (Adams et al., 1990). In both years of the study, the high input plots showed higher yields than the low input plots, 20\% more in 2003 and 18\% more in 2004 (Figure 8). These relatively small differences in yield between high and low input plots lead us to conclude that in certain situations (site specific) the cost of using compost may be greater than the benefit, especially when the effort of transportation and application are considered.

Tomato yields in this study were approaching the range of the national average yields in 2001, which were 75,398 kg/ha (ERS, 2005). In this study, tomato yields (over both years and treatments) ranged from 31915 to $66451 \mathrm{~kg} / \mathrm{ha}$. In 2003, there were no significant differences in tomato yields across treatments. However, in 2004 the high input tomato plots yielded 27\% higher than the low input plots (Figure 7). The tomato yield data suggests that tomatoes respond more than any other crop in this study to optimum weather conditions and well-fertilized soils. In 2004, we started seeing greater differences in certain soil nutrients such as $\mathrm{P}$ and $\mathrm{K}$ between high and low input treatments (Figures 17 and 16, respectively), a trend we expect to continue, and one that will most likely result in continuing divergences in yields between low and high input treatments.

The spring bean yields in this study, ranging from 7440 to $20086 \mathrm{~kg} / \mathrm{ha}$ (over both years and treatments), were within, and often well over, the yields to be expected in U.S. agriculture. Average bean yields for the U.S. range from $7974 \mathrm{~kg} / \mathrm{ha}$ (ERS, 2005) to $11648 \mathrm{~kg} / \mathrm{ha}$ (Smith, 2000). The high input bean plots showed higher yields than the low input plots during both years of the study - 28\% and 15\%, respectively, for 2003 and 2004 (Figure 4). The difference could be partially due to slightly higher emergence rates in the high input bean plots both years - 6.5 and 4.25\% higher, respectively, in years 2003 and 2004. Beans obtain less than half of their nitrogen 
needs through atmospheric nitrogen fixation. Most bean varieties show a more pronounced yield response with inorganic nitrogen sources (Manitoba government website, 2005). This could explain why the low input beans did not achieve yields as high as the high input beans.

The fall bean crops yielded much lower than the spring bean crops (Figure 5). This was in large part due to the fact that fall bean crops experienced heavy pressure from the already established Mexican bean beetle population. In addition, a single harvest each year was conducted because the winter cover crop of rye and hairy vetch was planted before the first expected frost, necessitating early termination of bean harvests.

The significant treatment effects on yield of the above-discussed crops supports, in large part, our hypothesis that high input plots will produce higher yields in the years following organic transition. This was true in all of the crops except lettuce and peas (Figures 10 and 3, respectively). In both years, the peas showed low emergence. The 2003 emergence rates were $12.5 \%$ in the high input plots and $15.5 \%$ in the low input plots (Figure 13). In 2004, emergence rates were $0.06 \%$ and lower. The seed rot that was observed and was responsible for the low mergence was a Pythium species that causes damping off in seedlings (Dr. James Kotcon, personal communication, June 24, 2005). In both years of our study, the low input pea plots showed higher yields than the high input pea plots - 38\% higher in 2003 and 36\% higher in 2004. A study by Cox et al. (2001) reported slightly higher, yet statistically insignificant, yields of peas in control (unamended) fields compared to fields that received compost, similar to our observations. However, in our study, a clear and significantly higher yield was observed in low input plots. Many legumes, including peas, will fix more nitrogen in low fertility conditions as part of an ecological adaptation strategy. Studies have shown that unfertilized, nodulated peas are able to achieve a higher shoot dry mass than those fertilized with a nitrogen solution (Bethlenfalvay et al., 1997). Despite the low germination rates, the pea yields were very near the average pea yields to be expected in the U.S., ranging from $3528 \mathrm{~kg} / \mathrm{ha}$ (Smith, 2000) to 4121 
kg/ha (ERS, 2005). In this study, pea yields ranged from 2180 to $3991 \mathrm{~kg} / \mathrm{ha}$ (over both years and treatments).

Lettuce yields did not exhibit a significant difference between the high and low input treatments (Figures 10 and 11). A study by Simonne et al. (2001) showed similar results using chemical fertilizers. The researchers used different levels and types of chemical fertilizers to grow three different varieties of lettuce. They found the nitrogen source to have no effect on marketable weight or the number of heads.

\section{Soil Fertility}

Most soil nutrient levels in the market garden were within acceptable ranges for both high and low input treatment plots according to the WVU soil resources fact sheet (Van Eck, 1990) -- calcium, magnesium, manganese, copper, and zinc were all within acceptable sufficiency ranges in both years and treatments. Major exceptions were potassium and phosphorus. Excessive potassium levels are considered to be $120 \mathrm{~kg} / \mathrm{ha}$ and above. Our potassium levels ranged from 156 to $258 \mathrm{~kg} / \mathrm{ha}$ over both years and treatments. The high input plots had nearly $100 \mathrm{mg} / \mathrm{kg}$ more potassium than the low input plots each year (Figure 16). A range considered sufficient for phosphorus is $25-40 \mathrm{~kg} / \mathrm{ha}$, while over $40 \mathrm{~kg} / \mathrm{ha}$ is excessive. The low input plots showed sufficient amounts of phosphorus at $32 \mathrm{~kg} / \mathrm{ha}$ in 2003 and $28 \mathrm{~kg} / \mathrm{ha}$ in 2004. The high input plots showed excessive amounts of available phosphorus in each year of the study - $56 \mathrm{~kg} / \mathrm{ha}$ in 2003 and $67 \mathrm{~kg} / \mathrm{ha}$ in 2004 (Figure 17).

Many studies have shown an increase in soil potassium and phosphorus (Reganold, 1988; Scow et al., 1994; Clark et al., 1998; Cox et al., 2001; Gagnon, 2004) in organic farming systems, mostly due to applications of manure or animal-based composts. The higher levels of phosphorus and potassium in the high input plots of this study seem to be a direct result of the compost amendments made in both years of our study. Phosphorus levels in the high input plots 
rose from year to year, while in the low input plots, phosphorus levels decreased. In addition to those observations, it should be noted that phosphorus has been known to become more available to plants as levels of organic matter increase (Havlin et al., 1999). Since significant increases in organic matter were observed, especially in the high input treatment plots, the increase in available phosphorus may have been the result of higher organic matter in addition to the application of additional phosphorus and potassium from animal-based composts.

\section{Organic Matter}

The increasing soil organic matter levels over the two years of this study (Figure 14) can be attributed to the incorporation of green manures, crop plant material, and mulches in low input plots, and also the addition of compost in the high input plots. Numerous studies have shown an increase in soil organic matter with the addition of animal manure based composts (Scow et al., 1994; Clark et al., 1998; Cox et al., 2001). However, the $0.23 \%$ increase in soil organic matter in the low input plots (attributed to the incorporation of green manures, crop plant material, and mulches) is an observation that, as far as we can ascertain, has not been made, especially in heavily tilled soil.

Although soil physical properties were not quantified in the field or laboratory, certain differences between treatments were noted. The soil in the low input plots was observed to “crust over” more rapidly when drying out after rains. The low input treatment soil was also more compacted and less friable than the soil in high input plots. These observations are in agreement with much of the literature on the subject of soil physical properties (Reganold, 1988;

Rose, 1991; Gerhardt, 1997). Rose (1991) found that additions of farmyard manures serve to decrease the bulk density of soils, as well as increasing the total porosity of soils. As a result of these soil improvements, the soil water holding capacity also increased. Researchers have also found that organically managed soils (receiving compost and green manures) are more friable, 
have a more granular structure, and have a lower modulus of rupture (Reganold, 1988). The modulus of rupture is an index that quantifies the level of surface crusting. A lower modulus of rupture makes it easier for seedlings to emerge, resulting in higher germination rates.

The only crops that showed a correlation between soil organic matter content and yield were peppers and zucchini. It is interesting to note that many of the other crop yields in our study showed a correlation to compost application, however, only peppers and zucchini showed a clear correlation between their respective yields and organic matter. Organic matter content of the soil and compost application clearly are related measurements. However, the fact that plants respond differently to both parameters must be due to the fact that compost applications more directly affect soil fertility, while organic matter content is an indicator of soil physical and chemical characteristics. Compost application can also affect the soil microbiology, which can, in turn, have effects on nutrient mineralization, nutrient availability, disease suppressiveness, and other biological effects on crop yield.

\section{Labor}

The main differences observed between treatments in the labor requirements of the market garden crops were found in compost application times and harvest times. High input plots, in all cases, had an additional hour added to their labor totals for compost application. Harvest times were closely correlated to overall yield of a crop. As most crops showed higher yields in the high input treatments, the high input plots also showed greater harvest times than the low input plots. The one exception to this rule was in the peas, where the low input plots showed higher yields. The labor expended in the harvest of low input peas was correspondingly higher (Figure 29). Beans required more harvest time and more time overall than any other crop (Figure 24). Tomatoes required the second-most amount of time, with the bulk of that time spent harvesting and mulching (Figure 25). 


\section{Chapter 5 - Conclusions}

With the increased demand for organically produced vegetables and the trend toward developing more sustainable agricultural systems, many farmers are making the conversion to organic practices. This study and experiments conducted by other researches have shown that organic production systems are a viable alternative to conventional agriculture (Smolik and Dobbs, 1991; Scow et al., 1994; Clark et al., 1998).

This study was able to show that spring beans, zucchini, pumpkins and spinach produce higher yields with the addition of manure-based compost. Depending on the level of increased yields, it may or may not be viable to use composts. Each farmer must weigh the costs and benefits of either production or purchase of compost, the transportation and application of compost, and whether or not these costs are worth the benefits in yield and soil fertility. This study has also shown that soil fertility can be maintained during and after the conversion to organic practices without the addition of manure-based composts. With the use of manure-based composts comes a concern regarding excessive phosphorus and potassium in the soil. It may not be necessary to apply compost yearly to maintain sufficiency ranges of certain soil nutrients. 


\section{Appendix A - Market garden map}

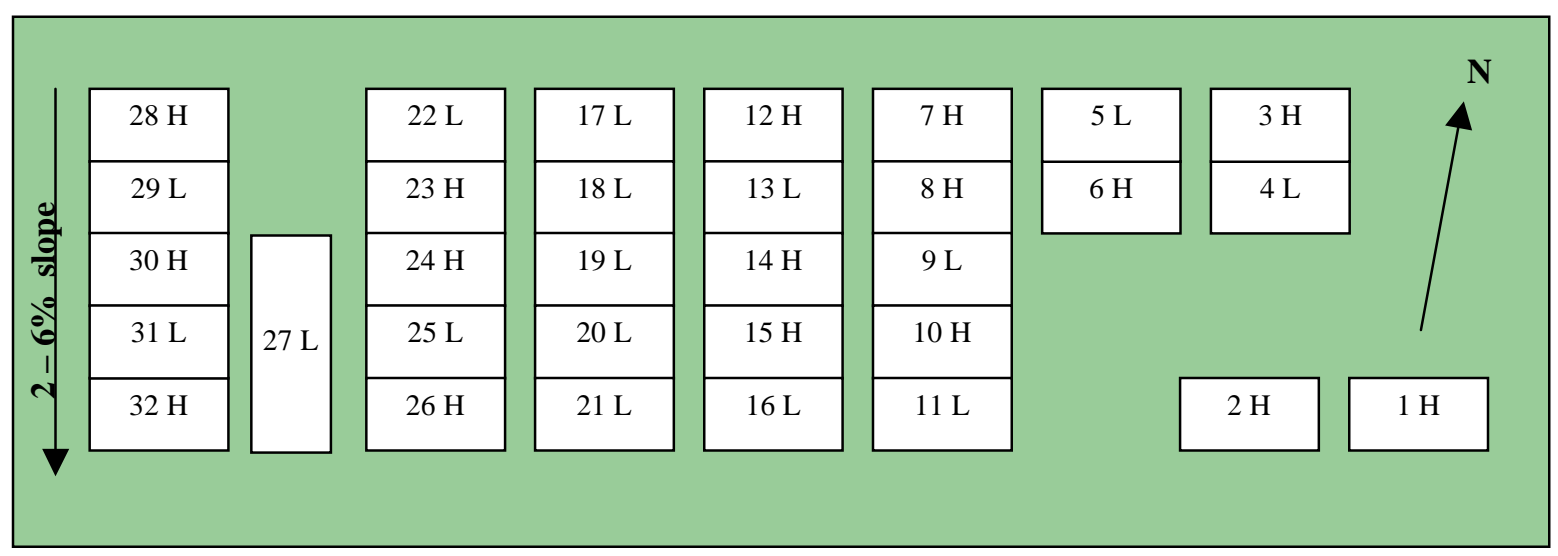

Numbers represent plot numbers. $\mathrm{H}=$ high input (10 tons/acre compost per year). $\mathrm{L}=$ low input (no compost added). 


\section{Appendix B: Yield (Crop Group)}

Table 4. Analysis of variance of crop yield by crop groups (Crop $1=$ Fabaceae, Crop $2=$ Solanaceae, Crop 3 = Cucurbitaceae, Crop 4 = Leafy crops). Value of yields were replaced by ranks.

\begin{tabular}{|l|l|l|l|l|l|}
\hline Source & DF & Type I SS & Mean Sq & F Value & Pr $>$ F \\
\hline Year & 1 & 4151.84 & 4151.84 & 52.15 & $<0.0001$ \\
\hline Trt & 1 & 616.54 & 616.54 & 7.74 & 0.0063 \\
\hline Year x Trt & 1 & 693.56 & 693.56 & 8.71 & 0.0038 \\
\hline Crop (Year) & 6 & 178630.68 & 29771.78 & 373.92 & $<0.0001$ \\
\hline Plant (Year x Crop) & 11 & 48776.42 & 4434.22 & 55.69 & $<0.0001$ \\
\hline Trt x Crop (Year) & 6 & 1563.47 & 260.58 & 3.27 & 0.0052 \\
\hline & & & & & \\
\hline Contrast & DF & Contrast SS & Mean Sq & F Value & Pr $>$ F \\
\hline Year Effect: Crop 1 & 1 & 2158.52 & 2158.52 & 27.11 & $<0.0001$ \\
\hline Year Effect: Crop 2 & 1 & 1485.13 & 1485.13 & 18.65 & $<0.0001$ \\
\hline Year Effect: Crop 3 & 1 & 420.5 & 420.5 & 5.28 & 0.0233 \\
\hline Year Effect: Crop 4 & 1 & 196.02 & 196.02 & 2.46 & 0.1194 \\
\hline Trt x Year: Crop 1 vs. Others & 1 & 0.66 & 0.66 & 0.01 & 0.9276 \\
\hline Trt x Year: Crop 2 vs. 3 \& 4 & 1 & 12.56 & 12.56 & 0.16 & 0.6919 \\
\hline Trt x Year Crop 3 vs. 4 & 1 & 219.13 & 219.13 & 2.75 & 0.0998 \\
\hline Error & 116 & 9235.98 & 79.62 & & \\
\hline
\end{tabular}




\section{Appendix C：Yield (Individual Crops)}

Table 5. Analysis of variance of crop yield by individual crops.

\begin{tabular}{|l|l|l|l|l|l|}
\hline Source: Peas & DF & Type I SS & Mean Sq & F Value & Pr>F \\
\hline Year & 1 & 714870.25 & 714870.25 & 0.45 & 0.5143 \\
\hline Trt & 1 & 7708952.25 & 7708952.25 & 4.87 & 0.0476 \\
\hline Year`Trt & 1 & 15500.25 & 15500.25 & 0.01 & 0.9288 \\
\hline & & & & & \\
\hline Contrast & DF & Contrast FF & Mean Sq & F Value & Pr>F \\
\hline 2003: low vs. high & 1 & 3516552 & 3516552 & 2.22 & 0.1619 \\
\hline 2004: low vs. high & 1 & 4207900.5 & 4207900.5 & 2.66 & 0.129 \\
\hline Error & 12 & 18995145 & 1582928.75 & & \\
\hline
\end{tabular}

\begin{tabular}{|l|l|l|l|l|l|}
\hline Source: Spring Beans & DF & Type I SS & Mean Sq & F Value & Pr>F \\
\hline Year & 1 & 345227221.5 & 345227221.5 & 70.88 & $<0.0001$ \\
\hline Trt & 1 & 39529848.4 & 39529848.4 & 8.12 & 0.0158 \\
\hline Year*Trt & 1 & 430815.4 & 430815.4 & 0.09 & 0.7717 \\
\hline & & & & & \\
\hline Contrast & DF & Contrast FF & Mean Sq & F Value & Pr>F \\
\hline 2003: low vs. high & 1 & 17369618 & 17369618 & 3.57 & 0.0856 \\
\hline 2004: low vs. high & 1 & 22591045.76 & 22591045.76 & 4.64 & 0.0543 \\
\hline Error & 11 & 53575873.7 & 4870534 & & \\
\hline
\end{tabular}

\begin{tabular}{|l|l|l|l|l|l|}
\hline Source: Fall Beans & DF & Type I SS & Mean Sq & F Value & Pr>F \\
\hline Year & 1 & 11987869.14 & 11987869.14 & 8.03 & 0.0253 \\
\hline Trt & 1 & 165991.96 & 165991.96 & 0.11 & 0.7486 \\
\hline Year*Trt & 1 & 2658157.23 & 2658157.23 & 1.78 & 0.224 \\
\hline & & & & & \\
\hline Contrast & DF & Contrast FF & Mean Sq & F Value & Pr>F \\
\hline 2003: low vs. high & 1 & 1535763.86 & 1535763.86 & 1.03 & 0.3443 \\
\hline 2004: low vs. high & 1 & 1288385.33 & 1288385.33 & 0.86 & 0.3839 \\
\hline Error & 7 & 10455245.67 & 1493606.52 & & \\
\hline
\end{tabular}

\begin{tabular}{|l|l|l|l|l|l|}
\hline Source: Peppers & DF & Type I SS & Mean Sq & F Value & Pr>F \\
\hline Year & 1 & 187998376.6 & 187998376.6 & 8.79 & 0.0118 \\
\hline Trt & 1 & 25601070.1 & 25601070.1 & 1.2 & 0.2954 \\
\hline Year*Trt & 1 & 845940.1 & 845940.1 & 0.04 & 0.8457 \\
\hline & & & & & \\
\hline Contrast & DF & Contrast FF & Mean Sq & F Value & Pr>F \\
\hline 2003: low vs. high & 1 & 8569800 & 8569800 & 0.4 & 0.5386 \\
\hline 2004: low vs. high & 1 & 17877210.13 & 17877210.13 & 0.84 & 0.3786 \\
\hline Error & 12 & 256626112.8 & 21385509.4 & & \\
\hline
\end{tabular}


Table 5 (con't). Analysis of variance of crop yield by individual crops.

\begin{tabular}{|l|l|l|l|l|l|}
\hline Source: Tomatoes & DF & Type I SS & Mean Sq & F Value & Pr>F \\
\hline Year & 1 & 2448369361 & 2448369361 & 19.75 & 0.0008 \\
\hline Trt & 1 & 383748510 & 383748510 & 3.09 & 0.104 \\
\hline Year*Trt & 1 & 259097312 & 259097312 & 2.09 & 0.1739 \\
\hline & & & & & \\
\hline Contrast & DF & Contrast FF & Mean Sq & F Value & Pr>F \\
\hline 2003: low vs. high & 1 & 6100524.5 & 6100524.5 & 0.05 & 0.8282 \\
\hline 2004: low vs. high & 1 & 636745298 & 636745298 & 5.14 & 0.0427 \\
\hline Error & 12 & 1487894608 & 123991217 & & \\
\hline
\end{tabular}

\begin{tabular}{|l|l|l|l|l|l|}
\hline Source: Zucchini & DF & Type I SS & Mean Sq & F Value & Pr>F \\
\hline Year & 1 & 579076096 & 579076096 & 5.27 & 0.0405 \\
\hline Trt & 1 & 754051600 & 754051600 & 6.87 & 0.0224 \\
\hline Year*Trt & 1 & 589824 & 589824 & 0.01 & 0.9428 \\
\hline & & & & & \\
\hline Contrast & DF & Contrast FF & Mean Sq & F Value & Pr>F \\
\hline 2003: low vs. high & 1 & 356231432 & 356231432 & 3.24 & 0.0968 \\
\hline 2004: low vs. high & 1 & 398409992 & 398409992 & 3.63 & 0.081 \\
\hline Error & 12 & 1317696372 & 109808031 & & \\
\hline
\end{tabular}

\begin{tabular}{|l|l|l|l|l|l|}
\hline Source: Pumpkins & DF & Type I SS & Mean Sq & F Value & Pr>F \\
\hline Year & 1 & 149719696 & 149719696 & 14.66 & 0.0024 \\
\hline Trt & 1 & 156250000 & 156250000 & 15.3 & 0.0021 \\
\hline Year*Trt & 1 & 20070400 & 20070400 & 1.96 & 0.1863 \\
\hline & & & & & \\
\hline Contrast & DF & Contrast FF & Mean Sq & F Value & Pr>F \\
\hline 2003: low vs. high & 1 & 32160200 & 32160200 & 3.15 & 0.1014 \\
\hline 2004: low vs. high & 1 & 144160200 & 144160200 & 14.11 & 0.0027 \\
\hline Error & 12 & 122583116 & 10215259.7 & & \\
\hline
\end{tabular}

\begin{tabular}{|l|l|l|l|l|l|}
\hline Source: Spinach & DF & Type I SS & Mean Sq & F Value & Pr>F \\
\hline Year & 1 & 59292.25 & 59292.25 & 0.48 & 0.5034 \\
\hline Trt & 1 & 1017072.25 & 1017072.25 & 8.16 & 0.0144 \\
\hline Year*Trt & 1 & 378840.25 & 378840.25 & 3.04 & 0.1067 \\
\hline & & & & & \\
\hline Contrast & DF & Contrast FF & Mean Sq & F Value & Pr>F \\
\hline 2003: low vs. high & 1 & 1318688 & 1318688 & 10.59 & 0.0069 \\
\hline 2004: low vs. high & 1 & 77224.5 & 77224.5 & 0.62 & 0.4464 \\
\hline Error & 12 & 1494885 & 124573.75 & & \\
\hline
\end{tabular}


Table 5 (con't). Analysis of variance of crop yield by individual crops.

\begin{tabular}{|l|l|l|l|l|l|}
\hline Source: Spring Lettuce & DF & Type I SS & Mean Sq & F Value & Pr>F \\
\hline Year & 1 & 2015 & 2015 & 12.21 & 0.005 \\
\hline Trt & 1 & 259.92 & 259.92 & 1.58 & 0.2355 \\
\hline Year*Trt & 1 & 29.64 & 29.64 & 0.18 & 0.6799 \\
\hline & & & & & \\
\hline Contrast & DF & Contrast FF & Mean Sq & F Value & Pr>F \\
\hline 2003: low vs. high & 1 & 223.44 & 223.44 & 1.35 & 0.2692 \\
\hline 2004: low vs. high & 1 & 66.13 & 66.13 & 0.4 & 0.5397 \\
\hline Error & 11 & 1815.17 & 165.02 & & \\
\hline Source: Fall Lettuce & DF & Type I SS & Mean Sq & F Value & Pr>F \\
\hline Trt & 1 & 8.33 & 8.33 & 0.19 & 0.6883 \\
\hline Error & 4 & 179 & 44.75 & & \\
\hline
\end{tabular}




\section{Appendix D: Organic Matter}

Table 6. Analysis of variance of organic matter (Crop $1=$ Fabaceae, Crop 2 = Solanaceae, Crop 3 = Cucurbitaceae, Crop 4 = Leafy crops)

\begin{tabular}{|l|l|l|l|l|l|}
\hline Source & DF & Type I SS & Mean Sq & F Value & Pr > F \\
\hline Year & 1 & 0.375 & 0.375 & 14.66 & 0.0002 \\
\hline Trt & 1 & 0.681 & 0.681 & 26.64 & $<0.0001$ \\
\hline Year x Trt & 1 & 0.133 & 0.133 & 5.2 & 0.0245 \\
\hline Crop (Year) & 6 & 0.534 & 0.089 & 3.48 & 0.0034 \\
\hline Trt x Crop (Year) & 6 & 0.526 & 0.088 & 3.43 & 0.0037 \\
\hline & & & & & \\
\hline Contrast & DF & Contrast SS & Mean Sq & F Value & Pr > F \\
\hline Year Effect: Crop 1 & 1 & 0.07 & 0.07 & 2.88 & 0.0925 \\
\hline Year Effect: Crop 2 & 1 & 0.12 & 0.12 & 4.54 & 0.0352 \\
\hline Year Effect: Crop 3 & 1 & 0 & 0 & 0.16 & 0.6923 \\
\hline Year Effect: Crop 4 & 1 & 0.43 & 0.43 & 16.89 & $<0.0001$ \\
\hline Trt x Year: Crop 1 vs. Others & 1 & 0.06 & 0.06 & 2.3 & 0.1318 \\
\hline Trt x Year: Crop 2 vs. 3 \& 4 & 1 & 0.09 & 0.09 & 3.54 & 0.0625 \\
\hline Trt x Year Crop 3 vs. 4 & 1 & 0.1 & 0.1 & 3.83 & 0.0528 \\
\hline Error & 116 & 2.96 & 0.03 & & \\
\hline
\end{tabular}




\section{Appendix E: Organic Matter x Yield}

Table 7. Analysis of variance correlating organic matter to yield of individual crops.

\begin{tabular}{|c|c|c|c|c|c|}
\hline Source & DF & Type I SS & Mean Sq & F Value & $\operatorname{Pr}>\mathrm{F}$ \\
\hline OM $\times$ Spring bean yield & 1 & 18966282.9 & 18966282.9 & 0.59 & 0.4571 \\
\hline Error & 13 & 419797476 & 32292113.5 & & \\
\hline $\mathrm{OM} \times$ Fall bean yield & 1 & 5596384.21 & 5596384.21 & 2.56 & 0.144 \\
\hline Error & 9 & 19670879.79 & 2185653.31 & & \\
\hline OM $\times$ Fall lettuce yield & 1 & 0 & 0 & 0 & 0.993 \\
\hline Error & 4 & 187.33 & 46.83 & & \\
\hline OM $\times$ Pea yield & 1 & 23189.11 & 23189.11 & 0.01 & 0.9149 \\
\hline Error & 14 & 27411278.64 & 1957948.47 & & \\
\hline OM x Pepper yield & 1 & 136763919.5 & 136763919.5 & 5.73 & 0.0313 \\
\hline Error & 14 & 334307580 & 23879112.9 & & \\
\hline OM x Pumpkin yield & 1 & 52728001.96 & 52728001.96 & 1.86 & 0.1936 \\
\hline Error & 14 & 395895210 & 28278229.3 & & \\
\hline OM x Spring lettuce yield & 1 & 151.93 & 151.93 & 0.5 & 0.4929 \\
\hline Error & 13 & 3967.81 & 305.22 & & \\
\hline OM x Spinach yield & 1 & 295084.87 & 295084.87 & 1.56 & 0.2327 \\
\hline Error & 14 & 2655004.88 & 189643.21 & & \\
\hline Om $\times$ Tomato yield & 1 & 629985225.5 & 629985225.5 & 2.23 & 0.1573 \\
\hline Error & 14 & 3949134565 & 282081040 & & \\
\hline OM x Zucchini yield & 1 & 1377813021 & 1377813021 & 15.15 & 0.0016 \\
\hline Error & 14 & 1273600871 & 90971491 & & \\
\hline
\end{tabular}




\section{Appendix F: Soil Nutrients}

Table 8. Analysis of variance of $\mathrm{pH}$, correlating $\mathrm{pH}$ to organic matter, and of individual soil nutrients. (Crop 1 = Fabaceae, Crop 2 = Solanaceae, Crop 3 = Cucurbitaceae, Crop 4 = Leafy crops)

\begin{tabular}{|c|c|c|c|c|c|}
\hline Source: $\mathrm{pH}$ & DF & Type I SS & Mean Sq & F Value & $\operatorname{Pr}>\mathrm{F}$ \\
\hline Year & 1 & 1.16 & 1.16 & 23.46 & $<0.0001$ \\
\hline Trt & 1 & 0.1 & 0.1 & 1.97 & 0.1664 \\
\hline Year $\times$ Trt & 1 & 0.01 & 0.01 & 0.21 & 0.6456 \\
\hline Crop (Year) & 6 & 0.07 & 0.01 & 0.25 & 0.9561 \\
\hline Trt x Crop (Year) & 6 & 0.46 & 0.08 & 1.56 & 0.1793 \\
\hline Contrast & DF & Contrast SS & Mean Sq & F Value & $\operatorname{Pr}>\mathrm{F}$ \\
\hline Year Effect: Crop 1 & 1 & 0.12 & 0.12 & 2.38 & 0.1292 \\
\hline Year Effect: Crop 2 & 1 & 0.5 & 0.5 & 10.02 & 0.0027 \\
\hline Year Effect: Crop 3 & 1 & 0.27 & 0.27 & 5.41 & 0.0243 \\
\hline Year Effect: Crop 4 & 1 & 0.35 & 0.35 & 7.04 & 0.0108 \\
\hline Trt x Year: Crop 1 vs. Others & 1 & 0.07 & 0.07 & 1.43 & 0.237 \\
\hline Trt x Year: Crop 2 vs. 3 \& 4 & 1 & 0.15 & 0.15 & 2.95 & 0.0921 \\
\hline Trt x Year Crop 3 vs. 4 & 1 & 0.08 & 0.08 & 1.53 & 0.2215 \\
\hline Error & 48 & 2.37 & 0.05 & & \\
\hline Source: $\mathrm{pH} \times \mathrm{OM}$ & DF & Type I SS & Mean Sq & F Value & $\mathrm{Pr}>\mathrm{F}$ \\
\hline Year & 1 & 5.7 & 5.7 & 5.98 & 0.0183 \\
\hline Trt & 1 & 10.74 & 10.74 & 11.26 & 0.0016 \\
\hline Year $\mathrm{x}$ Trt & 1 & 2.12 & 2.12 & 2.23 & 0.1423 \\
\hline Crop (Year) & 6 & 7.23 & 1.2 & 1.26 & 0.2925 \\
\hline Trt x Crop (Year) & 6 & 7.22 & 1.2 & 1.26 & 0.2929 \\
\hline $\mathrm{pH}$ & 1 & 4.27 & 4.27 & 4.48 & 0.0395 \\
\hline Error & 47 & 44.81 & 0.95 & & \\
\hline
\end{tabular}

\begin{tabular}{|l|l|l|l|l|l|}
\hline Source: & DF & Type I SS & Mean Sq & F Value & Pr > F \\
\hline Year & 1 & 138.65 & 138.65 & 16.55 & 0.0002 \\
\hline Trt & 1 & 95.08 & 95.08 & 11.35 & 0.0015 \\
\hline Year x Trt & 1 & 16.31 & 16.31 & 1.95 & 0.1694 \\
\hline Crop (Year) & 6 & 19.82 & 19.82 & 0.39 & 0.8792 \\
\hline Trt x Crop (Year) & 6 & 61.76 & 61.76 & 1.23 & 0.3086 \\
\hline & & & & & \\
\hline Contrast & DF & Contrast SS & Mean Sq & F Value & Pr > F \\
\hline Year Effect: Crop 1 & 1 & 13.53 & 13.53 & 1.61 & 0.21 \\
\hline Year Effect: Crop 2 & 1 & 64.9 & 64.9 & 7.74 & 0.0077 \\
\hline Year Effect: Crop 3 & 1 & 28.05 & 28.05 & 3.35 & 0.0735 \\
\hline Year Effect: Crop 4 & 1 & 42.5 & 42.5 & 5.07 & 0.0289 \\
\hline Trt x Year: Crop 1 vs. Others & 1 & 0.07 & 0.07 & 0.01 & 0.927 \\
\hline Trt x Year: Crop 2 vs. 3 \& 4 & 1 & 6.84 & 6.84 & 0.82 & 0.3708 \\
\hline Trt x Year Crop 3 vs. 4 & 1 & 10.68 & 10.68 & 1.27 & 0.2646 \\
\hline Error & 48 & 402.27 & 8.38 & & \\
\hline
\end{tabular}


Table 8 (con’t). Analysis of variance of $\mathrm{pH}$, correlating $\mathrm{pH}$ to organic matter, and of individual soil nutrients. (Crop 1 = Fabaceae, Crop 2 = Solanaceae, Crop 3 = Cucurbitaceae, Crop $4=$ Leafy crops)

\begin{tabular}{|l|l|l|l|l|l|}
\hline Source: K & DF & Type I SS & Mean Sq & F Value & Pr > F \\
\hline Year & 1 & 1515.16 & 1515.16 & 0.38 & 0.538 \\
\hline Trt & 1 & 136530.25 & 136530.25 & 34.66 & $<0.0001$ \\
\hline Year x Trt & 1 & 51.12 & 51.12 & 0.01 & 0.9098 \\
\hline Crop (Year) & 6 & 15622.67 & 2603.78 & 0.66 & 0.6812 \\
\hline Trt x Crop (Year) & 6 & 4709.59 & 784.93 & 0.2 & 0.9754 \\
\hline & & & & & \\
\hline Contrast & DF & Contrast SS & Mean Sq & F Value & Pr > F \\
\hline Year Effect: Crop 1 & 1 & 23.89 & 23.89 & 0.01 & 0.9382 \\
\hline Year Effect: Crop 2 & 1 & 10.93 & 10.93 & 0 & 0.9582 \\
\hline Year Effect: Crop 3 & 1 & 94.09 & 94.09 & 0.02 & 0.8778 \\
\hline Year Effect: Crop 4 & 1 & 3594.75 & 3594.75 & 0.91 & 0.3442 \\
\hline Trt x Year: Crop 1 vs. Others & 1 & 13.13 & 13.13 & 0 & 0.9542 \\
\hline Trt x Year: Crop 2 vs. 3 \& 4 & 1 & 515.34 & 515.34 & 0.13 & 0.7191 \\
\hline Trt x Year Crop 3 vs. 4 & 1 & 240.49 & 240.49 & 0.06 & 0.8059 \\
\hline Error & 48 & 189055.57 & 3938.66 & & \\
\hline
\end{tabular}

\begin{tabular}{|l|l|l|l|l|l|}
\hline Source: Ca & DF & Type I SS & Mean Sq & F Value & Pr > F \\
\hline Year & 1 & 590654.21 & 590654.21 & 2.83 & 0.099 \\
\hline Trt & 1 & 721561.59 & 721561.59 & 3.46 & 0.0691 \\
\hline Year x Trt & 1 & 87731.67 & 87731.67 & 0.42 & 0.5199 \\
\hline Crop (Year) & 6 & 1323336.48 & 220556.08 & 1.06 & 0.4014 \\
\hline Trt x Crop (Year) & 6 & 1040203.49 & 173367.25 & 0.83 & 0.5522 \\
\hline & & & & & \\
\hline Contrast & DF & Contrast SS & Mean Sq & F Value & Pr $>$ F \\
\hline Year Effect: Crop 1 & 1 & 42756.68 & 42756.68 & 0.2 & 0.6529 \\
\hline Year Effect: Crop 2 & 1 & 227603.54 & 227603.54 & 1.09 & 0.3016 \\
\hline Year Effect: Crop 3 & 1 & 306975.56 & 306975.56 & 1.47 & 0.2312 \\
\hline Year Effect: Crop 4 & 1 & 89503.81 & 89503.81 & 0.43 & 0.5157 \\
\hline Trt x Year: Crop 1 vs. Others & 1 & 29884.42 & 29884.42 & 0.14 & 0.7068 \\
\hline Trt x Year: Crop 2 vs. 3 \& 4 & 1 & 473762.84 & 473762.84 & 2.27 & 0.1385 \\
\hline Trt x Year Crop 3 vs. 4 & 1 & 348418.91 & 348418.91 & 1.67 & 0.2025 \\
\hline Error & 48 & 10018414.55 & 208716.97 & & \\
\hline
\end{tabular}


Table 8 (con’t). Analysis of variance of $\mathrm{pH}$, correlating $\mathrm{pH}$ to organic matter, and of individual soil nutrients. (Crop 1 = Fabaceae, Crop 2 = Solanaceae, Crop 3 = Cucurbitaceae, Crop $4=$ Leafy crops)

\begin{tabular}{|l|l|l|l|l|l|}
\hline Source: Mg & DF & Type I SS & Mean Sq & F Value & Pr > F \\
\hline Year & 1 & 4111.78 & 4111.78 & 7.4 & 0.0091 \\
\hline Trt & 1 & 73206.77 & 73206.77 & 131.7 & $<0.0001$ \\
\hline Year x Trt & 1 & 1540.61 & 1540.61 & 2.77 & 0.1025 \\
\hline Crop (Year) & 6 & 7086.66 & 1181.11 & 2.12 & 0.0675 \\
\hline Trt x Crop (Year) & 6 & 1706.2 & 284.37 & 0.51 & 0.7966 \\
\hline & & & & & \\
\hline Contrast & DF & Contrast SS & Mean Sq & F Value & Pr > F \\
\hline Year Effect: Crop 1 & 1 & 4820.09 & 4820.09 & 8.67 & 0.005 \\
\hline Year Effect: Crop 2 & 1 & 1987.82 & 1987.82 & 3.58 & 0.0647 \\
\hline Year Effect: Crop 3 & 1 & 2553.72 & 2553.72 & 4.59 & 0.0372 \\
\hline Year Effect: Crop 4 & 1 & 1317.69 & 1317.69 & 2.37 & 0.1302 \\
\hline Trt x Year: Crop 1 vs. Others & 1 & 4.62 & 4.62 & 0.01 & 0.9278 \\
\hline Trt x Year: Crop 2 vs. 3 \& 4 & 1 & 562.76 & 562.76 & 1.01 & 0.3194 \\
\hline Trt x Year Crop 3 vs. 4 & 1 & 603.06 & 603.06 & 1.08 & 0.3028 \\
\hline Error & 48 & 26682.28 & 555.88 & & \\
\hline
\end{tabular}

\begin{tabular}{|l|l|l|l|l|l|}
\hline Source: P & DF & Type I SS & Mean Sq & F Value & Pr > F \\
\hline Year & 1 & 225.25 & 225.25 & 0.26 & 0.6158 \\
\hline Trt & 1 & 15363.83 & 15363.83 & 17.4 & 0.0001 \\
\hline Year x Trt & 1 & 949.47 & 949.47 & 1.08 & 0.305 \\
\hline Crop (Year) & 6 & 5803.33 & 967.22 & 1.1 & 0.3789 \\
\hline Trt x Crop (Year) & 6 & 2428.09 & 404.68 & 0.46 & 0.8355 \\
\hline & & & & & \\
\hline Contrast & DF & Contrast SS & Mean Sq & F Value & Pr $>$ F \\
\hline Year Effect: Crop 1 & 1 & 202.37 & 202.37 & 0.23 & 0.6343 \\
\hline Year Effect: Crop 2 & 1 & 804.01 & 804.01 & 0.91 & 0.3448 \\
\hline Year Effect: Crop 3 & 1 & 170.78 & 170.78 & 0.19 & 0.6621 \\
\hline Year Effect: Crop 4 & 1 & 3543.75 & 3543.75 & 4.01 & 0.0508 \\
\hline Trt x Year: Crop 1 vs. Others & 1 & 29.91 & 29.91 & 0.03 & 0.8548 \\
\hline Trt x Year: Crop 2 vs. 3 \& 4 & 1 & 614.08 & 614.08 & 0.7 & 0.4085 \\
\hline Trt x Year Crop 3 vs. 4 & 1 & 13.41 & 13.41 & 0.02 & 0.9024 \\
\hline Error & 48 & 42388.72 & 883.1 & & \\
\hline
\end{tabular}


Table 8 (con't). Analysis of variance of $\mathrm{pH}$, correlating $\mathrm{pH}$ to organic matter, and of individual soil nutrients. (Crop 1 = Fabaceae, Crop 2 = Solanaceae, Crop 3 = Cucurbitaceae, Crop $4=$ Leafy crops)

\begin{tabular}{|l|l|l|l|l|l|}
\hline Source: Cu & DF & Type I SS & Mean Sq & F Value & Pr > F \\
\hline Year & 1 & 0.5 & 0.5 & 1.4 & 0.2433 \\
\hline Trt & 1 & 1.66 & 1.66 & 4.58 & 0.0374 \\
\hline Year x Trt & 1 & 0.14 & 0.14 & 0.4 & 0.5302 \\
\hline Crop (Year) & 6 & 2.11 & 0.35 & 0.98 & 0.452 \\
\hline Trt x Crop (Year) & 6 & 0.37 & 0.06 & 0.17 & 0.9829 \\
\hline & & & & & \\
\hline Contrast & DF & Contrast SS & Mean Sq & F Value & Pr > F \\
\hline Year Effect: Crop 1 & 1 & 0.8 & 0.8 & 2.22 & 0.1424 \\
\hline Year Effect: Crop 2 & 1 & 0.06 & 0.06 & 0.16 & 0.6922 \\
\hline Year Effect: Crop 3 & 1 & 0.14 & 0.14 & 0.38 & 0.5404 \\
\hline Year Effect: Crop 4 & 1 & 1.29 & 1.29 & 3.56 & 0.0653 \\
\hline Trt x Year: Crop 1 vs. Others & 1 & 0.01 & 0.01 & 0.03 & 0.8672 \\
\hline Trt x Year: Crop 2 vs. 3 \& 4 & 1 & 0.03 & 0.03 & 0.09 & 0.7608 \\
\hline Trt x Year Crop 3 vs. 4 & 1 & 0.11 & 0.11 & 0.32 & 0.5764 \\
\hline Error & 48 & 17.34 & 0.36 & & \\
\hline
\end{tabular}

\begin{tabular}{|l|l|l|l|l|l|}
\hline Source: & Mn & Type I SS & Mean Sq & F Value & Pr > F \\
\hline Year & 1 & 2170.22 & 2170.22 & 4.21 & 0.0455 \\
\hline Trt & 1 & 7764.03 & 7764.03 & 15.08 & 0.0003 \\
\hline Year x Trt & 1 & 230.85 & 230.85 & 0.45 & 0.5063 \\
\hline Crop (Year) & 6 & 5969.75 & 994.96 & 1.93 & 0.0946 \\
\hline Trt x Crop (Year) & 6 & 1025.7 & 170.95 & 0.33 & 0.9168 \\
\hline & & & & & \\
\hline Contrast & DF & Contrast SS & Mean Sq & F Value & Pr > F \\
\hline Year Effect: Crop 1 & 1 & 1595.65 & 1595.65 & 3.1 & 0.0847 \\
\hline Year Effect: Crop 2 & 1 & 2732.35 & 2732.35 & 5.31 & 0.0256 \\
\hline Year Effect: Crop 3 & 1 & 1196.81 & 1196.81 & 2.32 & 0.1339 \\
\hline Year Effect: Crop 4 & 1 & 1131.73 & 1131.73 & 2.2 & 0.1447 \\
\hline Trt x Year: Crop 1 vs. Others & 1 & 153.94 & 153.94 & 0.3 & 0.5871 \\
\hline Trt x Year: Crop 2 vs. 3 \& 4 & 1 & 0.01 & 0.01 & 0 & 0.9972 \\
\hline Trt x Year Crop 3 vs. 4 & 1 & 456.1 & 456.1 & 0.89 & 0.3513 \\
\hline Error & 48 & 24714.75 & 514.89 & & \\
\hline
\end{tabular}


Table 8 (con't). Analysis of variance of $\mathrm{pH}$, correlating $\mathrm{pH}$ to organic matter, and of individual soil nutrients. (Crop 1 = Fabaceae, Crop 2 = Solanaceae, Crop 3 = Cucurbitaceae, Crop $4=$ Leafy crops)

\begin{tabular}{|l|l|l|l|l|l|}
\hline Source: Zn & DF & Type I SS & Mean Sq & F Value & Pr > F \\
\hline Year & 1 & 54.21 & 54.21 & 4.79 & 0.0335 \\
\hline Trt & 1 & 128.96 & 128.96 & 11.4 & 0.0015 \\
\hline Year x Trt & 1 & 0.11 & 0.11 & 0.01 & 0.923 \\
\hline Crop (Year) & 6 & 26.67 & 4.45 & 0.39 & 0.88 \\
\hline Trt x Crop (Year) & 6 & 64.77 & 10.79 & 0.95 & 0.466 \\
\hline & & & & & \\
\hline Contrast & DF & Contrast SS & Mean Sq & F Value & Pr > F \\
\hline Year Effect: Crop 1 & 1 & 1.26 & 1.26 & 0.11 & 0.74 \\
\hline Year Effect: Crop 2 & 1 & 44.45 & 44.45 & 3.93 & 0.0532 \\
\hline Year Effect: Crop 3 & 1 & 21.67 & 21.67 & 1.92 & 0.1728 \\
\hline Year Effect: Crop 4 & 1 & 5.2 & 5.2 & 0.46 & 0.501 \\
\hline Trt x Year: Crop 1 vs. Others & 1 & 9.19 & 9.19 & 0.81 & 0.3721 \\
\hline Trt x Year: Crop 2 vs. 3 \& 4 & 1 & 15.78 & 15.78 & 1.39 & 0.2434 \\
\hline Trt x Year Crop 3 vs. 4 & 1 & 1.78 & 1.78 & 0.16 & 0.6934 \\
\hline Error & 48 & 543.05 & 11.31 & & \\
\hline
\end{tabular}




\section{Appendix G: Pests}

Table 9. Confidence intervals, means, and t-tests of emergence rates for peas in 2003 and spinach in 2003 and 2004.

\begin{tabular}{|l|l|l|l|l|l|l|l|l|l|}
\hline Emergence & & & $\begin{array}{l}\text { Lower } \\
\text { CL }\end{array}$ & & $\begin{array}{l}\text { Upper } \\
\text { CL }\end{array}$ & $\begin{array}{l}\text { Lower } \\
\text { CL }\end{array}$ & & $\begin{array}{l}\text { Upper } \\
\text { CL }\end{array}$ & \\
\hline Variable & Trt & N & Mean & Mean & Mean & St Dev & St Dev & St Dev & St Error \\
\hline Peas 2003 & High & 4 & 4.54 & 12.5 & 20.46 & 2.83 & 5 & 18.64 & 2.5 \\
\hline Peas 2003 & Low & 4 & 12.45 & 15.5 & 18.55 & 1.08 & 1.91 & 7.14 & 0.96 \\
\hline Peas 2003 & Diff (1-2) & & -9.55 & -3 & 3.55 & 2.44 & 3.79 & 8.34 & 2.68 \\
\hline Spin 2003 & High & 4 & 7.09 & 14.25 & 21.41 & 2.55 & 4.5 & 16.78 & 2.25 \\
\hline Spin 2003 & Low & 4 & 6.32 & 11.25 & 16.18 & 1.75 & 3.1 & 11.54 & 1.55 \\
\hline Spin 2003 & Diff (1-2) & & -3.68 & 3 & 9.68 & 2.49 & 3.86 & 8.5 & 2.73 \\
\hline Spin 2004 & High & 4 & 6.92 & 20.75 & 34.58 & 4.93 & 8.69 & 32.42 & 4.35 \\
\hline Spin 2004 & Low & 4 & 11.25 & 26.75 & 42.25 & 5.52 & 9.74 & 36.33 & 4.87 \\
\hline Spin 2004 & Diff (1-2) & & -21.98 & -6 & 9.98 & 5.95 & 9.23 & 20.33 & 6.53 \\
\hline
\end{tabular}

T-Tests
\begin{tabular}{|l|l|l|l|l|l|}
\hline Variable & Method & Variances & DF & t Value & Pr > t \\
\hline Peas 2003 & Pooled & Equal & 6 & -1.12 & 0.3053 \\
\hline Peas 2003 & Satterthwaite & Unequal & 3.86 & -1.12 & 0.3273 \\
\hline Spin 2003 & Pooled & Equal & 6 & 1.1 & 0.3141 \\
\hline Spin 2003 & Satterthwaite & Unequal & 5.32 & 1.1 & 0.3192 \\
\hline Spin 2004 & Pooled & Equal & 6 & -0.92 & 0.3935 \\
\hline Spin 2004 & Satterthwaite & Unequal & 5.92 & -0.92 & 0.394 \\
\hline
\end{tabular}

Table 10. Analysis of variance of tomato early blight in 2004

\begin{tabular}{|l|r|r|r|r|r|}
\hline Source & DF & Type I SS & Mean Sq & F Value & Pr > F \\
\hline Trt & 1 & 88.8 & 88.8 & 3.54 & 0.1087 \\
\hline Time & 1 & 1131.01 & 1131.01 & 45.15 & 0.0005 \\
\hline Time*Trt & 1 & 55.45 & 55.45 & 2.25 & 0.184 \\
\hline
\end{tabular}




\section{References}

Adams, R.G., Ashley, R.A., and M.J. Brennan. 1990. Row covers for excluding insect pests from broccoli and summer squash plantings. J. Econ. Ent. 83(3): 948-954.

Allen, P., D. Van Dusen, J. Lundy, and S. Gliessman. 1991. Integrating social, environmental, and economic issues in sustainable agriculture. Amer. J. Alt. Agr. 6(1):34-39.

Arcury, T.A. and S.A. Quandt. 1998. Chronic agricultural chemical exposure among migrant and seasonal farmworkers. Soc. Nat. Resour. 11(8): 829-843.

Bauer, A. and A.L. Black. 1994. Quantification of the effect of soil organic matter content on soil productivity. Soil Sci. Soc. Am. J. 58, 185-193.

Bessin, R, W. Nesmith, and B. Rowell. 2002. Squash bug control and impact on cucurbit yellow vine decline in acorn squash. University of Kentucky website. Retrieved June 28, 2005. http://www.ca.uky.edu/agc/pubs/pr/pr470/PR470C.HTM\#vegetables

Bethlenfalvay, G.J., G. Andrade, and C. Azcon-Aguilar. 1997. Plant and soil responses to mycorrhizal fungi and rhizobacteria in nodulated or nitrate-fertilized peas (Pisum sativum L.). Biol. Fertil. Soils 24: 164-168.

Blobaum, R. 1982. Barriers to conversion to organic farming practices in the midwestern United States. p. 263-278. In W. Lockeretz (ed.) Environmentally Sound Agriculture. Selected Papers from the Fourth International Conference of International Federation of Organic Agriculture Movements, Cambridge, MA, August 18-20, 1982.

Clark, M.S., W.R. Horwath, C. Shennan, and K.M. Scow. 1998. Changes in soil chemical properties resulting from organic and low-input farming practices. Agron. J. 90(5): 662-671.

Cox, D., M. Fauci, and D. Bezdicek. 2001. Effects of compost, coal ash, and straw amendments on restoring the quality of eroded Palouse soil. Biol. Fertil. Soils 33(5): 365-372.

Dabbert, S. and P. Madden. 1988. An economic model of a farm's transition to organic agriculture. p. 45-53. In Global Perspectives on Agroecology and Sustainable Agricultural Systems; Proceedings of the Sixth International Scientific Conference of the International Federation of Organic Agriculture Movements. Santa Cruz, CA Agroecology Program, University of California.

Dahlberg, K.A. 1987. Redefining development priorities: genetic diversity and agroecodevelopment. Conserv. Biol. 1:311-322.

Diebel, P.L., D.B. Taylor, and S.S. Batie. 1993. Barriers to low-input agriculture adoption: A case study of Richmond County, Virginia. Amer. J. Alt. Agr. 8(3): 120-127.

Eckert, D. and J. T. Sims. 1995. Recommended soil pH and Lime Requirement Tests. In Recommended Soil Testing Procedures for the Northeastern United States, $2^{\text {nd }}$ edition. Univ. of Delaware Agric. Exp. Stn. Bull. 493. 
Economic Research Service - USDA, 2005. Vegetables and melons outlook. Retrieved July 3, 2005. http://www.ers.usda.gov/Publications/vgs/

Economic Research Service - USDA, 2004. Data: organic production. Retrieved January 22, 2004. http://www.ers.usda.gov/Data/organic/

Economic Research Service - USDA, 2001. Greene, C., C. Dimitri, and N. Richman. Organic marketing features fresh foods and direct exchange. Food Review 24(1): 31-37 Retrieved January 22, 2004. http://www.ers.usda.gov/publications/FoodReview/Jan2001/FRV24I1f.pdf

Fernandez-Cornejo, J., C. Greene, R. Penn, and D. Newton. 1998. Organic vegetable production in the U.S.: Certified growers and their practices. Amer. J. Alt. Agr. 13(2): 69-78.

Gagnon, B. 2004. Contribution of on-farm and industrial composts to soil $\mathrm{pH}$ and enrichment in available nutrients and metals. Canadian J. Soil Sci. 84(4): 439-445.

Gerhardt, R.A. 1997. A comparative analysis of the effects of organic and conventional farming systems on soil structure. Biol. Agric. Hortic. 14(2): 139-157.

Goldstein, W.A., M.J. Scully, D.H. Kohl, and G. Shearer. 1998. Impact of agricultural management on nitrate concentrations in drainage waters. Amer. J. Alt. Agr. 13(3): 105-110.

Hald, A.B. 1999. Weed vegetation (wild flora) of long established organic versus conventional cereal fields in Denmark. Ann. Ap. Biol. 134:307-314.

Hamilton, P.A. and D.R. Helsel. 1995. Effects of agriculture on ground-water quality in five regions of the United States. Ground Water 33:217-226.

Harper, C.R. and D. Zilberman. 1992. Pesticides and worker safety. Amer. J. Agr. Econ. 74(1): 68-78.

Havlin, J.L., J.D. Beaton, S.L. Tisdale, and W.L. Nelson. 1999. Soil Fertility and Fertilizers. $6^{\text {th }}$ ed. Prentice Hall, Upper Saddle River, NJ.

International Trade Center. UNCTAD/WTO, 2004. Organic products website. Retrieved January 22, 2004. http://www.intracen.org/mds/sectors/organic/welcome.htm

Kirchmann, H. and L. Bergstrom. 2001. Do organic farming practices reduce nitrate leaching? Commun. Soil Sci. Plant Anal. 32(7\&8), 997-1028.

Klaas, E.E. 1982. Effects of pesticides on non-target organisms. In R.B. Dahlgren (Compiler) Proceedings of the Midwest Agricultural Interfaces with Fish and Wildlife Resources Workshop. Iowa Coop. Wild. Res. Unit, Iowa State University, Ames. pp. 7-9.

Lampkin, N. 2002. Organic Farming. $2^{\text {nd }}$ ed. Old Pond Publishing, Ipswich, U.K.

Larney, F.J., C.W. Lindwall, B.M. Olson, H.H. Janzen. 2000. Soil quality and productivity responses to simulated erosion and restorative amendments. Canadian J. Soil Sci. 80(3): 515522. 
Larsson, M. and B. Gerhardson. 1992. Disease progression and yield losses from root diseases caused by soilborne pathogens of spinach. Phytopathol. 82(4): 403-406.

Liebman, M. and A.S. Davis. 2000. Integration of soil, crop, and weed management in lowexternal-input farming systems. Weed Res. 40:27-47.

Lockeretz, W. 1988. Open questions in sustainable agriculture. Amer. J. Alt. Ag. 3(4): 174181.

Manitoba government website. 2005. Manitoba agriculture, food, and rural initiatives.

Retrieved July 7, 2005. http://www.gov.mb.ca/agriculture/soilwater/soilfert/fbd02s13.html

McSorley, R. 2002. Nematode and insect management in transitional agricultural systems. HortTech. 12(4): 597-600.

McSorley, R., M. Ozores-Hampton, P.A. Stansly, and J.M. Conner. 1999. Nematode management, soil fertility, and yield in organic vegetable production. Nematropica 29:205-213.

Nelson, D.W. and L.E. Sommers. 1996. Total carbon, organic carbon, and organic matter. p. 961-1010. In J.M. Bartels and J.M. Bigham (ed.) Methods of Soil Analysis: Part 3 - Chemical Methods. Soil Sci. Soc. Am. (publisher), Madison, Wisconsin.

Ngouajio, M. and M.E. McGiffen. 2002. Going organic changes weed population dynamics. HortTech. 12(4): 590-596.

Nielson, E.G., and L.K. Lee. 1987. The magnitude and costs of groundwater contamination from agricultural chemicals: A national perspective. Agric. Econ. Rep. 576, Econ. Res. Serv., U.S. Dept. of Agric., Washington, D.C.

O’Keeffe, M. and O. Kennedy. 1998. Residues - a food safety problem? J. Food Saf. 18(4): 297-319.

Organic Farming Research Foundation. August, 2001. Final results of the third biennial national organic farmers' survey. Retrieved January 23, 2004.

http://www.ofrf.org/publications/survey/1997.html.

Papendick, R.I.L.F. Elliott, and R.B. Dahlgren. 1986. Environmental consequences of modern production agriculture: How can alternative agriculture address these issues and concerns?

Amer. J. Alt. Agr. 1(1):3-10.

Poincelot, R.P. 2004. Sustainable Horticulture: Today and Tomorrow. $1^{\text {st }}$ ed. Prentice-Hall, Upper Saddle River, NJ.

Poudel, D.D., W.R. Horwath, J.P. Mitchell, and S.R. Temple. 2001. Impacts of cropping systems on soil nitrogen storage and loss. Agric. Syst. 68(3): 253-268.

Power, J.F. and J.W. Doran. 1984. Nitrogen use in organic farming. P. 585-598. In R.D. Hauck (ed.) Nitrogen in Crop Production. ASA, Madison, WI. 25-27 May, 1982. 
Reganold, J.P. 1988. Comparison of soil properties as influenced by organic and conventional farming systems. Amer. J. Alt. Agr. 3(4): 144-155.

Rose, D.A. 1991. The effect of long-continued organic manuring on some physical properties of soils. P. 197-205. In W.S. Wilson (ed.) Advances in Soil Organic Matter Research: The Impact on Agriculture and the Environment. The Royal House of Chemistry. Cambridge, England

Ruttan, V. 1988. Sustainability is not enough. Amer. J. Alt. Agr. 3(2\&3): 128-130.

Scow, K.M., O. Somasco, N. Gunapala, S. Lau, R. Venette, H. Ferris, R. Miller, and C. Shennan. 1994. Transition from conventional to low-input agriculture changes soil fertility and biology.

Calif. Agr. 48(5):20-26.

Sellen, D., J.H. Tolman, G.R. McLeod, A. Weersink, and E.K. Yiridoe. 1995. A comparison of financial returns during early transition from conventional to organic vegetable production. J. Veg. Crop Prod. 1(2): 11-39.

Sims, J. Thomas. 1995. Recommended soil tests for micronutrients: manganese, zinc, copper, and boron. In Recommended Soil Testing Procedures for the Northeastern United States, $2^{\text {nd }}$ edition. Univ. of Delaware Agric. Exp. Stn. Bull. 493.

Simonne, E., A. Simonne, and L. Wells. 2001. Nitrogen source affects crunchiness, but not lettuce yield. J. Plant Nutr. 24(4/5): 743-751.

Smith, R.C. 2000. Vegetable maturity dates, yield, and storage. North Dakota State Univ. Extension Service website. Retrieved July 1, 2005.

http://www.ext.nodak.edu/extpubs/plantsci/hortcrop/h912w.htm

Smolik, J.D. and T.L. Dobbs. 1991. Crop yields and economic returns accompanying the transition to alternative farming systems. J. Prod. Agr. 4(2): 153-161.

Soil Conservation Service. 1982. Soil survey of Marion and Monongalia Counties, West Virginia. USDA-SCS and WVU Ag. Exp. Station. U.S. Gov. Print. Office, Washington, D.C.

Stanhill, G. 1990. The comparative productivity of organic agriculture. Agric. Ecosystems Environ. 30:1-26.

Thompson, G. 2000. International consumer demand for organic foods. HortTech. 10(4):663674.

USDA (January, 2004). Jones, K., Program manager. National organic program overview. Retrieved January 21, 2004. http://www.ams.usda.gov/nop/NOP/standards/FullText.pdf

Van Eck, W. 1990. Soil resources fact sheet. West Virginia University Extension Service, USDA.

Van Elsen, T. 2000. Species diversity as a task for organic agriculture in Europe. Agric. Ecosystems Environ. 77:101-109. 
Wolf, A. and D. Beegle. 1995. Recommended soil tests for macronutrients: phosphorus, potassium, calcium, and magnesium. In Recommended Soil Testing Procedures for the Northeastern United States, $2^{\text {nd }}$ edition. Univ. of Delaware Agric. Exp. Stn. Bull. 493.

Zinati, G. 2002. Transition from conventional to organic farming systems: challenges, recommendations, and guidelines for pest management. HortTech. 12(4):606-610. 